\title{
Das Halluzinationsproblem.
}

\author{
Von \\ Dr. med. et phil. J. Rülf.
}

(Aus der Universitätsklinik und Poliklinik für Psychisch- und Nervenkranke zu Bonn [Direktor: Geh. Rat Prof. Dr. Westphal].)

(Eingegangen am 24. Februar 1914.)

Einleitung. (S. 183).

Inhaltsüborsicht:

1)ie Einführung des erkenntnistheoretischen Gesichtspunktes.

A. Die normale Wahrnehmung.

1. Die Wahrnehmung vom psychogenetischen und biologischen Standpunkt. (S. 186.)

2. Die Wahrnehmung vom erkenntnistheoretischen Standpunkt. (S. 192.)

3. Die Wahrnehmung vom psychologischen Standpunkt. (S. 202.)

B. Die pathologische Wahrnehmung - die Halluzination.

1. Wesen und klinische Abgrenzung der Halluzination. (\$. 211.)

2. Die Bewußtseinsstellung des Halluzinierenden zu seinen Trugwahrnehmungen und die Halluzination als Apperzeptionsprozeß. (S. 218.)

3. Die psychologischen Merkmale der Halluzination. (S. 235.)

C. Die Entstehung der Halluzination.

1. Die psychopathologischen Entstehungsbedingungen der Halluzination. (S. 249.)

2. Die gehirnpathologischen Entstehungsbedingungen der Halluzination. (S. 268.)

\section{Einleitung.}

Als Hagen im Jahre 1868') und Kandinsky im Jahre 1885²) $^{\mathbf{2}}$ ) in größeren Abhandlungen zur Theorie der Halluzinationen sich zu äußern unternahmen, schickten sie ihren Betrachtungen Entschuldigungen darüber voraus, daß sie zu einem schon so häufig behandelten Thema, in welchem kaum mehr etwas Neues gesagt werden könnte, das Wort ergriffen.

Als Goldstein im Jahre 19083) jene ebenso umfassende wie tiefgehende Untersuchung veröffentlichte, welche den Anlaß zu so mannigfachen Diskussionen gab, glaubte er sich im Beginn seiner Aus25. 1868 .

1) Hagen, Zur Theorie der Halluzinationen. Allgem. Zeitschr. f. Psych.

2) Kandinsky, Kritische und klinische Betrachtungen im Gebiete der Sinnestäuschungen. Berlin 1888.

3) Goldstein, Zur Theorie der Halluzinationen. Archiv f. Psych, 44. 1908. 
führungen darüber beklagen zu müssen, daß das Interesse für das Halluzinationsproblem in letzter Zeit sich verringert hätte. In der Tat ist es ihm auch gelungen, das Problem wieder in lebhaften Fluß zu bringen.

Es gibt Probleme, welche immer wieder von neuem in den Mittelpunkt der Erörterung dringen, weil in ihnen gewisse Grundfragen der Erkenntnis ruhen, die ihrer eigenen Natur nach niemals völlig ausgeschöpft werden können. Dazu gehört in erster Linie das Erkenntnis problem selbst.

Die normale Wahrnehmung ist die Grundlage der Erkenntnis. Nihil est in intellectu, quod non prius fuerit in sensu, sagte der englische Philosoph Locke und legte mit diesem Ausspruch zuerst die Axt an die scheinbar so festgefügten Fundamente der bisherigen Spekulation.

Der Psychiater trifft nun in dem von ihm erforschten Symptomengebiet auf einen Wahrnehmungsvorgang, welcher tatsächlich gar keiner ist, welcher jedoch dem Subjekt, welches ihn hat, ganz genau so imponiert wie eine normale Wahrnehmung.

Das Problem, das in dieser Scheinwahrnehmung - wir nennen sie gewöhnlich Halluzination - steckt, muß deshalb das Interesse des Psychiaters, ja jedes Denkenden überhaupt erregen wie kaum ein zweites. Beginnt doch sogar die Lehre von der normalen Erkenntnis, dieses Problem immer mehr für ihr eigenes Forschungsgebiet zu verwerten. -

Es wird hier nun zum ersten Male ein neuer Gesichtspunkt in die Betrachtung des Halluzinationsproblems eingeführt, der er ken n $t$ n is theoretische.

Die Berechtigung, ja Notwendigkeit hierzu erscheint dem Verfasser gegeben durch den Umstand, daß der wesentliche Unterschied zwischen der Wahrnehmung und damit auch der Trugwahrnehmung einerseits und der Vorstellung andererseits auf erkenntnistheoretischem Gebiete liegt und nicht auf ps ychologischem.

Bezüglich der Wahrnehmung ist das leicht einzusehen. Denn das, wodurch sich die Wahrnehmung grundlegend von der Vorstellung unterscheidet, ist die Beziehung auf eine auBerhalb des erkennenden Geistes bestehende Wirklichkeit. Diese Beziehung ist aber ebensowenig psychologisch zu erklären wie die Wirklichkeit selbst, auf welche sie übergreift. Sie ist ein rein erkenntnispraktischer, wissenschaftlich gefaßt, erkenntnistheoretischer Vorgang.

Andere Gründe, aus welchen die erkenntnistheoretische Seite der Geistesfunktion von der Psychiatrie nicht vernachlässigt werden darf, werden wir weiter unten kennen lernen.

Während nun zwischen normaler Wahrnehmung und Vorstellung außer erkenntnistheoretischen Unterschieden sehr markante psycho- 
logische Unterschiede existieren, werden wir die letzteren bei der Trugwahrnehmung sogar prinzipiell in den Hintergrund treten sehen.

Wenn wir darum auch das eigentliche Wesen der Halluzination als psychischen Tatbestandes hauptsächlich auf der erkenntnistheoretischen Seite zu suchen haben werden, so werden wir doch das Zustandekommen der Halluzination, die kausale Genese, auf rein pathopsychischem, bzw. psychopathologischem Gebiete finden.

Indem wir bewußt zum ersten Male den erkenntnistheoretischen Gesichtspunkt in die Betrachtung des Halluzinationsproblems einführen, soll damit doch nicht gesagt werden, daß dieser Gesichtspunkt tatsächlich hier zum ersten Male zur Analyse des Problems der normalen und der trügerischen Wahrnehmung verwandt wird.

Der Autor, der, freilich ohne sich dessen bewußt zu werden, ohne es wenigstens auszusprechen, diesen Gesichtspunkt in ausgiebigster Weise angewandt hat, ist Goldstein selbst, trotzdem, oder gar weil der Ausgang seiner Theorie ein rein psychologischer ist. Denn indem dieser Autor die ,,prinzipielle Identität von Wahrnehmung und Vorstellung als psychischer Tatbestände" behauptete, so mußte er natürlich neue erkenntnistheoretische Gesichtspunkte einführen, um der Wahrnehmung eine Erkenntnisbeziehung auf die Wirklichkeit zu geben. Er führte zu diesem Zwecke sogar einen logisch-erkenntnistheoretischen Gesichtspunkt ein.

Freilich ist der Autor mit seiner Grundannahme auf fast einstimmigen Widerspruch gestoßen. Wir glauben auch nicht, daß er mit seiner neuesten Veröffentlichung ${ }^{1}$ ) mehr Erfolg haben wird. Dabei wird sich herausstellen, daß noch nicht einmal die tiefsten Gründe gegen seine Ansicht ins Feld geführt worden sind.

Auf der anderen Seite werden wir jedoch zu zeigen haben - und das ist wohl verkannt worden, das hat sogar der Autor selbst nicht in seiner ganzen Tragweite zur Darstellung gebracht —, daß in seiner Lehre von der Mitwirkung des Urteils, so wenig wir ihr eine bedeutungsvolle Stelle im normalen Wahrnehmungsvorgange einräumen können, doch ein wertvoller Kern für das Verständnis des Halluzinationsvorganges und seiner Genese steckt, der nur zum Schaden des Problems selbst wieder verloren gehen könnte.

Utber Polemik und Zustimmung hinaus verfolgt diese Abhandlung den Hauptzweck, das Halluzinationsproblem nochmals von allen Seiten einer erneuten Betrachtung zu unterziehen, wobei wir uns freilich auf die Herausstellung der wesentlichsten Punkte zu beschränken haben werden.

Indem wir nun zum Verständnis der trügerischen Wahrnehmung zunächst den normalen Wahrnehmungsvorgang in seinem Wesen z.u

1) Goldstein, Weitere Bemerkungen zur Theorie der Halluzinationen. Zeitschr. f. d. ges. Neur. u. Psych. 1913. 
begreifen suchen werden, werden wir doch nicht mit dem erkenntnistheoretischen Gesichtpunkt beginnen. Das würde uns für eine philosophische Abhandlung passend erscheinen. Wir werden vielmehr mit dem psychogenetisch-biologischen Gesichtspunkt den Anfang machen.

\section{A. Die normale Wahrnehmung.}

1. Die Wahrnehmung vom psychogenetischen und biologischen Standpunkt.

Wir unterscheiden bekanntlich drei Grundarten von Bewußtseinsphänomenen oder psychischen Vorgängen. Es gibt solche, in welchen wir uns in irgendeiner Weise zuständlich erregt finden: das sind die Ge$\mathrm{fühle}$ und die sich aus diesen entwickelnden Affekte. Zweitens gibt es solche, in welchen wir uns in unserm Bewußtsein auf etwas gerichtet finden, in welchen ein intentionales, ein hinstrebendes Moment zum Ausdruck kommt: das sind die Woll ungen. Aus den undifferenzierten Gefühlen und Wollungen gehen die Triebe und Instinkte hervor. Die dritte Art der Bewußtseinsvorgänge sind diejenigen, in welchen ein gegenständliches Moment zum Ausdruck kommt: die Vorstellungen.

Die Vorstellungen zerfallen nun in die Wahrnehmungsvorstellungen, kurzweg Wahrnehmungen genannt, $d . h$. diejenigen Bewußtseinsphänomene, deren gegenständlicher Inhalt durch die unmittelbare Einwirkung der Außenwelt auf unsere Sinnesorgane entsteht, und zweitens in die Eigenvorstellungen ${ }^{1}$ ): die Vorstellungen im engeren Sinne, diejenigen gegenständlichen Inhalte, welche ohne unmittelbare Einwirkung eines äußeren Reizes durch die eigene psychische Tätigkeit erweckt in unserem Bewußtsein auftauchen. Die Vorstellungen selbst teilen wir noch zweckmäßig ein in Erinnerungsvorstellungen, Phantasievorstellungen und Gedankenvorstellungen. Auf den letzteren beruht die in Urteil, Schluß und Begriff zum Ausdruck kommende höhere intellektuelle Tätigkeit.

Die Voraussetzung nun für die produzierende oder besser ausgedrückt, für die reproduzierende Tätigkeit, durch welche Vorstellungen irgendwelcher Art und irgendwelchen Inhalts im Bewußtsein auftauchen, ist die Wahrnehmung. Man kann nicht vorstellen, wenn man nicht vorher wahrgenommen hat. Nihil est in intellectu usw.

Ist das richtig - und niemand kann es bezweifeln, der nicht auf die seit drei Jahrhunderten abgetane Lehre von den angeborenen Vor-

1) Der Begriff der Eigenvorstellung, von welchem ich im Gegensatz zu dem der Wahrnehmungsvorstellung im folgenden Gebrauch machen werde, ist nicht ganz unzweideutig. Man kann bei ihm an die Vorstellung der cignen Person, die Körperlichkeit mit eingeschlossen, denken. Da jedoch die Anwendung des Begriffs Eigenvorstellung in diesem Sinne bisher nicht gebräuchlich gewesen ist, so darf ich ihn wohl der Kürze halber im Sinne der „Vorstellung im engeren Sinne" der Wahrnehmungsvorstellung gegenübersetzen. 
stellungen zurückgreifen will -, so ist es deutlich, daß die Wahrnehmung ursprünglich und prinzipiell ein auf sich selbst gestellter Bewußtseinsvorgang in dem Sinne sein muß, dil $\beta$ kein irgendwie gearteter anderer gegenständlicher Bewußtseinsvorgang hinzuzutreten braucht, um den Wahrnehmungsvorgang selbst in Tätigkeit zu setzen oder in seiner Eigenart zu bestimmen, denn sonst wäre es eben nicht der ursprüngliche, gegenständliche Bewußtseinsvorgang, aus welchem der Geist den ganzen Schatz seines Inhaltes bezicht.

Selbst wenn sich also herausstellen sollte, daß in dem entwickelten menschlichen Bewußtsein Vorgänge aus dem Bereiche des Vorstellungslebens, Begriffe, Urteile, Schlüsse aufgezeigt worden können, welche bei manchen, vielleicht bei allen Wahrnehmungsakten eine Rolle spielen, so bleibt doch als Grundtatsache prinzipiell bestehen, daß der Wahrnehmungsvorgang, durch welchen wir der Außenwelt innewerden, selbst beim entwickeltsten Lebewesen, dem Menschen, ein unmittelbar durch sich selbst betätigter Akt ist.

Ganz ohne Einschränkung ist dieser Grundsatz bei denjenigen Lebewesen anzuerkennen, denen wir nieht das Recht haben, ein höheres Gedankenleben zuzuerkennen. Ob die höheren Tiere zu urteilen und schließen imstande sind, können wir sogar dahin gestellt sein lassen. Es gibt aber eine Grenze, bei welcher die Möglichkeit für eine solche Annahme von vornherein fortfällt, ohne daß wir im Hinblick auf vorhandene Sinnesorgane an dem Vorhandensein von Wahrnehmungsvorgängen zu zweifeln uns für berechtigt halten könnten.

Würde deshalb die von Goldstein gemachte Annahme von der prinzipiellen Identität von Wahrnehmung und Vorstellung richtig sein so müßten zunïchst schon die Tiere, denen man wohl ein Vorstellungsleben als solches wird zusprechen müssen - Träume der Hunde! denen aber die meisten besonnenen Beurteiler die Fähigkeit zu entwickelten Urteilen und Schlüssen absprechen, rettungslos der Verwechslung von Wahrnchmung und Vorstellung verfallen. Der Hund, der sich auf der Spur des Herrn abmüht, müßte jeden Augenblick mit Suchen innehalten, da er die offenbar immer von neuem und mit immer größerer Lebhaftigkeit in ihm auftauchende Vorstellung des gesuchten Herm von der Wahmehmung des gesehenen Herrn nicht unterscheiden könnte und deshalb jeden Augenblick glauben müßte, ihn gefunden zu haben, bis er sich durch das Ausbleiben anderer Wahrnehmungsmomente von der fehlenden Realität seiner Gesichtsvorstellung überzeugt hïtte. Der Löwe im Käfig, den wir um die Fütterungszeit so unruhig werden sehen, weil er den Wärter an den Nebenkäfigen hantieren hört, müßte jerlen Augenblick in die Luft schnappen, weil er das lebhaft vorgestellte Fleischstück nicht von dem tatsächlich gesehenen unterscheiden könnte. 
Vielleicht können aber die Tiere urteilen, oder, wemn das nicht der Fall ist, vielleicht ersetzen ihnen Assoziationen Urteil und Schluß.

Nun sehen wir aber, daß das eben aus dem Ei gekrochene Hühnchen nach den vorgelegten Körnern pickt. Diese nimmt es offenbar wahr, und deren Gesichtsbild prägt sich ihm ein, so daß es auch eine Vorstellung von den Körnern hat. Denn es pickt immer nur nach den Körnern, nicht nach den Kieselsteinen, am wenigsten in die Luft, etwa weil es die Vorstellung der Körnchen mit der Wahrnehmung verwechselte.

Offenbar wertet das Hühnchen schon das Gesichtsbild des ersten Körnchens als Außenweltsgegenstand, denn sonst würde es sich diesen nicht einverleiben. Daß das Hühnchen und wohl auch das ausgewach. sene Huhn diese Wertung instinktiv anstellt, nicht mit bewußter Uberlegung, ist selbstverständlich, um so selbstverständlicher, als das erstere nicht einmal Eigenvorstellungen hat, mit denen es Außenvorstellungen vergleichen könnte. Wir wollen hier nur auf den Naturtrieb hindeuten, der die Organismen zwingt, Dinge, die zur Befriedigung ihrer $\mathrm{Be}$ dürfnisse dienen, sich einzuverleiben, d. h. Dinge, die es durch Augenschein wahrnimmt, aber sich noch nicht einverleibt hat, eben als der Außenwelt angehörig instinktiv zu betrachten.

Nicht anders steht es beim jungen Kinde, das soeben anfängt, Gesichtswahrnehmungen zu differenzieren.

Das Kind lernt allmählich seine Umgebung erkennen. Es beginnt die Personen, welche sich mit ihm beschäftigen, zu unterscheiden. Wir wissen ganz sicher, daß es vor Erkenntnis der Welt eine Innenvorstellung nicht besitzt. Erst lernt es die Außenwelt erkennen, bevor sich ihm daraus eine Innenwelt aufbaut.

Wir haben also als gewiß anzunehmen, daß die erkennenden Wesen, seien es Tiere oder Menschen, all das, was sie von vornherein als äußeres Erfahrungsmaterial erwerben, unmittelbar als solches werten, weil sie keiner Innenwelt als Vergleichsgegenstand teilhaft sind, an der sie die Außenwelt zu messen vermöchten.

Verfolgen wir nun die werdende Erkenntnis der Außenwelt beim Kinde etwas näher, und zwar die Erkenntnis durch den Gesichtssinn, der uns die mannigfaltigste Kunde von der Außenwelt gibt!

Wir werden es als ganz sicher betrachten, daß das Kind, bevor es die Gegenstände der Außenwelt als gesonderte Wahrnehmungsgebilde in sich aufzunehmen vermag, mit allen physiologischen Fähigkeiten ausgestattet ist, welche ihm die Gewinnung eines Außenweltbildes ermöglichen. Das Kind kann sicher sehen, bevor es erkennt, d. h. bevor es gesonderte Wahrnehmungsbilder in sich aufnimmt. Das Sehen ist die Voraussetzung des Erkennens. Zu Lichtreaktionen ist das Kind sicher schon gleich nach der Geburt fähig. Denn es schließt das Auge 
reflektorisch, wenn es dem grellen Licht ausgesetzt wird. Es wird auch sicher sehr bald zu Farbenperzeptionen befähigt sein, da ja die Stäbchen und Zapfen seiner Netzhaut als solche wohl ausgebildet sind.

Es fällt also dem Kinde die gesamte Außenwelt von vornherein ins Auge. Aber erst allmählich lernt es, die Außenweltsgegenstände räumlich voneinander abzugrenzen. Diese Außenwelt ist das feststehende äußere Gebilde, an welchem sich allmählich erst eine Innenwelt von flüchtigen Formen bildet.

Die dreidimensionale Mannigfaltigkeit freilich, die wir mit unserem Tastsinn wahrnehmen, die vielfarbigen Flächen, die sich dem Auge darbieten, müssen wir allmählich differenzieren lernen. Wir müssen lernen, die farbigen Flächen mit dem Getasteten in Beziehung zu setzen und das mit dem Auge Wahrgenommene nicht mehr flächenhaft, sondern körperlich zu sehen. Zugleich lernen wir die Abgrenzung des Gesehenen in Ubereinstimmung mit dem Getasteten und ebenso die Beziehung der Qualitäten, welche wir mit unseren anderen Sinnen aufnehmen, auf das Gesehene und Getastete.

Das alles müssen wir lernen. Aber nicht lernen wir, das Draußensein dieser Welt überhaupt zu erkennen. Alles Erkennen ist ein Differenzieren. Es existiert aber zunächst gar nichts, wovon wir ein „Draußen" differenzieren lernen könnten.

Daß später, wenn auch unsere Innenwelt sich gefestigt hat und die Phantasiewelt lebhaftere Formen angenommen hat, Täuschungen über das Existentialmoment vorkommen können, daß Kinder und Naturmenschen die (iebilde ihrer lebhaften Phantasietätigkeit, besonders ihre Träume, zuweilen hinterher mit den Dingen der Außenwelt verwechseln, ist richtig. Man darf aber diesen gelegentlichen Verwechslungen, die sich auch im wesentlichen auf die spätere Verwertung des phantastisch Vorgestellten für die Handlungsweise beschränken, nicht als Beweismomente einer von vornherein bestehenden prinzipiellen Unterschiedslosigkeit innerer und äußerer Existenz ins Feld führen. Prinzipiell steht die äußere Existenz der Welt für die Erkenntnis von vornherein fest, und wenn auch jene Verwechslung der Phantasiewelt mit der Welt der Wirklichkeit im naiven Menschheits- und Kindheitsstadium zuweilen vorkommt, so ereignet sich doch nie das Umgekehrte. Nie passiert es im normalen Leben und unter normalen Verhältnissen, daß dic Wirklichkeitswelt für phantastischer Schein gehalten wird.

Erst wenn der Prozeß des Erkennens der Außenwelt so weit vorgeschritten ist, daß er für das erste praktische Bedürfnis des Zurechtfindens als relativ abgeschlossen betrachtet werden kann, beginnt die Phantasiewelt, die Welt der Eigenvorstellungen sich zu regen, aber zugleich sich als Bildwelt von der Wirklichkeitswelt abzuheben; 
denn die bleibende Außenwelt, welche zunächst allein da ist, verliert natürlich dadurch nicht ihren Außenweltcharakter, daß flüchtige Bilder in der Seele auftauchen, die gelegentlich - übrigens selten genug so lebhaft werden können, daß sie für das Individuum vorübergehend Wirklichkeitswert anzunehmen vermögen, und niemals verflüchtigt sich infolge der wachsenden Lebhaftigkeit der Eigenvorstellungen das Außenweltsding zu einem so wirklichkeitslosen Schein, da $\beta$ es der Erkenntnis als Phantasieprodukt erscheinen könnte und damit in die Reihe der Eigenvorstellungen hinüberwechselte.

So bewahrt sich die Welt der Erfahrung, aus der wir unser ganzes Vorstellungsmaterial beziehen, den Außenweltcharakter, mit welchem sie von vornherein dem Bewußtsein gegenübertritt. Sie bewahrt sich diesen selbst, nachdem der Geist begonnen hat, sich eine Innenwelt zu schaffen und sie als Bildwelt der Wirklichkeitswelt gegenüberzustellen. -

Eine biologische Betrachtung, die wir im vorhergehenden schon angedeutet finden, soll uns nun durch ihre nähere Ausführung den Außenweltswert des Wahrnehmungsmaterials noch tiefer begründen helfen. Durch sie soll der Wirklichkeitscharakter, die "Leibhaftigkeit" der Welt, zum biologischen Wert selbst umgestempelt werden.

Wir erwähnten, daß es der Trieb resp. Instinkt ist, welcher das eben geborene Tier sein Nahrungsmaterial unmittelbar aus Außenweltsgegenstand werten läßt. Betrachten wir nun das Verhältnis der Wahrnehmung zum Triebe in seiner prinzipiellen Grundlage! Durch den Grundtrieb alles Lebenden, den Erhaltungstrieb, wird der Bestand des Lebens gesichert. Der Erhaltungstrieb kann sich aber nur dadurch betätigen, daß das Individuum den Zerfall seiner Substanz durch Aufnahme und Einverleibung fremder, noch nicht zu seiner individuellen Körperlichkeit gehörender Substanz kompensiert. Die Assimilation des Umgebungsmaterials ist die notwendige Folge der Dissimilation des eigenen Materials, die nun einmal die grundlegende Begleiterscheinung jeder Lebensäußerung ist.

Im Pflanzenreich und auf der niedersten Stufe des Tierreichs vollzieht sich dieser Assimilatationsprozeß rein physikalisch-chemisch ohne das Hinzutreten eines Wahrnehmungsmoments. Ob ganz ohne seelisches Moment, können wir natürlich nicht mit Sicherbeit sagen. Aber mögen wir auch annehmen, daß schon etwa bei den einzelligen Lebewesen irgendein, wenn auch noch so schwach entwickelter Seelenprozeß, etwa in Form eines dunklen Gefühlszustandes den Lebensprozeß begleiten möchte - diese Annahme könnte sich methorlisch vielleicht empfehlen, weil wir sonst ein unvermitteltes Entstehen des Geistigen auf den höheren Stufen des tierischen Lebens annehmen müßten -, so wäre das doch eine rein spekulative Annahme, die aus unseren Erwägungen auszuscheiden hätte. Was wir jedoch mit einer gewissen Sicher- 
heit leugnen können, ist clas Vorhandensein eines Frrkenntnisprozesses auf den niedersten Stufen des Lebens, den wir als Wahrnehmung bezeichnen könnten. Denn es fehlen noch Sinnesorgane, an die wir auf den höheren Stufen des Lebens den Wahrnehmungsprozeß geknüpft sehen.

Wenn nun der Erhaltungstrieb darauf ausgeht, das Außenweltsubstrat in sich aufzunehmen, um es an die Stelle des zersetzten und ausgeschiedenen Eigensubstrats zu setzen und damit das Leben aufrechtzuerhalten, so werden wir auch annehmen dürfen, daß die später auftretenden Sinnesorgane, welche zunächst völlig im Dienste des Er haltungstriebes stehen, ihm vielleicht seine Entstehung verdanken, auch gemäß den Bestrebungen des Erhaltungstriebes ihre Funktion zur Ausbildung bringen. Der Tastsinn, der Gesichtssinn, der Gehörsinn usw. entstehen und vervollkommnen sich also im Dienste des der Außenwelt zugewandten Erhaltungstriebes. Der Trieb „treibt"den Sinn a uf die Außenwelt, um dem Individum sein Lebensmaterial z u verschaffen. Durch den Gesichtssinn und Gehörsinn erspäht das Individuum schon auf größere Entfernungen die Fremdsubstanz, clie zur Eigensubstanz werden soll usw.

Wir brauchen diese Betrachtung nicht weiter zu führen, denn es fst klar, daß auf diese Weise der Außenweltscharakter der Erfahrungsgegenstände jenen biologischen Wert gewinnt, durch welchen er eine durch das Leben und seine Grundfunktion begründete unverrückbare Beziehung zu dieser selbst, zur Erhaltung des Lebens, gewinnt. So wie der Trieb das Individuum zwingt, sich ein Außenweltsubstrat einzuverleiben, so zwingt der im Dienste die. ser Triebe stehende Sinn von vornherein das Individuum ohne das Hinzutreten einer weiteren intellektuellen Funktion, die Außenwelt zu konstatieren, welche dem Trieb das Material für seine Betätigung liefert.

Ohne Urteil und Schluß nicht nur, die ja auf den niederen Stufen des Lebens noch nicht in Wirksamkeit treten, sondern auch ohne Assoziation, die etwa an Stelle von Urteil und Schluß das Individuum die Unterscheidung von Innen- und Außenwelt lehrten, erzwingt die im Dienste des Triebes stehende Sinneswahrnehmung durch sich selbst die Anerkennung einer Außenwelt. Und dieser unmittelbar wirkende Zwang bleibt bestehen; selbst nachdem sich der Sinn von der alleinigen Motivierung durch den Trieb emanzipiert hat, nachdem er, dem praktischen Zwange entwachsen, sich in den Dienst des theoretischen Erkennens gestellt hat, nachdem Philosophen und philosophierende Mediziner die Wahrnehmungsgebilde in reine Vorstellungsgebilde aufgelöst haben, von denen es nun nicht mehr klar zu sein scheint, ob sie wirklich theoretisch sicher zu stellende Kennzeichen besitzen, durch welche sich diese von jenen unterscheiden. 
2. Die Wahrnehmung vom Standpunkt der Erkenntnistheorie.

Die Erkenntnistheorie kann sich nun freilich um biologische Betrachtungen nicht kümmern. Sie hat nicht die Verpflichtung, ja nicht einmal die Berechtigung, den Erwägungen der Biologie ihr Ohr zu leihen. Und die Medizin? Man sollte meinen, die hat sich nicht einmal um die Erkenntnistheorie zu kümmern. Die Medizin ist eine Tatsachenwissenschaft wie jede andere Naturwissenschaft. Nur das Was und Wie dieser Tatsachen ist ihr Problem, nicht das $\mathrm{Ob}$ überhaupt. In der nach ihrer Existenz unbesehen hingenommenen Außenwelt steckt die Medizin ebenso wie jede andere Wissenschaft ihr Feld ab und beginnt nun über den Inhalt dieses Feldes ihre Forschungen anzustellen. Aber das Feld ist da. Hierüber gibt es für die empirische Wissenschaft kein Problem.

Nun beschäftigt sich aber die Medizin nicht nur mit eben dieser Außenwelt, näher mit dem in dieser Außenwelt abgesteckten Felde, dem menschlichen Körper, sondern auch mit jener Innenwelt, durch welche wir uns erst der Außenwelt bewußt werden. Und der bestimmte Teil der Medizin, welcher die pathologischen Vorgänge in dieser Innenwelt zum Objekt seines Forschens macht, die Psychiatrie, stößt auf Krankheitserscheinungen, durch welche das Gegebensein der Außenweltphänomene selbst eine pathologische Form erhält.

Damit erscheint der Mediziner selbst mitten in das erkenntnistheoretische Grundproblem hineingestellt, denn um die falsche erkenntnispraktische Stellungnahme der erkrankten Psyche richtig zu würdigen, müßte er doch nun auch die normale erkenntnispraktische Stellung des Bewußtseins, soweit wenigstens der Existentialfaktor in Frage kommt, einer wissenschaftlichen Untersuchung würdigen. Gilt für die Erforschung der körperlichen Krankheiten die Erkenntnis der normalen körperlichen Eigenschaften und Funktionen als unerläßliche Voraussetzung, so kann wohl kein Zweifel darüber bestehen, daß auch das Studium der normalen Erkenntnisvorgänge unbedingt der Erforschung der krankhaften Erkenntnisvorgänge, insbesondere also dem Studium der Halluzinationen vorauszugehen hat.

Gegen diese Schlußfolgerungen könnte der Psychiater zwei Einwendungen machen. Die eine als Psychopathologe. Als solcher könnte er sich zunächst auf den psychologischen Standpunkt zurückziehen. Ebenso wie der Psychologe sich nicht um die Erkenntnis der Weltexistenz kümmert, sondern diese Erkenntnis ebenso wie die Welt selbst einfach voraussetzt und nur nach den psychologischen und physiologischen Bedingungen forscht, unter welchen wir von dieser Welt nähere Kunde erhalten, so müßte auch der Psychopathologe die Welterkenntnis 
als solche voraussetzen und nur nach den Abweichungen von jenen Bedingungen fragen.

Bei dieser Einwendung wird aber übersehen, daß das Feld des Psychopathologen prinzipiell ein viel weiteres ist als das des Psychologen. Der letztere beschäftigt sich eben nur mit den psychologischen Vorgängen als solchen. Der Psychopathologe aber zieht in seinen Bereich die Erkrankungen der gesamten psychischen Sphäre. Unter diese fallen aber nicht nur Abweichungen von den psychologischen Vorgängen im engeren Sinne, sondern auch von den logischen, erkenntnispraktischen, ja ethischen usw. Demenz, pathologische Charaktere usw. sind ebenfalls das Objekt seiner Forschung. Stellt sich also heraus, da $\beta$ der normale Erkenntnisvorgang, durch welchen wir das Bewußtsein einer Außenwelt gewinnen, ein erkenntnispraktischer Vorgang ist und kein psychologischer, so kann der Psychiater die pathologische Abweichung von diesem Bewußtseinsvorgang zunächst natürlich auch nur vom erkenntnistheorətischen Gesichtspunkt würdigen.

Den zweiten Einwand könnte der Psychiater als Gehirnpathologe machen. Er könnte sagen, für ihn sei die Halluzination weder ein psychologisches noch ein erkenntnistheoretisches Problem, sondern ein gehirnphysiologisches bzw. -pathologisches. Dieser Einwand kann nur durch den Gang der Untersuchung selbst widerlegt werden. Denn nur diese kann zeigen, ob wir dem Halluzinationsproblem von der gehirnpathologischen Seite allein gerecht werden können.

Schließlich hat die historische Entwicklung selbst zur Geltendmachung des erkenntnistheoretischen Standpunktes geführt, und es ist auch niemandem eingefallen, die Forscher, die das getan haben, zu tadeln. Daß man dabei nicht merkte, daß sie erkenntnistheoretische Ausführungen machten, ist gleichgültig, und ebenso ist es gleichgültig, da $\beta$ diese Forscher selbst erkenntnistheoretische Betrachtungen abzulehnen scheinen. Wenn z. B. Goldstein auf der einen Seite sagt, daß er mit dem Außenweltsproblem sich nicht beschäftige, auf der anderen Seite aber die Funktion leugnet, durch welche man bisher glaubte, die Welt erkennen zu können, so stellt er sich damit natürlich selbst mitten in das erkenntnistheoretische Problem hinein.

Sehen wir gleich zu, wie dieser Autor die Frage der Außenweltserkenntnis behandelt. Wir können daran am besten unseren eigenen Standpunkt anknüpfen.

Nachdem Goldstein die Unterschiede zwischen Wahrnehmung und Vorstellung auf rein graduelle reduziert hat, versucht er durch Einführung der Urteilsfunktion die Welterkenntnis wiederzugewinnen. Er argumentiert ungefähr so:

Wir stellen durch die Erfahrung die Diskontinutät zwischen reproduzierten Vorstellungen, den Eigenvorstellungen, wie wir sie genannt 
haben, und den Wahrnehmungsvorstellungen fest. Kontinutät haben nur die Eigenvorstellungen untereinander. Zwischen Wahrnehmungsvorstellungen einerseits und Eigenvorstellungen andererseits aber besteht Diskontinutät. Wir stellen also durch vielfältige Erfahrung fest, daß die Räumlichkeit der Dinge, von welcher wir vermittels der Wahrnehmung Kunde erhalten, nicht in die Räumlichkeit hineinpaßt, in der sich uns unsere Eigenvorstellungen, die Erinnerungsvorstellungen und Phantasievorstellungen, innerlich darstellen. Diese tausendfach gemachte Erfahrung wenden wir auf den jeweiligen Bestand unserer Eigenvorstellungen und der im Augenblick gemachten Wahrnehmungen an. Indem wir auf Grund der Erfahrung konstatieren, daß ein eben wahrgenommener Gegenstand nicht in die Räumlichkeit unserer Eigenvorstellungen hineinpaßt, wohl aber in die Räumlichkeit der früher erlebten Wahrnehmungen und des augenblicklich vor uns stehenden ,,wirklichen Wahrnehmungsfeldes", sehen wir uns veranlaßt, jenen Gegenstand der Außenwelt als Bestandteil zuzuerkennen. So blitzschnell uns auch die jeden Augenblick gemachte Erfahrung von der räumlichen Kontinutät der einzelnen Wahrnehmungen untereinander und der einzelnen Vorstellungen untereinander und der räumlichen Diskontinutät beider Reihen gegeneinander die Einordnung jeder gemachten Wahrnehmung in den Außenweltsraum gestattet, so blitzschnell, daß wir ohne weiteres die ,Leibhaftigkeit" der Wahrnehmungsgegenstände im Wahrnehmungsakte konstatieren, so ist doch diese Leibhaftigkeit eben nicht durch den Wahrnehmungsakt gegeben, der als solcher keinen prinzipiellen Unterschied von einem Vorstellungsakt zeigt, sie ist lediglich gegeben durch ein kompliziertes Schlußverfahren, welches sich auf der Gesamtheit unserer früheren und augenblicklichen inneren und äußeren Erlebnisse aufbaut.

Wie wir sehen, reflektiert Goldstein bei dieser Beweisführung nur auf die räumliche Kontinuität und Diskontinuität. Er hätte auch noch die kausale zu Hilfe rufen können. Denn bekanntlich haben die beiden Reihen der äußeren und inneren Vorgänge auch ihre eigene Kausalität, die man bei letzterer nur gewöhnlich Motivation nennt.

Goldstein meint von seiner Theorie, daß sie berufen sein dürfte, sowohl den normalen psychologischen wie den mannigfachen halluzinatorischen Vorgängen besser als die bisherige Lehre von der prinzipiellen Differenz von Wahrnehmung und Vorstellung gerecht zu werden. Wäre diese Erwartung gerechtfertigt, so könnte sich Goldstein noch ein viel weitgehenderes Verdienst zuschreiben. Seine Theorie würde eine der bedeutungsvollsten Fortschritte sein, welche das menschliche Denken, im speziellen die Erkenntnistheorie, je gemacht hätte ${ }^{1}$ ).

1) Man sollte meinen, daß irgend einer der Philosophen, die sich berufsmäßig mit Erkenntnistheorie beschäftigen, die Identität von Wahrnehmung und Vorstel- 
Eines scheint freilich Goldstein und scheinen auch alle seine Kritiker übersehen zu haben, daß nümlich unter Voraussetzung der prinzipiellen Identitït von Wahrnehmung und Vorstellung auch das sog. ,wirkliche Wahmohmungsfeld" sjeh ebenfalls in eine Vorstellung auflöst, vielleicht in eine Vorstellung von etwas dauernderem Bestande, aber in reine Vorstellung.

Die motaphysischen Konsequenzen, welche sich aus einer solchen Annahme ergeben wüıden, kömen wir hier wohl füglich beiseitelassen. Die Widerlegung der Annahme selbst kann jedoch, falls eine solche überhatupt notwendig ist, nur auf erkemmistheoretischen Wege durchgeführt werlen. Auch die Gegner Goldsteins haben sich, soweit sie sich mit clieser seiner Ansicht beschäftigten, in erkenntnistheoretischen Gertankengängen bewegt.

Wir stcllen also cinfach fest, daß wir durch die Wahmehmung selbst auf eine Außenwelt hingewiesen werden. Wie die Wahrnehmung es fertig bringt, über sich hinauszugehen, um außer ihr noch etwas für sie Existierendes zu konstatieren, geht uns nichts weiter an. Dieses Problem fällt dem Erkenntnisteorethiker zur weiteren Behandlung zu.

Die instinktiv gefïhlte Schwierigkeit, die uns die transzendierende Fïhigkeit der Wahmehmungsvorstellung, die doch, von der psychologischen Seite betrachtet, auch nichts anderes als cine Vorstellang ist, bietet, die Schwierigkeit, die darin besteht, daß sie uns noch etwas anderes zeigen soll als sich selbst, ist wohl auch der Grund für die nunmehr auch in die Medizin übergreifenden Versuche, die Wahnneh. mung nach jeder Rjchtung als nichts anderes zu betrachten denn als jede andere Vorstellung auch.

Man erkennt leicht, wie bei einem solehen Versuch das erkenntnispraktische Moment der Wahrnehmung, das eben in dem Hinweis auf ein außer ihr bestehendes Etwas liegt, einfach unter den Tisch fïllt. In der wissenschaftlichen Betrachtung wird aber dadurch dic erkenntnistheoretische Bedeutung der Wahrnehmung als eines Außenweltsindicators überhaupt ausgeschaltet. Die Wahmohmung bietet dann nur noch psychologisehe Angriffspunkte. Sie mag dann noch gewisse Cnterschiede der Intensitä, der Verlaufsirt, des Eintretens, Verschwindens, Bestandes usw. zeigen, durch welche sie sich von der Eigenvor-

lung längst als Theorie aufgestellt hätte, wenn sie einige Nussicht auf wissenschaftliche Glaubw ürdigkcit hätte. Iaß das nicht geschehen ist, könnte uns von vornherein schon gegen Coldsteins Theorie sehr skeptisch stimmen. Einige Ähnlichkeit der letzteren könnte man höchstens mit der von dem englischen Philosophen Brokeley im 18. Jahrhundert entwickelten Anschauung entdecken. Auch dieser Philosoph suchte auf psychologischem Wege die Unterschiede zwischen Wahmelmung und Vorstellung zu reduzieren. Lir führte aber, was hier nicht weiter auseinandergesetzt werden kann, den Versuch an den lieziehungen des Frkennens zur Außenwelt durch. 
stellung unterscheidet, ihre unmittelbare Beziehung zur Außenwelt aber hat sie verloren.

Wenn dann trotzdem diese durch bestimmte, rein psychologisch zu qualifizierende Merkmale ausgezeichneten Vorstellungen, sog. Wahrnehmungsvorstellungen, zum Mittler einer außer uns bestehenden Welt werden sollen, so müssen ihr eben noch andere Helfer zur Seite treten. Ein logisches Schlußverfahren wird ihr nach Goldstein zum Sprungbrett, durch das sie sich auf eine außer ihr liegende Welt hinüberschwingen soll. Das erkennitnispraktische Moment, durch welches sich der naive Mensch bisher unmittelbar einer Außenwelt bewußt zu werden glaubte, wird aus der Wahrnehmung herausgeworfen und ihr zum Ersatz ein logisches an die Seite gestellt.

Wie wenig nun die Logik zu transzendentem Fluge geeignet ist, ist freilich der Erkenntnistheorie von jeher klar gewesen. Man kann eine Außenwelt nicht beweisen, wenn man nicht ihrer durch die Wahrnehmung gewiß ist. Und diese Unmöglichkeit bleibt natürlich bestehen, selbst wenn wir mit Goldstein die - vom erkenntnistheoretischen Standpunkte freilich ganz unhaltbare - Inkonsequenz begehen und zwischen Gegenständen, welche dem ,,wirklichen" Wahrnehmungsfelde angehören, und solchen, deren Wirklichkeit erst erschlossen werden muß, unterscheiden würden.

Wir sehen also jedenfalls: kann uns die Wahrnehmung nicht durch sich eine außer uns bestehende Welt, Einzelgegenstände oder ,,wirkliches" Wahrnehmungsfeld, aufzeigen, so ist nicht einzusehen, wie wir sonst zu einer solchen gelangen sollten. Nur die Wahrnehmung ist transzendent, alle anderen Funktionen der Psyche sind immanent ${ }^{1}$ ).

Spielen nun frühere Urteile über die Wirklichkeit der wahrgenommenen Gegenstände und die „Unwirklichkeit" unserer Vorstellungen beim Wahrnehmungsakte überhaupt keine Rolle? Wir würden es für falsch halten, das zu behaupten. In allen unseren Wahrnehmungen klingen früher gefällte Urteile in einer Ausdehnung an, von welcher wir im gewöhnlichen Leben keine Ahnung haben. Wir werden das bei der Betrachtung des Apperzeptionsvorganges noch näher zu untersuchen haben. Es würde ja auch mit eigentümlichen Dingen zugehen, wenn sich die Psyche bei der Apperzeption der Erfahrungsgegenstände nur diejenigen früheren Erfahrungen und Urteile, welche sie über die Qualität der Dinge, und nicht auch diejenigen, welche sie über die Existenz der Dinge und die Nichtexistenz des nur Vorgestellten gewonnen hat, zunutze machen würde.

Aber die früher beurteilte Existenz hat nur eine nebensächliche Bedeutung für unsere Wahrnehmungsakte und sie kann selbst sich nur

1) Die Begriffe transzendent und immanent sind hier natürlich immer im erkenntnistheoretischen Sinne genommen und nicht im metaphysischen. 
dardurch in letzteren betätigen, daß wir uns in früheren Wahrnehmungsakten schon unmittelbar der Außenwelt vergewissert hatten. Eine größere Rolle spielt sie nur in den selteneren Perzeptionsvorgängen, in welchen wir über die Existenz des Perzipierten im Zweifel sind.

Helmholtz führt ein derartiges Beispiel an. Wenn wir im Dunkeln gehen, so sind wir zweifelhaft, ob ein seitwärts auftretender schwacher Lichtschein von einem wirklich existierenden Lichtreiz verursacht wird, oder ob wir nur eine entoptische Wahrnehmung haben. Hier wird die Apperzeption alle Hilfen heranziehen und auch die Urteile, die wir doch früher über Wirklichkeit und Nichtwirklichkeit gefällt haben.

Ein weiteres Beispiel wäre jene experimentell hervorgerufene Ungewißheit, wie sie in den Versuchen $\mathrm{K} u ̈ l$ pes ${ }^{1}$ ) durch Darbietung ganz schwacher, entoptischen Wahrnehmungen gleichender Lichtreize im Dunkelzimmer und ganz schwacher Eigenerregungen der Haut gleichender Hautreize hergestellt wurde ${ }^{1}$ ).

Aber das sind Ausnahmefälle. Wir mögen jedoch jetzt schon voraussehen, daß bei Halluzinierenden die Ungewißheit häufiger und infolge deren auch das Mitwirken eines Urteils häufiger gegeben sein wird.

Selbstverständlich kann sich, wie das aus dem eben Gesagten schon hervorgeht, an den Wahrnehmungsakt ein Urteil über die Existenz anschließen. Dann wird eben die schon im Wahrnehmungsakt implizite erkannte äußere Existenz nur nachträglich explizite im Urteil gedacht und vielleicht ausgesprochen. Ein ausdrückliches Wirklichkeitsbewußtsein ist sogar in der Wahrnehmung meistens gar nicht vorhanden. Es wird einfach nur, wie sich $J$ aspers so glücklich ausdrückt, mit der Wirklichkeit ,gerechnet", also gewissermaßen als selbstverständlich hingenommen ${ }^{2}$ ). Der Wahrnehmungsakt als solcher enthält eben, wie wir oben sagten, schon im plizite die Anerkennung einer äußeren Existenz, die Auffassung eines Objekts als Bestandteiles einer Außenwelt.

Einer sehr eigenartigen Auffassung ('oldsteins vom Realitätsurteil müssen wir noch Erwähnung tun. In seiner neuesten Arbeit über das Halluzinationsproblem (l. c.) führt er die von Jaspers gebrauchte Unterscheidung in unvermittelte und vermittelte Realitätsurteile in sehr eigentümlicher Weise weiter. Als vermittelte Realitätsurteile bezeichnet $\mathrm{J}$ as pers ganz richtig diejenigen Urteile, in welchen die Wirklichkeit der Gegenstände auf Grund von Erinnerungsvorstellungen oder anderen Urteilen anerkannt wird, als unvermittelte solche, in welchen ohne solche ein ausdrückliches Urteil gefällt wird. Wenn ich bei der

1) Külpe, Objektivierung und Subjektivierung von Sinnescindrücken (Wu ndts Phil. Stud. 19. 1902).

2) Das nähere Verhältnis vom Urteil zum Akt der Wahrnehmung s. bei Jasp.ers (zur Analyse der Trogwahrnehmungen; Leibhaftigkeit und Realitätsurteil, J)iese Zeitschr, 1911), der diese Beziehung trefflich behandelt hat, 
Wahrnehmung des Sonnenuntergangs das Urteil fälle: „Die Sonme geht unter", so ist das ein unvermitteltes Realitätsurteil, wenn ich sage: „Die Erde hat sich gedreht", so ist das ein vermitteltes Realitätsurteil. Denn es stützt sich auf die durch wissenschaftliche Forschung erworbene Erkenntnis. Diesen Unterschied wertet nun Goldstein um in Urteile über „Wirklichkeitsgrade“. Das Realitätsurteil wird ihm zum „Werturteile", welches den Grad der Wirklichkeit eines Objekts oder eines Vorganges bestimmt. Sowohl der Untergang der Sonne wie rlie Erddrehung sollen wirklich sein; nur ist die letztere ,wirklicher", weil sie unserer wissenschaftlichen Kenntnis besser gerecht wird.

Wenn nun Wirklichkeit so viel bedeutet wie Dasein in der Außenwelt, äußere Existenz - und in diesem Sinn faßt ja wohl auch Goldst 2in den Begriff der Wirklichkeit ${ }^{1}$ ) 一, so kann natürlich von Graden nicht gesprochen werden. Das Dasein hat keine Grade. Etwas ist oder ist nicht. Und ,Werturteile" iiber Existenz gibt es, so modern auch diese Urteilswertung selbst ist, im eigentlichen Sinne nicht. Der Begriff des Wertens, den wir freilich selbst in der biologischen Betrachtung angewandt haben, kann in bezug auf die Existenz nur in übertragenem Sinne gebraucht werden. Er bedeutet hier soviel wie „Konstatierung“. Seine eigentliche Bedeutung gewinnt er in den Wissenschaften, die sich nicht mit dem Sein, sondern mit dem Sollen beschäftigen, in den Wertwissenschafton als solchen, in der Ethik und Ästhetik. Wenn ich sage: etwas ist besser oder schöner als etwas anderes, so ist das ein sinngemäßes Werturteil. Abcr etwas ist ,dasciender" als etwas anderes - das kann ich nicht sagen.

Es gilbt nur eine Wirklichkeit. Diese lehrt uns in der Regel die Sinneswahrnehmung. Freilich kommen auch Sinnestäuschungen in dem später noch näher zu besprechenden Sinne vor, Sinnestäuschungen, die nicht als Halluzinationen, als Trugwahrnehmungen im pathologischen Sinne, zu bezcichnen sind, die vielmehr durch unsere Organisation und die äußeren Bedlingungen hervorgerufen sind, unter welchen wir die Dinge wahrnehmen. Der Untergang der Sonne ist eine solche Sinnestäuschung. In Wirklichkeit ist nur die Drehung der Erde da. Selbstverständlich hören wir nicht auf, vom Sonnenuntergang zu sprechen, nachdem sich die kopernikanische Weltanschauung durchgesetzt hat. Praktisch bleibt für uns das Verschwinden der Sonne, ihr Untergang, bestehen. Praktisch ist es, nach Dunkelwerden sogar für die uns umgebende Natur so, als ob die Sonne verschwunden, untergegangen wäre. Die Praxis ist für die Betrachtung der Dinge im gewöhnlichen Leben und ihren urteilsmäßigen Ausdruck das allein Bestimmende. In der wissenschaftlichen Betrachtung halten wir es zwar

1) Im weiteren Sinne sind natürlich auch unsere Vorstellungen ,wirklich“. Joch haben wir hiervon bei der obigen Betrachtung abzuschen. 
anders. Deshalb wäre es doch schief, zu sagen: Die Drehung der Erde ist ,,wirklicher" als der Sonnenuntergang.

Wir dürfen also an die Existenz oder die Wirklichkeit weder den Maßstab des Wertes legen, noch sie in Grade einteilen. Diese Betrachtungsweise muß sich aber leicht einer Auffassung aufdrängen, welche den eigentlichen Wertmesser der Wirklichkeit, der in unseren Sinnen liegt, verloren hat, und ihn deshalb durch mehr oder minder gut begründete Urteile zu ersetzen sucht. Die Wahrscheinlichkeitswerte und -grade dieser Urteile werden dann in Wirklichkeitswerte und -grade umgesetzt. -

Nachdem wir uns so der Wahrnehmungsfunktion als unmittelbar wirkenden $A$ u $B$ enweltsindikators vergewissert haben, wollen wir uns einer weiteren erkenntnispraktischen Konsequenz, die uns hiermit gegeben ist, zuwenden.

In der Außenwelt existieren, heißt räumlich existieren. Mit der Existenz der Dinge ist also zugleich ihre Räumlichkeit mitgesetzt. Auf welchen erkenntnispraktischen Bedingungen diese Raumsetzung der Dinge beruht, ob sie nach Kant auf einer a priori wirkenden Funktion unserer Anschauung beruht - eine Ansicht, der sich Goldstein zuzuneigen scheint - oder rein a posteriori durch die Erfahrung bedingt ist, lassen. wir hier dahingestellt. Die Entscheidung dieser Frage fällt wieder a usschließlich der Erkenntnistheorie zu. Wir haben hier wieder nur zu konstatieren, daß mit der Wahrnehmung der Außenwelt zugleich deren Räumlichkeit gegeben wird.

Auf cliese unmittelbar in der Wahrnehmung konstatierte äußere Räumlichkeit haben nun dieselben Betrachtungen Anwendung zu finden wie auf die Existenz selbst. Indem sich vor unserer Erkenntnis die Außenwelt aufbaut, bevor als subjektives Abbild dieser eine Innenwelt, die Eigenvorstellungen, zustande kommen, muß auch zunächst eine äußere Räumlichkeit vor unserem Geiste entstehen, bevor als sein Gegenbild eine innere Räumlichkeit, der ,,subjektive Raum" sich bilden kann.

Das ist selbst dann sicher, wenn wir mit Kant die Raumanschauung durch eine a priori wirkende Funktion unserer Anlage entstehen lassen. Denn sicher hat Kant diese Funktion sich nicht im Sinne eines schon ausgebildeten Raumbildes gedacht. Nur die Form der Raumanschauung soll uns gegeben sein. Diesen Gerlanken begrifflich oder bildlich weiter auszuführen, ist freilich unmöglich, da wir nur in fertigen Raumanschauungen, d.h. in vollständig ausgebildeten Vorstellungen eines äußeren oder inneren Raumes unsere Vorstellungen sich bewegen lassen können.

Wenn nun der äußere Raum die unmittelbar durch die Wahrnehmung mit der Existenz gesetzte Daseinsform der Außenwelt ist, 
als deren Abbild erst hinterher ein subjektiver Innenraum sich bildet, so werden wir es auch für sicher halten, daß eine weitere Funktion unseres Geistes, sei es Urteil, sei es Assoziation, nicht hinzuzutreten braucht, um ein durch die Wahrnehmung konstatiertes Objekt an die richtige Raumstelle zu setzen. Nie wird es vorkommen, daß wir etwa einen wahrgenommenen Gegenstand aus Versehen, anstatt im äußeren Raume zu lokalisieren, in unseren subjektiven Innenraum versetzen. Das Umgekehrte kann bei lebhafter Phantasietätigkeit als Ausnahmevorgang wohl sich ereignen. Wir wiesen schon darauf hin, daß Kinder und Wilde gelegentlich, aber wohl nur nachträglich, ihre Phantasien und Träume für Wirklichkeit, also als äußere Gegenstände werten.

Daß selbst der Erwachsene seine Traumhalluzinationen, solange er noch in der Bewußtseinsveränderung verharrt, welche der Schlaf herbeiführt, als äußere Geschehnisse wertet, ist richtig. Das ist aber eben nur die Folge einer Bewußtseinsveränderung, die für das normale wache Leben keine Gültigkeit hat. Wir werden darauf später noch zurückkommen.

Nicht nur also die Existenz, sondern auch der Raum oder die Räumlichkeit der Dinge wird durch die Wahrnehmung unmittelbar erfaßt.

Wäre die Zeit, in welcher die äußeren Vorgänge sich abspielen, eine andere als diejenige, in welcher unsere Eigenvorstellungen verlaufen, so müßten wir auf diese wiederum dieselben Betrachtungen anwenden, wie auf Existenz und Raum. Hier gibt es aber glücklicherweise keine Schwierigkeiten. Innere und äußere Vorgänge sind in denselben Zeitverlauf eingeordnet und erfreuen sich derselben Zeitform.

Die Art und Weise, in welcher uns das räumliche Ding zugleich mit seinen in den Empfindungen sich widerspiegelnden Eigenschaften gegeben ist, bedarf nun einer kurzen Analyse, zumal sich an diese Beziehungen bei der Diskussion des Halluzinationsproblems - freilich im Anschluß an bedeutende philosophische Vorbilder - sehr eigentümliche Betrachtungen geknüpft haben.

Mit der Räumlichkeit der Gegenstände ist uns zugleich die Raumform, die ihnen anhaftet, die Gestalt gegeben, von welcher wir uns durch das Zusammenarbeiten des Tastsinnes und des optischen Sinnes überzeugen. Durch diese räumliche Gestaltung werden uns die Gegenstände der Außenwelt erst zu Dingen. Denn sie gestatten erst die Abgrenzung der Gegenstände voneinander. Ohne solche Abgrenzung würden wir keine gesonderten Dinge wahrnehmen können.

Wenn ich also eine Schachtel betrachte, die ich in der Hand herumdrehe, so machen meine Sinne die verschiedensten, durch ihre Spezifität bedingten Wahrnehmungen. Diese alle aber haften an jener räumlich begrenzten Figur, durch welche uns erst das Wahrgenommene zu dem bestimmten Dinge wird, das ich Schachtel nenne. Da mir ohne diese räumliche Begrenzung jene durch die Spezifität der 
Sinne bedingten Einzelwahmehmungen, welche ich an dem Gegenstande, mache, nie gegeben sind, so fühle ich mich veranlaßt, indem ich zugleich auf das subjektiv Bedingte dieser durch die Spezifität der Sinne hervorgerufenen Einzelwahrnehmungen reflektiere, diese mit einem anderen Namen zu belegen. Ich nenne sie Empfindungen.

Diese verschiedenartigen Empfindungen erscheinen mir nun vom subjektiven Standpunkte aus als die Elemente, aus welchen das Ding zusammengesetzt ist, nur daß sie nicht wie die Elemente der Natur sich im räumlichen Auseinander, sondern Ineinander befinden. Sie scheinen sich gewissermaßen zu durchdringen. Die Schachtel ist nicht hier farbig, dort schwer, an einer dritten Stelle mit einer bestimmten Temperatur behaftet, sie ist dies alles überall ${ }^{1}$ ).

Die räumliche Wahrnehmung orler die Wahrnehmung der räumlichen Abgegrenztheit ist also dasjenige, wodurch mir das Wahrgenommene als Ding erscheint, und woran alle meine Empfindungen haften.

Jas pers ${ }^{2}$, dem sich dann Goldstein anschloß, hat nun auf Grund der Psychologie $\mathrm{Husserls^{3 }}$ ) eine besondere psychische Funktion angenommen, durch welche die Erkenntnis der Dinge zustande kommen soll. So wie die verschiedenen Eigenschaften des Dinges durch die Empfindungen aufgefaßt werden, so sollen nach $\mathrm{Husserl}$ zur Konstatierung des Dinges selbst bestimmte, ,intentionale Erlebnisse“ oder „,Akte“" gehören, wie sie Husserl im Anschluß an Brentano nennt. ,,Ich sehe ein Ding, z. B. diese Schachtel, ich sehe nicht meine Empfindungen. Ich sehe immerfort diese eine und dieselbe Schachtel ..." Es bleibt das gleiche „Meinen" der Schachtel als Gegenstand, derselbe Akt, während die Empfindungen wechseln können.

Eine eingehendere Widerlegung dieser Ansicht, auf der man eine ganz neuartige Psychologie aufgebaut hat, kann an dieser Stelle nicht gegeben werden ${ }^{4}$ ).

1) Wird nicht auf die Subjektivität Rücksicht genommen, so können in dem Gegensatz, welchen die viele $\mathbf{n}$ ineinander befindlichen Eigenschaften zum räumlichen Auseinander haben, große Schwierigkeiten gefunden werden. Das Ding mit den vielen Eigenschaften ist in der Tat der Ansatz zur ganzen metaphysischen Spekulation eines Herbart und $\mathrm{Hegel}$ geworden.

2) 1 . $\mathrm{c}$.

3) Husserl, Logische Untersuchungen. Halle 1901.

4) Messer spricht von einer Funktionspyschologie gegenüber der Assoziationspsychologie. Er scheint eine völlige Disjunktion aus diesen beiden Begriffen machen zu wollen (Messer: Empfindungen und Denken. Leipzig 1908) und zu meinen, wer der einen nicht huldigt, müsse die andere anerkennen. Das ist natürlich ganz unberechtigt. Man kann von der Unzulänglichkeit der Assoziationspsychologie voll überzeugt sein, ohne sich einer zunächst wohl noch etwas nebelhaft erscheinenden Funktionspsychologie in die Arme werfen zu müssen. 
Nach unserer obigen Darstellung ist die Wahrnehmung der Räumlichkeit, der räumlichen Gestalt, d.h. des erkenntnispraktischen Elements selbst, dasjenige, was mir das Ding schafft, nicht ein psychologischer ,Akt", ,eine Intention". Was ich in der Tat als Akt und Intention in mir bei der Wahrnehmung des Dinges finde, das ist die Richtung des Willens oder der Aufmerksamkeit auf die räumliche Abgegrenztheit, durch welche rnir das Objekt als einzelner Gegenstand, als Ding gegeben wird, während ich von der subjektiven Zutat meiner Sinne, nämlich den spezifischen Empfindungen, mehr oder weniger abstrahiere $\left.^{1}\right)$.

Die ferneren erkenntnispraktischen Merkmale, durch welche wir die Dinge der Außenwelt charakterisieren, ergeben sich aus den Vorgängen und Beziehungen, die wir an den räumlich aufgefaßten, mit Qualitäten ausgestatteten Dingen wahrnehmen.

Im Vordergrunde stehen dabei die kausalen Beziehungen. Der herabfallende Stein, den ich wahrnehme, kann mich verletzen, töten, der vorgestellte Stein tut das nicht. Dieses Wirken der Dinge aufeinan der und auf uns ist jenes bedeutungsvolle Moment, welches die beziehungsreiche deutsche Sprache in der Bezeichnung der Wahrnehmungswelt als ,Wirklichkeit" zum Ausdruck bringt.

Hier treten allerdings die früheren Erfahrungen mit ins Spiel, die sich in Assoziationen und Urteilen, bei Tieren wohl in Assoziationen allein, niederschlagen, also Elemente, welche nicht unmittelbar in der Wahrnehmung selbst gegeben, sondern aus ihr entnommen sind, um bei späteren Wahrnehmungen das Wirklichkeitsbewußtsein mit hervorzurufen. An diesem Wahrnehmungsinhalt bildet sich jener Begriff der Kausalität als Form der Beziehungen der Gegenstände zueinander im Gegensatz zur Motivation als Form der inneren Beziehungen unserer Eigenvorstellungen zueinander.

3. Die Wahrnehmung vom psychologischen Standpunkt aus.

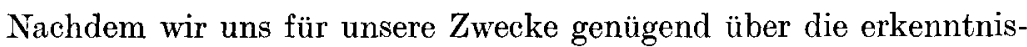
praktischen Merkmale der Wahrnehmung orientiert haben, wenden wir uns der psychologischen Charakterisierung der Wahrnehmung zu.

Die psychologische Analyse der Wahrnehmung als solcher, ganz abgesehen von den Entstehungsbedingungen dieser, bedeutet im wesentlichen eine Charakterisierung der Merkmale, durch welche sie sich von der Vorstellung unterscheidet.

1) Wenn man die Raumanschauung ebenfalls als Empfindung auffaßt, so hat man überhaupt nur noch Empfindungen, die, weil sich auf ihnen nunmehr alles Subjektive und Objektive aufbaut, zu „Elementen" schlechtweg werden. So Ma ch, Analyse der Empfindungen. 
Wir wollen jedoch zunïchst ein Kennzeichen hervorheben, in welchem Wahrnehmung und Vorstellung in Ubereinstimmung sind, und zwar in einer solchen Ubereinstimmung, daß ihre Unterscheidung voneinander sehr schwierig erscheinen könnte.

Wir nannten zu Beginn unserer Darstellung Vorstellung denjenigen psychischen Akt, durch wolchen uns etwas Gegenständliches gegeben ist, im Gegensatz zum Willen, welcher das Intentionale, und zum Gofühl, welches das emotionale Element unseres psychischen Lebens berleutet.

Vom Standpunkt dieser Charakterisierung sind Wahrnehmung und Vorstellung überhaupt nicht zu unterscheiden. Denn auch die Wahrnehmung ist ein pswehischer Akt, in welchem mir etwas Gegenständliches gegeben ist. Insofern ist die Wahrnehmung ja selbst Vorstellung.

Iie erkenntnistheoretischen Konsequenzen dieser so weitgehenden Identität sind bekannt und von uns angedeutet: Sie spielen aber auch ins Psychologische hinein. Denn wenn die erkenntnistheoretische Bedoutung der Wahrnehmung, welche eben in ihrer unmittelbaren Bezichung auf die Außenwelt liegt, vernachlässigt oder verkannt wird, was letyteres wir oben bei Goldste in fanden, so werden Wahrnehmung und Vorstellung im Grunde absolut identisch. Fs gibt dann auch nichts mehr Prinzipielles, was sie als, psychologische" Tatbestände voneinander unterscheiden könnts.

Das in der Wahrnehmungsvorstellung liegende transzendente Erkenntniselement, die Fähigkeit der Wahrnehmung, etwas außer ihr Bestehendes, die Außenwelt, zur Erkenntnis zu bringen, ist nun etwas, was einer psychologischen Erklärung, wie einer Erklärung überhaupt nicht zugïnglich ist. Ws ist überhaupt nichts ,Psychologisches", sondern eben etwas Erkenntnispraktisches.

Das erkenntnispraktische Moment jedoch, welches in der Wahrnehmung liegt, ist so grundlegend für die Unterscheidung der Wahrnehmung von der Vorstellung, daß alle Unterschiede, welche rom rein psychologischen Standpunkt zwischen beiden gemacht werden können, dagegen zurïcktreten. $\mathrm{Ob}$ es rom rein psychologischen Standpunkt wirklich absolute Unterschiede zwischen Wahrnehmung und Vorstellung gibt, kann sogar bezweifelt werden. Welche Bedeutung das für das Wesen der Halluzination hat, werden wir später sehen.

Immerhin sind die psychologischen Unterschiede zwischen Wahrnehmungsrorstellung und Eigenvorstellung so bedeutsam, daß sie meist allein genügen, um die eine von der anderen zu unterscheiden. Hinige Tuterschicle könnte inan geneigt sein, für fast ebenso charakteristiseh $z u$ halten $w$ ic den erkenntnispraktisehen.

An erster Stelle kommt die Räumlichkeit in Betracht. Zunächst möchte man meinen, daß gorade dieses Moment die geringsten Schwierig- 
keiten bieten könnte. Wir erkannten ja, daß mit der ̈̈ußeren Existenz zugleich die Räumlichkeit gegeben ist. Man sollte deshalb meinen, daß die Räumlichkeit an der Sicherheit und Untrüglichkeit, mit welcher die Wahrnehmung sich auf die Wirklichkeit bezieht, teilnehmen würde. Das ist aber nur in concreto der Fall. Sobald wir die Räumlichkeit vom wirklichen Ding loslösen und auf die Vorstellungsbilder übertragen, treten sofort die Schwierigkeiten zutage. Der tiefste Grund dafür, der uns am Schlusse unserer Betrachtungen noch näher beschäftigen wird, liegt offenbar darin, daß, rein für sich genommen, der Raum sein Wirklichkeitsmoment, das er nur an der Außenwelt hat, einbüßt, und zu einem reinen Vorstellungsgebilde wird. Ein leerer Raum ist eine Abstraktion, die in der Tatsächlichkeit nicht erfahren werden kann. So werden Raumwahrnehmung und Raumvorstellung schließlich ununterscheidbar.

Das zeigt sich sogleich, wenn wir die von den einzelnen Sinnen gebotenen Raumwahrnehmungen mit den Raumvorstellungen vergleichen.

$\mathrm{Da}$ ist zunächst der Sehraum, der uns die weiteste, wenn auch vielleicht nicht die prägnanteste Form der Äußerlichkeit bietet. Auch in der reinen Vorstellung weitet sich der Raum nach allen Richtungen, und ich kann mir an allen Punkten dieses vorgestellten Raumes, der mit dem wahrgenommenen Raum geometrisch zusammenfällt, irgendein Ding , vorstellen“. Es ist in der Tat schwer zu sagen, worin sich dieser vorgestellte Raum von dem ,wahrgenommenen“ unterscheiden sollte. Was dem letzteren seine größere Deutlichkeit gibt, ist nicht er selbst, sondern es sind die Dinge, welche wir in ihm wahrnehmen. Extensiv ergibiger ist sogar der vorgestellte Raum. Denn wenn auch mein Auge bis zu den letzten Sternen schweift, die Vorstellung des Raumes greift auch noch darüber hinaus.

Der Tastwahrnehmungsraum erhält seine Prägnanz ebenfalls nur durch die getasteten Dinge. Er ist aber in der Tat so markant, daß die Tast vorstellung der Dreidimensionalität an Deutlichkeit ganz zurücktritt und meist dem Sehraum die Vervollständigung durch die Vorstellungsfunktion überläßt.

Ganz schlimm steht es mit der Unterscheidung der Raumwahrnehmungen und -vorstellungen, wie sie durch die übrigen Sinne geboten werden. Kann man von einem primären Seh- und Tastwahrnehmungsraum noch mit Sicherheit sprechen, so wird das sehr zweifelhaft beim Hörraum. Es scheint in der Tat, als wenn es einen primären Hörraum gar nicht gibt, daß wir unsere Hörwahrnehmungen einfach in den Sehraum einordnen, und daß die Lokalisierung der Hörwahrnehmungen im übrigen mit Hilfe anderer Sinneseindrücke, Intensität, Fmpfindung des durch die Schallwellen verursachten Luftdruckes usw. zustande kommt. 
Die übrigen Sinne fallen überhaupt aus, da Geschmacks-, Geruchsund Temperaturempfindungen durch sich selbst überhaupt kein räumliches Moment bieten.

Nicht geringere Schwierigkeiten als die räumlich-quantitative Seite bietet die qualitativ-intensive Seite des Gegenständlichen für die Unterscheidung der Wahrnehmung von der Vorstellung.

Was zunächst die Qualität selbst betrifft, so ist sie als bedingt durch die Spezifität unserer Sinne zunächst etwas rein Subjektives. Je größer die Erinnerungstreue des Individuums ist, um so deutlicher wird deshalb im allgemeinen die reproduzierte Vorstellung der Wahrnehmung gleichen. Dabei gibt es bekanntlich große individuelle Unterschiede: der eine hat ein besonders gut ausgebildetes optisches, der andere ein ebensolches akustisches Gedächtnis. Auf dem Gebiete der niederen Sinne, die an differenzierter Inhaltlichkeit den höheren Sinnen so außerordentlich nachstehen, ist die Erinnerungstreue im allgemeinen geringer.

So weit würde es prinzipielle Unterschiede zwischen wahrgenommener und vorgestellter Qualität überhaupt nicht geben. Die Unterschiede wären nur relative. Aber die Qualität tritt stets mit einer Intensität behaftet auf, und da scheinen sich in der Tat prinzipielle Differenzen herauszustellen. Es ist ja immer darauf hingewiesen worden, daß die erinnerte Schall- und Lichtintensität mit der wahrgenommenen nicht gut verglichen werden kann, daß selbst der leiseste gehörte Schall noch immer ,lauter" ist als der lauteste vorgestellte Donner, das schwächste gesehene Licht noch immer ,heller" als die stärkste, in der Erinnerung reproduzierte Helligkeit.

Wäre diese Steigerung richtig, so würde sie freilich das Gegenteil von dem beweisen, was bewiesen werden soll. Sie würde zeigen, daß die Unterschiede nur quantitative, aber nicht prinzipielle sind. Aber sie erscheinen in der Tat als letztere, und zwar aus dem Grunde, weil wahrgenommene und vorgestellte Intensität überhaupt nicht miteinander verglichen werden können. Die wahrgenommenen und vorgestellten Empfindungen haben andersartige Intensitäten.

Wir kommen nun zu denjenigen Unterschieden zwischen Wahrnehmung und Vorstellung, welche die Gesamtheit ihrer Elemente, das Räumlich-Quantitative und das Qualitativ-Intensive zugleich treffen. Diese Unterschiede liegen in der Verlaufsart, in der Beziehung zum Subjekt und in den psychophysiologischen Begleit- und Folgeerscheinungen. Wir wollen sie ganz kurz charakterisieren.

Die Wahrnehmungen sind beständig oder können es doch sein. Die wahrgenommene Wirklichkeit steht dauernd vor unseren Sinnen da. Die Vorstellungen sind undeutlich ,zerflattern", ja sind, je abstrakter wir denken, als Gegenstandsbilder im Bewußtsein kaum nachweisbar, 
meist überhaupt nicht vorhanden. Wort und Begriff ersetzen das Bild.

Die Vorstellungen wechseln, können jedenfalls nicht dauernd festgehalten werden. Das Auftreten der Vorstellungen ist durch innere Gründe, Motivation, bestimmt, das der Wahrnehmung durch äußere Gründe, Kausalität, oder, wie es meist scheint, zufälligerweise vorhanden oder nur durch die tatsächlichen Umstände erklärbar.

Indem sich die Vorstellungen als Produkt unserer eigenen psychischen Tätigkeit erweisen, sind sie, wie alles Psychische überhaupt, unmittelbar lediglich dem Subjekt erfahrbar. Anderen können sie nur bekannt werden durch das Mittel der Ausdrucksbewegungen, der HandIungen und der Sprache.

Dadurch, daß die Vorstellungen als eigenes Produkt des Subjekts entstehen, sind sie auch in hohem Grade abhängig von dem Willensmoment. Wir sagen nur: in hohem Grade; denn es handelt sich nicht um eine absolute Abhängigkeit. Vorstellungen können auch gạnz ohne Zutun unserer augenblicklichen Willenstätigkeit in uns auftauchen. Auf der anderen Seite liegt es auch häufig genug an unserer Willenstätigkeit, ob wir uns einem Wahrnehmungsgegenstande zuwenden, also überhaupt eine Wahrnehmung haben, oder nicht.

Die Vorstellungen sind also unmittelbar nur dem Subjekt erfahrbar, welches sie produziert. Daraus darf man nicht schließen, daß dieses Subjekt als selbstbewußtes Ich stets bei den von ihm produzierten Vorstellungen dabei ist undsich als Produzent dieser Vorstellungen fühlt. ${ }^{1}$ ) Unser Ich als reflektiertes oder auch nur gefühlsmäßig bewußt gewordenes Subjekt tritt sowohl bei den Wahrnehmungen wie bei den Vorstellungen meist ganz zurück. Was im Bewußtsein jedesmal gefunden wird, ist eigentlich nur der wahrgenommene oder vorgestellte Inhalt. Es bedarf meist eines besonderen Bewußtseinsaktes, um das Ich in den Vordergrund des Bewußtseins zu bringen.

Aus diesem Zurücktreten des bewußten Ichs gegen den bewußt gewordenen Inhalt ergibt sich auch, daß das Gefühl oder Bewußtsein der Aktivität, welches man mit der Produktion von Vorstellungen, und dasjenige der Passivität, welches man mit dem Auftreten von Wahrnehmungen $\mathrm{zu}$ verknüpfen pflegt, meistens ebenfalls nicht vorhanden ist. Auch hier gehört bei den Vorstellungen ein besonderer Bewußtseinsakt dazu, um sich als Produzenten der Vorstellung zu fühlen, und selbst dann erscheinen wir uns keineswegs immer in der ausgesprochonen Rolle des Akteurs. Gerade die Gedanken und Vorstellungen, welche für unser Bewußtsein den größten Wert haben, tauchen nicht selten fertig vor unserem Bewußtsein auf, ohne daß wir uns einer besonderen H. 2.

1) So z. B. Heverach, Zur Theorie der Halluzinationen. Arch. f. Psych. 48, 
Intention bei deren Produzierung bewußt werden. Für die Eigenart der Halluzinationen hat dieses „freie Aufsteigen" der Vorstellungen keine geringe Bedeutung.

Umgekehrt können wir selbst dann, wenn wir auf uns als Subjekt beim Wahrnehmungsakt reflektieren, in der Regel überhaupt nicht das Moment finden, das wir im eigentlichen Sinne als Passivität zu bezeichnen berechtigt wären. Wir können nur konstatieren, daß uns das Objekt von außen gegeben ist. Zugleich fühlen wir uns bei dieser Reflexion auf das Ich auch um so aktiver, je intensiver der Aufmerksamkeitsakt ist, mit welchem wir uns aus eigenem Willen auf das Objekt einstellen. Erst dann, wenn auch starke Gefühlsmomente mit durch das Objekt hervorgerufen werden - Schmerz, Schreck usw. - , fühlen wir uns bei der Reflexion auf das Ich als das ,passive“, das im eigentlichen Sinne des Wortes leidende Individuum.

Wenn also auch durchaus nicht immer das Ich bei den Vorstellungen mit im Bewußtsein ist oder gar sich diesem gegenüber in der alstiven Rolle fühlt, und das Ich auch keineswegs bei der Hervorrufung der Wahrnehmungen auszuscheiden und sich diesen gegenüber in der passiven Rolle zu fühlen braucht, so kann doch prinzipiell das Subjekt im normalen Zustande seiner als des eigentlichen Urhebers seiner Eigenvorstellungen bewult werden, und das ist ein weiterer, wesentlicher Unterschied dieser gegenüber den Wahrnehmungen, bei welchen das normale Subjekt den transsubjektiven Reiz als Ursache seines Bewußtseinsinhaltes stets festzustellen in der Lage ist.

Die Tatsächlichkeit (Realität) des wahrgenommenen Inhaltes zieht nun die einfache Folge nach sich, daß die Tatsächlichkeit konstante Beziehungen zu unserem Körper und unseren Sinnesorganen zeigt ${ }^{\mathbf{1}}$ ), und daß sie auch durch die Wahrnehmung anderer konstatiert werden kann. Die Welt ist für uns alle dieselbe. Doch ist diese Konsequenz. nicht eigentlich eine psychologische, sondern eine erkenntnispraktische.

Eine weitere Folge der Tatsächlichkeit der äußeren Wahrnehmungen ist es, daß deren Inhalte als Gegenstände der Außenwelt nicht nur

1) Bezüglich der Gesichtswahrnehmungen gibt Störring (Vorlesungen über Psychopathologie, Leipzig 1900, S. 71) folgende Bestimmung: ,Der Objektivitätscharakter der Wahrnehmungen des Gesichts im Gegensatz zu dem Subjektivitätscharakter der Pseudohalluzinationen - und wir können gleich sagen auch der Vorstellungen - hängt davon ab, daß die Wahrnehmungsinhalte dem Individuum in den im gegebenen Moment wahrgenommenen Raum eingeordnet erscheinen und drmselben eine konstante durch Erfahrung ihm bekannt gewordene Abhängigkeit von den Bewegungen des Sinnesorgans und des Gesamtkörpers zeigen." Diese Definition dürfte auch für die Objekte der Tastwahrnehmungen stimmen, und es wäre nur hinzuzufügen, daßß durch die Erfahrung dem Individuum auch die konstante Abhängigkeit der Seh- und Tastobjekte von anderen wahrnehmenden Individuen bekannt geworden ist, und daß diese Erfahrung in besonders hohem Maße dem Individuum die Tatsächlichkeit seiner eigenen Wahrnehmungen verbürgt. 
ei ne $m$ Sinne zugänglich sind. Durch die verschiedensten auf der Spezifität unserer Sinnesorgane beruhenden Modalitäten können wir die Erfahrungsgegenstände in unser Bewußtsein aufnehmen und so einen Sinn durch den anderen kontrollieren. In unseren Vorstellungen dagegen spiegelt sich der gegenständliche Inhalt meist nur durch das Bild ein er Modalität. In der Regel ist es das Bild der sog. objektiven Sinne, ,der Sinne der Ferne", durch welche der Inhalt uns in der Vorstellung gegeben wird. Gewil sind wir auch zu Tast-, Geruchs- usw. Reproduktionen fähix, und sie setzen sich nicht selten an Gesichtsvorstellungen an oder rufen sie hervor. Aber sie sind seltener als diese.

Auch nur die aus den objektiven Sinnen stammenden Erfahrungsinhalte sind mit größerer Deutlichkeit als Vorstellungsbilder reproduzierbar, während diese um so undeutlicher werden, je ,subjektiver" der Sinn ist, aus welchem die Vorstellung ursprünglich ihr Material bezogen hat.

Die Ursache hierfür liegt bekanntlich darin, daß die objektiven Sinne, Gesicht und Gehör, hauptsächlich zur Gewinnung eines Außenweltsbildes, eben des Objektiven, dienen. Unser Sehorgan ist, solange wir Bewußtsein und die Augen offen haben, überhaupt immer in Tätigkeit. Auf dieser beruht im wesentlichen die Weite und Mannigfaltigkeit des in uns aufgenommenen, von der Tatsächlichkeit gebotenen Objektmaterials. Nicht so wichtig für die Erfassung als für die weitere Verarbeitung des Erfahrungsmaterials ist der Gehörsinn. Denn durch diesen gewinnen wir die Möglichkeit einer Verständigung mit dem Mitmenschen, für die Ausbildung einer Sprache, der Vorbedingung aller weiteren intellektuellen Bildung und der sozialen Beziehungen ${ }^{1}$ ).

Gegenüber der Bedeutung der objektiven Sinne für die Erkenntnis der Außenwelt tritt die der subjektiven Sinne sehr zurück. Diese, als die sog. niederen Sinne, die besonders beim Tier eine so feine Ausbildung erfahren haben, dienen hauptsächlich der Befriedigung der Triebe. Es sind deshalb auch mit diesen in der Regel viel stärkere Gefühlregungen verknüpft, während sie bei den höheren Sinnen, bei denen eine zu starke Hervordrängung des Subjektiven nur störend für die objektive Auffassung wirken würde, meist fehlen.

Doch handelt es sich hier nur um den primären Gefühlston. Was aber die sekundär erregten, besonders die sog. Gemütsgefühle betrifft,

1) Goldstein nimmt an, daß die aus den Muskelempfindungen entstehenden Raumvorstellungen, welche bei Geruch und Geschmack fehlen, das Utberwiegen der größeren Treue der durch die anderen Sinne gewonnenen Raumvorstellungen mit ihrem Inhalt bewirkt. Die Muskelempfindungen haben aber, wie hier nicht weiter auseinandergesetzt werden kann, für den Gesichtssinn wohl nicht die ihnen von manchen Autoren zugeschiiebene ausschlaggebende Bedeutung. Für den Gehörssinn kommen sie sicherlich kaum in Betracht. Bezüglich des Gesichtssinnes s. u. a. Jodl, Iehrbuch d. Psychologie, 3. Aufl. Bd. 1, S. 414. 1908. Hier auch Literatur. 
so setzen diese sich hauptsïchlich an die Erfahrungsobjekte an, welche wir durch die höheren Sinne in uns aufnehmen. Diese Gemütsgefühle werden sich uns sogar von grundlegender Bedeutung für die Entstehung der Halluzinationen erweisen.

Aus der Bedeutung der objektiven Sinne für die Gewinnung des Erfahrungsmaterials und dessen weitere Verarbeitung ergibt sich auch unmittelbar die große Rolle, welche die Gesichts- und Gehörvorstellungen nicht nur in den Erinnerungen, abstrakten und Phantasievorstellungen, sondern auch in clen Halluzinationen spielen. Ja es scheint, als wenn die Gehörvorstellungen hier von noch größerer Wichtigkeit sind als die Gesichtsvorstellungen, trotzdem sie doch nicht entfernt ein so mannigfaltiges Material von der Außenwelt liefern wie diese. Aber die Gehörsvorstellungen bieten durch Vermittlung der Sprache die Möglichkeit für die Ausbildung des Intellekts, der sozialen Bezichungen und der mit letzteren vorknüpften Gemütsgefühle, und dadurch gewinnen sie im Verein mit den durch sie erweckten Eigenvorstellungen eine so große Berleutung für die Entstehung der Halluzination.

Dadurch, daß die Vorstellungen nur eine Gehirnerregung als materielles Korrelat besitzen, bei den Wahrnehmungen zugleich ein Sinnesorgan mit in Erregung gesetzt wird, ergeben sich weitere Unterschiede. So ist die Organempfindung bei Erregung der niederen Sinne (,Kontaktsinne") stet;, bei den höheren Sinnesorganen, Auge und Ohr, freilich in der Regel nicht verstanden, aber sie kann auch hier vorhanden sein. Denn, wenn wir auch beim Sehen und Hören in der Regel nur das Objektive, das Gesehene und Gehörte, im Bewußtsein haben, so treten doch bei starken Eindrücken (Blendung, lauter Schall) auch Empfindungen, die vom Auge und Ohr selbst ausgehen, mit ins Bewußtsein. Bei Vorstellungen sind Organempfindungen meist überhaupt nicht oder doch nur andeutungsweise vorhanden.

Es fehlen ferner den Vorstellungen die Bewegungsempfindungen, welche mit der Erregung und Betätigung der Sinnesorgane im Wahrnehmungsakt verknüpft sind. Dagegen kommen in Begleitung der Vorstellungen ebenso wie der Wahrnehmungen wohl Muskelempfindungen vor, die sich als Spannungsempfindungen in den betreffenden Organen kundgeben. Diese Spannungsempfindungen dürften auch das Ganze dessen ausmachen, was einige als ,Innervationsempfindung“ glauben bezeichnen $\%$ müissen ${ }^{1}$ ). Schließlich ist es kaum möglich, gewisse Empfindungen auszuschalten, die sich leicht bemerkbar machen, wenn z. B. innerliches Sprechen und Singen sich mit tatsächlichen Empfindungen der Sprachorgane, von denen jal stets (jedenfalls vom Munde) Tast-

1) Schon Lotze hielt es wohl mit Recht für unmöglich, die motorische Innervation, d. h. „,den Willen im Schwunge seines Vollzuges“ empfinden zu können.

Z. f. d. g. Neır. u. Psych. O. XXIV. 
wahn nehmungen ausgehen, verlinüpfen. Auch geht das innerliche Sprechen sehr leicht in Bewegungen der Sprachorgane selbst über.

Es fehlen ferner den Vorstellungen Kontrasterscheinungen und Nachbilder, da solche nur Folge von tatsächlicher Erregung der peripheren Sinnesflächen selbst sind. Was über Nachbilder von Vorstellungen berichtet wird, ist höchst unsicher.

Schließlich wäre noch zu erwähnen, daß die Vorstellungen mit dem bewegten Auge mitgchen können, während die wahrgencmmenen Gegenstände natürlich ihren Standort behalten.

Mit diesen kurzen Andeutungen über die psychophysiologischen Begleiterscheinungen von Wahrnehmungen und Vorstellungen müssen wir uns an dieser Stelle begnü̈gen.

Es wäre noch eines Momentes im Zustandekommen von Wahrnehmung und Vorstellung zu gedenken, das wir bei der Halluzination sich in bemerkenswerter Weise werlen hervortreten sehen. Die Vorstellungen spielen nämlich beim Wahrnelimungsakt selbst eine außerordentlich wichtige Rolle. Jeder Parzaptionsakt ist zugleich ein Apporzeptionsakt. Indem frühere Vorstellungen, die als ,Residuen“ orler „Dispositionen" - man gebraucht in der Psychologie diese unverbindliche Ausdrucksweise, um nicht den widerspruchsvollen Begriff der unbewußten Vorstellungen anwenden zu müissen - unter der Schwclle des Bewußtseins geschlummert haben, von dem in der Wahrnehmung gegebenen Inhalt geweckt werden, rerschmelzen sie mit diesem unmittelbar zu einem neuen Prorlukt. Auf diesem Apperzeptionsakt - ron Wundt Assimilation genannt, weil or den Begriff Apperzeption in anderem Sinne gebraucht - beruht das eigentliche Erkennen, das zum reflektiert-bewußten Wiedererkennen wird, wenn die früheren Vorstellungen, die sich im Wahrnehmungsalit unmittelbar mit dem neuen Bewußtseinsinhalt verbinden, selbständigen Bewußtseinswert gewinnen, d. h. als gesondarte Vorstellungen zur Reproduktion gelangen und nun den Vergleich des neuen Bewußtseinsinhaltes mit dem früher gegebenen gestatten.

Im Unterschiede hiervon ist die Vorst sllung ein reiner A perzepzionsakt, da ja bei ihr keine neuen Wahrnehmungsinhalte gegeben sind, mit welchen ein Vorstellungsresiduum verschmelzen könnte. Freilich können die Vorstellungen, bzw. ihre Residuen dadurch, daß sie im Unterbewußtsein in assoziativem Zusammenhange stehen, selbst zur Verschmelzung gebracht werden, um dann bei erneuter Reproduktion als ein mit reicheren Merkmalen behaftetes Gebilde aufzutreten. Es findet also etwas Ähnliches wie beim Apperzeptionsakte in der Wahrnehmung statt.

Wir müssen endlich noch kurz auf eine sehr wichtige psychische Folgeerseheinung eingehen, durch welche sich Wahrnehmung und Vor- 
stellung.nicht unterscheiden, sondern die ihnen sehr wesentlich gemeinsam ist.

Wir bemerkten bereits, daß3 mit den Empfindungen ein Gefühlston verknüpft ist, der bei Erregung der Kontaktsinne besonders stark vorschlägt, jedoch auch den Empfindungen der höheren Sinne eigen ist. Was aber die letzteren besonders auszeichnete, das waren die sekundären Gefühle, die nicht sowohl durch die Empfindungsclemente als durch die Wahrnehmungen, in welche sie eingehen, erweckt werden.

Diese sekundär und assoziativ erregten Gemütsgefühle verdanken ihre Entstehung der Mitwirkung der gesamten Psyche. In ihnen spricht sich die zuständliche Erregung aus, die ihre Quelle in der Beziehung unseres Ichs zu den Mitmenschen und zu der gesamten Umgebung hat und zugleich durch die persönliche Veranlagung des Individuums bestimmt wird. Sie entstehen deshalb durch ausgedehnte assoziative Wirkungen in der Seele, selbst wenn der äußere Reiz, der zuerst Anla B zu ihrer Entstehung gab, längst geschwunden ist. Ihre besondere Bedeutung für unser Problem gewinnen aber diese Gefühle, die mit den tiefsten Wurzeln unseres Wesens verknüpft sind, dadurch, daß sie die Vorstellungen, die mit ihnen assoziiert sind, in besonders lebhafter Weise zur Reproduktion zu bringen vermögen.

Für unsere Betrachtung werden sich besonders diejenigen Gefühle von Wichtigkeit erweisen, die wir als Persönlichkeitsgefühle kennzeichnen können. Die positive Seite dieser Gefühle stellen alle jene zuständlichen Erregungen dar, in welcher wir uns in unserem Selbstgefühl gehoben finden, in welchem wir unserer Bedeutung auf irgendeinem Gebiet der menschlichen Tätigkeit und der sozialen Beziehungen bewußt werden. Die negative Seite des Persönlichkeitsgefühls kennzeichnet sich durch alle jene zuständliche Erregungen, in welchen wir uns in unserem Selbstgefühl herabgemindert finden, in welchen wir uns insuffizient für irgendeine Leistung, für die soziale Betätigung, hauptsächlich in moralischer Bezichung, finden.

Natürlich sind hier auch die Grundgefühle der I ust und Unlust und deren Widerhall in den sekundären Gemütsgefühlen zu erwähnen. Durch ihre assoziativen Beziehungen zum gesamten psychischen Leben werden wir sie bei der pathologischen Umwandlung der Psyche eine besondere Wirksamkeit in der halluzinatorischen Umbildung der mit ihnen verknüpften Vorstellungen entfalten schen.

\section{B. Die pathologische Wahrnehmung - die Halluzination.}

1. Wesen, Definition und klinische Abgrenzung der Halluzination.

Bevor wir uns den verschiedenen Gesichtspunkten zuwenden, von welchen wir die Halluzination und ihre Entstehung zu betrachten haben 
werden, erscheint es wohl angebracht, Wesen und Begriff der Halluzination selbst festzustellen und die Abgrenzung dieses Phänomens von anderen ähnlichen Bewußtseinsphänomenen kurz zu besprechen.

Es ist selbstverständlich, daß vom rein subjektiv-psychologischen Standpunkt die Halluzination prinzipiell zu einer der drei Grundphänomene gerechnet werden muß, welche wir auch im Bereiche der normalen Bewußtseinsvorgänge vorfinden, und die wir zu Beginn unserer Darstellung kurz gekennzeichnet haben. Es ist auch weiter selbstverständlich, daß wir die Halluzination zu den Vorstellungsvorgängen rechnen werden und nicht zu den Gefühls- oder Willensvorgängen.

Nun sahen wir aber, daß die Vorstellungen sich gliedern in Wahrnehmungsvorstellungen oder kurzweg Wahrnehmungen und Vorstellungen im engeren Sinne. Und da zeigt sich denn das eigentümliche Phänomen, daß die Halluzination vom Standpunkte des Halluzinierenden eine Wahrnehmung, vom Standpunkte des beurteilenden Sachverständigen eine Vorstellung ist.

Wenn wir uns fragen, woher wir die Berechtigung nehmen, die Selbstbeobachtung und Selbstbeurteilung, die doch schließlich die letzte Grundlage für die Feststellung der subjektiv-psychischen Phänomene ist, welche wir in uns erleben, in diesem Falle als belanglos auszuschalten, so können wir nur auf das Wahrnehmungsfeld rekurrieren, welches dem normalen Individuum zu Gebote steht. Finden wir hier nicht den Gegenstand, welcher den Inhalt einer behaupteten Wahrnehmung sein soll, so werden wir annehmen müssen, daß es sich eben nicht um eine solche gehandelt hat, sondern um die für Wahrnehmung gehaltene Vorstellung eines Geisteskranken. Vorausgesetzt ist freilich, daß begründeter Verdacht besteht, da $\beta$ das betreffende Individuum noch andere psychotische Symptome zeigt, welche uns berechtigen, dasselbe für geisteskrank zu erklären.

Auch so noch ist es nicht unter allen Umständen sicher, daß die behauptete Wahrnehmung nur eine Vorstellung ist. Mit Recht führt deshalb Ziehen als erstes von denjenigen Phänomenen, von welchen die Halluzination unterschieden werden muß, die Empfindung selbst an - sagen wir besser die Wahrnehmung.

Ist es sicher, daß kein äußerer Reiz vorhanden ist, der als Ursache des behaupteten Wahrnehmungsphänomens des Kranken anzusprechen wäre, dann erst können wir mit Bestimmtheit erklären, daß es sich nicht um eine Wahmehmung, sondern um eine Vorstellung handelt. Wir nennen sie aber, um den Wahrnehmungscharakter, welchen diese Vorstellung für den Kranken selbst hat, zum Ausdruck zu bringen, trotzdem eine Wahrnehmung, aber eine Wahrnehmung ganz bestimmter Art, eine solche, welche nur den ,trügerischen Schein" einer Wahrnehmung hat. Wir nennen sie eine Trugwahrnehmung. 
In der Tat dürfte diese Bezeichnung, insofern wir durch sie den Grund der Umwandlung des Vorstellungscharakters in den Wahrnehmungscharakter als in der trügerischen Auffassung des Kranken selbst gelegen bezeichnen, am besten das Wesen der Halluzination zum Ausdruck bringen. Bezeichnungen, welche nur das Manko in der Außenwelt, nicht aber die eigentümliche Umwandlung des Reproduktionsvorganges zum Ausdruck bringen, entsprechen nicht den Anforderungen einer vollkommenen Definition der Halluzination. Wenn wir z. B. mit Ball die Halluzination als ,gegenstandslose Perzeption" bezeichnen würden, so würden wir nicht zum Ausdruck bringen, daß es sich um eine Perzeption, also um eine Wahrnehmung im normalen Sinne des Wortes, gar nicht handelt, sondern daß nur ein äußerer Gegenstand für die Perzeption fehlt.

Wir haben übrigens schon in der Breite des Normalen, gegenstandslose Perzeptionen", die als Trugwahrnehmungen zu bezeichnen wir berechtigten Anstand nehmen würden. Hierher gehören die entoptischen und entotischen Phänomene.

Diese Phänomene, die so große Ähnlichkeit mit Empfindungen, d. h. elementaren Wahrnehmungen haben, sind jedoch Vorstellungen. Denn es fehlt bei ihnen eben der äußere Gegenstand, der zum Zustandekommen der echten Wahrnehmungen unbedingt gehört. Ihre Ursache liegt lediglich in Veränderungen des Sinnesorgans selbst. Manchmal fehlt freilich nicht der äußere Gegenstand, der zur Entstehung des entoptischen oder entotischen Phänomens Anlaß gibt. Er wirkt nur entweder nicht unmittelbar auf die Sinnesfläche, zu deren Qualitätenbereich der Reiz gehört, den er gewöhnlich ausübt, oder neben solchen Wirkungen entfaltet er noch eine weitere Wirkung auf eine Sinnesfläche, welche entsprechend ihrer Spezifität nicht das Wesen des Gegenstandes, sondern nur ihre eigene Erregung zum Ausdruck bringt. Wenn ich einen Schlag gegen mein Auge erhalte, so habe ich neben Berührungsempfindungen, welche der gegenständlichen Einwirkung adäquat sind, und Schmerzempfindungen, auch Lichterscheinungen, welchen keine Erregung durch einen adäquaten Sinnesreiz entspricht. Ebenso finde ich für das Klingen in meinem Ohr keinen adäquaten Reizvorgang in der Außenwelt, welchen ich als Anlaß hierfür zu beschuldigen imstande wäre. In beiden Fällen aber habe ich gegenstandslose ,Perzeptionen“ nur in einer Weise, in welcher diesem - ebenso wie unser Wort Vorstellung - zweideutigen Fremdwort das Moment der Wahrnehmung im objektiven Sinne des Wortes nicht zukommt.

Will man nun den Mangel eines äußeren Gegenstandes, der ja ein wesentliches - negatives - Merkmal der Halluzination ist, in der Bezeichnung dieses Phänomens mit zum Ausdruck bringen, so darf man doch nicht vergessen, den intrapsychischen Faktor als die eigentlich 
positiv auslösende Ursache der Halluzination mit in die Definition zu setzen. Nicht also als gegenstandslose Wahrnehmung, sondern als gegenstandslose Trugwahrnohmung kennzeichnet sich die Halluzination.

Noch weniger freilich dïrfen wir in der Bezeichnung der Halluzination die Unwirklichkeit eines gegenständlichen Reizes in die Unwirklichkeit des Bewußtseinsphänomens selbst transformieren. Das aber würde geschehen, wenn wir mit Hoppe die Halluzination eine ,unwirkliche Wahrnehmung" nennen würden. Die Wahrnehmung ist da, wenn auch nur als Trugwahrnehmung eines kranken Individuums.

Schließlich werden wir dem Wesen der Halluzination nicht gerecht werden, wenn wir eine kausale Definition wählen, welche das trügerische Moment weder in die intrapsychische Sphäre, noch in die äußere Welt, sondern in das Sinnesorgan selbst zu legen scheint, auf welches der Kranke sein abnormes Bewußtseinsphänomen bezieht. Diesen Fehler scheinen wir aber zu begehen mit der Bezeichnung der Halluzination als ,Sinnestäuschung".

Es ist ja bis zu einem gewissen Grade gleichgültig, wie wir einen Gegenstand oder einen psychischen Vorgang definieren. Und wenn wir, wio selbstverständlich, stillschweigend annehmen, daß die ,,Sinnestäuschung“ als welche wir die Halluzination so häufig bezeichnen, nicht cine Täuschung des äußeren Sinnesorgans, sondern des Bewußtseins in seiner vermeintlichen Wahrnehmungstätigkeit bedeuten soll, so läßt sich auch ein erheblicher Einwand gegen diese Bezeichnung nicht ins Feld führen. Aber abgesehen davon, daß das Bessere der Feind des Guten ist, und da 3 uns aus diesem Grunde im Begriff der Trugwahrnehmung das subjektivpsychische Moment als Ursache des Halluzinationsphänomens besser zum Ausdruck zu kommen scheint als in dem Begriff der Sinnestäuschung, so ist der letztere bereits von der normalen Psychologie für Sinnesphänomene in Beschlag genommen, die auch im Bereich des gesunden Bewußtseins vorkommen, ja täglich in die Erscheinung treten.

Es ist eine Sinnestäuschung, wenn uns das Verschwinden der Sonne am Abend als eine Bewegung dieser selbst unter den Horizont und nicht als Folge der Erddrehung erscheint, wenn wir den Mond durch die Wolken ziehen lassen usw. Hier von Trugwahmehmungen zu sprechen, scheut sich mit Recht der Psychologe und auch der gewöhnliche Sprachgebrauch. Ein jeder hat wohl die Empfindung, daß im Begriff der Trugwahrnehmung ein auf die intrapsychische Sphäre zu beziehendes pathologisches Moment liegt, welches keine innere Beziehung zu dem Wesen der durchaus im Bereich, des Normalen liegenden Simnestäuschungen hat, trotzdem uns natürlich niemand hindern könnte, ein Übereinkommen zu treffen, auch liese normalen Sinnestäuschungen als trügerische 
Wahrnehmungen, also als Trugwahrnehmung zu bezeichnen. Aber zweckmäßig wäre eine solche Ubereinkunft nicht.

Jenes psychopathologische Moment aber, welches in dem Begriff der Trugwahrnehmung besonders treffend zum Ausdruck zu kommen scheint, ist die real unfundierte Beziehung auf einen supponierten Gegenstand ïberhaupt, der ja bei dem von der normalen Psychologie als Sinnestäuschung bezeichneten Phänomene prinzipiell vorhanden ist. Tnd da möchten wir besonders auf jene experimentell erzeugte Sinnestäuschung hinweisen, welche neuerdings von Pick zur Stiitze der Goldsteinschen Theorie herangezogen ist.

Es handelt sich um den sog. Stratonschen Versuch, bei welchem durch ein vor das normale Auge gesetztes Prismensystem clie Welt um $180^{\circ}$ gedreht wird. In ca. 2 Tagen lemt der Mensch seine Tasteindrücke den lokalisatorisch veränderten Gesichtseindrücken anzupassen, so daß er mit seinen Füßßen nicht mehr den tatsächlich unter sich gefühlten, sondern den über sich gesehenen Ful3boden zu berühren glaubt.

Aber erstlich handelt es sich in diesem Versuche nicht um eine Täuschung des Realitïts-, sondem nur des Lokalisationsbewubtseins, und z.weitens wird diese Täuschung nicht durch veränderte Urteile, sondern durch eine anders geriehtete Assoziationswirkung verursacht. Durch Assoziation werden die Tasteindrücke nunmehr auf die rerkehrt lokalisierten (iesichtseindrücke bezogen ${ }^{1}$ ).

Was wir aber zunïchst festhalten und auch womöglich definitorisch zum Ausdruck bringen mïssen, ist das Vorh indensein äuberer Gegenstandsreizo bei den Sinnestäuschungen, deren Fehlen bei den Halluzinationen oder Trugwahmohmungen.

Freilich werden wir zur Vermeidung unnötiger Längen bei der Bezeichnung der auf die versehiedenen Simmesphänomene bezogenen Halluzinationen wohl nicht aufhören, von Gehörs-, Gesichts- usw. Täuschungen zu sprechen. Aber in diesen Wortzusimmensetzungen fehlt auch das Wort ,Sinn“" welches der sprachgebrauch mehr auf die Bezeichnung der peripheren Perzeptionsorgane beschränkt. Durch die Auffindung der zentralen "Sinnesstaitten" hat freilich der Begriff Sinn im wissenschaftlichen Sprachgebrauch eine mehr als peripherische Bedeutung erlingt.

In einem Falle könnte die Bezeichnung der Halluzination als Sinnestäuschung, wem auch nicht gleichberechtigt mit Trugwahrnehmung, wohl aber nicht unbegründet erscheinen, damn nämlich, wenn die Erlirankung der peripheren Sinnesorgane selbst Anlab zur Entstehung von Hallurinationen wircl. Hier scheint es ja der Simn wirklich zu sein, weleher den ersten Anstol zur Halluzination gibt. Und zweitens liegt bei den unkomplizierten Fällen diexer Art nicht einmal eine geistige 1) Das Nähere siehe in der eingehenden $\mathrm{b}$ ritik dieses $V$ rersuches bei J a s pers, l.e. 
Erkrankung im engeren Sinne vor, die wir als die „Ursache" des Truges beschuldigen könnten ${ }^{1}$ ).

Trotzdem empfiehlt es sich wohl kaum, diese Art von Halluzinationen durch eine besondere Bezeichnung von den übrigen Halluzinationen zu trennen. Denn erstlich liegen hier nicht die Bedingungen vor wie bei den von der normalen Psychologie als Sinnestäuschung bezeichneten Phänomenen. Es ist ja gar nicht der Sinn, welcher durch bestimmte gegenständliche Vorgänge in der Außenwelt getäuscht wird. Diese gegenständlichen Vorgänge fehlen, und damit ist die eine wesentliche Voraussetzung der Halluzination als Trugwahmehmung gegeben. Zweitens aber befindet sich, wie wir sicher annehmen können, auch in diesem Falle die eigentliche Ursache für die Entstehung der Halluzination in der Hirnrinde, spielt sich also an dem materiellen Korrelat der geistigen Vorgänge selbst ab.

Periphere Veränderungen der Sinnesorgane werden wir nur als Auslösungsbedingungen gelten lassen dürfen, die keine Wirkung entfalten könnten, wenn nicht das Zentrum selbst sich in einem abnormen Zustande befinden würde. Der beste Beweis dafür ist, daß im Verhältnis zu der ungeheuren Häufigkeit peripherer Erkrankungen der Sinnesorgane diese Art von Halluzinationen als enorm selten zu betrachten ist. Der abnorme Zustand des Zentrums spricht sich von der geistigen Seite nur nicht als Psychose im eigentlichen Sinne des Wortes aus. Wir halten es aber für sehr wahrscheinlich, daß vielleicht in allen Fällen funktionelle Veränderungen im Sinne von psychopathischer oder hysterischer Veranlagung vorliegen. In einem von uns beobachteten Falle handelte es sich um ausgesprcchene Hysterie, die augenblicklich sogar einen echten psychotischen Erregungszustand hervorgebracht hat. In einem anderen Falle, der in unserer Beobachtung stand, haben wir sehr erheblichen Grund, hysterische Veranlagung zu vermuten. In einem dritten Falle handelte es sich wohl ebenso sicker um einen Psychopathen ${ }^{2}$ ).

Also auch die Halluzinationen auf Grund peripherer Erkrankung der Sinnesorgane erweisen sich uns als Trugwahrnehmungen im definierten Sinne.

Es finden sich in der Literatur noch eine große Anzahl weiterer Definitionen der Halluzination. Wir haben hier nur die hauptsächlichsten Typen berücksichtigen können.

In bezug auf die klinische Abgrenzung der Halluzination müssen wir uns ebenfalls im wesentlichen nur auf die Aufzählung der mit der

$\left.{ }^{1}\right)$ Kraepelin (Über Tonwahrnehmung, Vierteljahresschr. f. wiss. Philo. sophie 5) empfiehlt deshalb auch für diese Art Halluzinationen die Bezeichnung, Sinnestäuschung.

$\left.{ }^{2}\right)$ Über die Unwahrscheinlichkeit der peripheren Entsehung der Halluzination überhaupt s. bei Goldstein (l. c.), der diesesProblem in ausführlicher Weise von allen Seiten beleuchtet hat. 
Halluzination leicht verwechselbaren pathologischen Phänomene beschränken.

Das erste Phänomen, welches gar kein pathologisches ist, die normale Wahrnehmung, haben wir schon oben kurz berührt. Das pathologische Phänomen aber, von welchen die Halluzination am häufigsten und zugleich am schwierigsten abzugrenzen ist, die Illusion, hat nur für die Klinik ein besonderes Interesse, nicht aber für eine grundlegende Darstellung rom Wesen der Halluzination. Denn in der Illusion steckt ja selbst ein halluzinatorisches Moment, dessen Erklärung der Theorie der Halluzination obliegt.

Es gibt nun weiter Bewußtseinsphänomene, welchen wir die Bezeichnung Halluzination nicht vorenthalten können, trotzdem sie sich nicht als pathopsychische Phänomene im engeren Sinne des Wortes erweisen, da sie auch im Bereiche des normalen Bewußtseinslebens vorkommen. Sie werden uns sogar eine wesentliche Hilfe zur Erklärung der Halluzination als pathologischen Vorganges liefern. Da ist zunächst jener Bewul3tseinsvorgang, welcher auch in der wissenschaftlichen Sprache ohne weiteres als Halluzination bezeichnet wird, die hypnagoge Halluzination.

Nicht so häufig pflegen wir als Halluzination jedoch die im Tra u me auftretenden Vorstellıngen mit Wahrnehmungscharakter zu bezeichnen, offenbar deshalb, weil sie durch die tiefergehende Trübung des Bewußtseins, an welche sie geknüpft sind, den Entstehungsbedingungen der echten Halluzination sich als ferner stehend erweisen als die im Halbschlaf auftretenden hypnagogen Halluzinationen. Um Trugwahrnehmungen im definierten Sinne des Wortes handelt es sich aber in beiden Fällen trotz gleichzeitigen Fehlens der wirklichen Wahrnehmungswelt für das Bewußtsein.

Im selben Sinne wie die Träume sind die Vorstellungen mit Wahrnehmungscharakter zu beurteilen, welche überhaupt bei Aufhebung bzw. Trübung des Bewußtseins, z. B. in der Ohnmacht oder infolge von Bewußtseinstrübung nach Schädeltraumen, durch Narkose oder durch Intoxikation entstehen.

Der traumatischen Entstehung der traumhaften Halluzinationen stehen nahe jene traumhaften Zustände, die durch Chokwirkung entstanden zu denken sind. Hierher gehört der von Cle mens erwähnte Fall von einer Dame, die bei der Entfernung eines Splitters aus dem Finger in einen traumhaften Zustand verfiel, in welchem sie sich an den Rand eines Baches versetzt glaubte und allerlei Visionen hatte. Auch durch rein psychische Wirkung mögen solche halluzinatorischen $\mathrm{Zu}$ stände entstehen.

Die sog. Wachträumereien sind aber von Halluzinationen prinzipiell abzutrennen, weil es sich bei diesen nicht um Vorstellung mit 
Wahrnehmungscharakter handelt, sondern nur um lebhafte Phantasievorstellungen. Im selben Sinne sind die von Ziehen sog. Phantasmien $\mathrm{zu}^{\circ}$ beurteilen. Vielleicht gehört hierher auch ein Teil jener von Bleuler sog. ,,extrakampinen“ Halluzinationen, in welchen Szenen in weit entfernt liegenden Gegenden erlebt werden.

Ebenso sind aus bekannten Gründen prinzipiell von den Halluzinationen zu trennen die Konfabulationen und Erinnerungstäuschungen.

Ob wir aber mit Hagen (1. c.) auch die Delirien der Schiffbrüchigen, Hungernden usw. prinzipiell von den Halluzinationen ausschließen sollen, muß zweifelhaft erscheinen. Insofern bei diesen Delirien echte Halluzinationen vorkommen, werden wir dazu kein Recht haben.

Wohl aber werden wir natürlich mit $\mathrm{Hagen}$ die fixen Ideen von den Halluzinationen abzutrennen haben, selbstverständlich auch äbnliche Gebilde, wie überwertige Ideen, Zwangsvorstellungen usw.

Es können jedoch Vorstellungen von großer sinnlicher Lebhaftigkeit und Dauerhaftigkeit und unabhängig vom Willen ihres Trägers auftauchen; es fehlt ihnen nur die Beziehung auf die Außenwelt. In solchen Fällen haben wir es mit dem wichtigen Phänomen der Pseudohalluzination zu tun, das uns noch eingehend beschäftigen wird.

Schließlich ist der Wahn selbst, den wir zwar in engster genetischer Beziehung zur Halluzination finden werden, der aber natürlich selbst kein halluzinatorisches Phänomen ist, prinzipiell von dieser zu trennen. Die Schwierigkeit der klinischen Abgrenzung der Halluzination von der wahnhaften Auslegung, die eben in jener engen genetischen Beziehung ihren Grund hat, sind bekannt.

2. Die BewuBtseinsstellung des Halluzinierenden zu seinen Trugwahrnehmungen und die Halluzination als Apperzeptionsprozeß.

Wenn wir nun nach der Bewußtseinsstellung fragen, in welcher sich der Halluzinierende gegenüber seiner Trugwahrnehmungen befindet, so werden wir fordern müssen, daß diese in der Hauptsache keine andere ist als diejenige des normalen Bewußtseins zu den echten Wahrnehmungen. Denn wenn die Halluzination eine Trugwahrnehmung ist, d. h. eine Wahrnehmung, die der Kranke in demselben Sinne zu haben glaubt, wie der Normalsinnige die wirkliche Wahrnehmung tats̈̈chlich hat, so muß auch seine Stellung zu dem vermeintlichen Wahrnehmungsinhalt prinzipiell die gleiche sein wie die des normalen Menschen zu dem auf Grund eines realen Sinnreizes aufgefaßten Gegenstande der Außenwelt. Vom erkenntnistheoretischen Standpunkte werden wir also verlangen müssen, daß der halluzinierte Inhalt ebenso wie der tatsächlich wahrgenommene unmittelbar als Gegenstand der Außenwelt aufgefaßt wird. 
Daraus ergibt sich zunächst, daß der Halluzinierende den Inhalt des Halluzinationsaktes nicht etwa zuerst als Vorstellung apperzipiert trotzdem dieser Inhalt nichts weiter als Vorstellung ist - und dann erst in die Außenwelt projiziert, sondern unmittelbar kommt die Vorstellung mit dem Realitätscharkter, wie er den Wahrnehmungen eignet, zur Apperzeption, und eben durch die a uf pathologischem Wege sich vollziehende unmittelbare Verknüpfung der Vorstellung mit dem Realitätscharakter wird die Vorstellung dem Halluzinierenden zur Wahrnehmung, für den diesem BewuBtsoinsvorgang beurteilenden Normalsinnigen zur nur scheinbaren Wahrnehmung, zur Trugwahrnehmung.

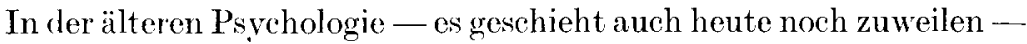
hat man die normale Wahrnehmung ebenfalls häufig als einen Projektionsvorgang dargestellt. Da ja die Wahrnehmung schließlich auch eine Vorstellung ist, so hat man zur psychologischen (harakterisierung jener gegenüber dieser den Wahrnehmungsvorgang als einen Vorstellungsvorgang gekennzeichnet, bei welchem der Vorstellungsinhalt in die Außenwelt projiziert wird. Diese Auffassung ist deshalb irrig, weil nicht im Subjekt der Grund der Externalität des Wahmehmungsinhalts liegt, sondern im Objekt. Dieses is $t$ ein außerbewußtes, wirl nicht erst vom Bewußtsein zu einem solehen gemacht, und als dieses außerhalb des auffassenden Individuums stehendes Objekt wird es unmittelbar im Wahrnehmungsakt festgestellt. Von einer projizierenden Leitung des Individuums kann dabei also keine Rede sein. Wie es möglich ist, dal3 in der Erkenntnis cin Wahrnehmungsinhalt unmittelbar sich als ein Gegenstand der AuBenwelt darstellt, ist eine Frage, die wir hier nicht weiter zu beantworten haben.

Anclers verhält es sich bei der Halluzination. Hier kann man von einer Projektion sprechen'), muß man sogar in gewissem Sinme eine solche annehmen. Denn ein Gegenstand der Außenwelt ist nicht vorhanden. Da nun der Halluzinierende seinen vermeintlichen Wahrneh. mungsinhalt ebenso als Gegenstand der Außenwelt auffaßt wie der Normalsinnige, so bleibt zunächst keine andere Deutung übrig als die, daß der Halluzinierende eine Vorstellung oder, wenn man diese Ausdrucksweise nicht für richtig hält, den Inhalt einer Vorstellung in dio Außenwelt projiziert, und daß 3 dieser ihm hicrdurch zurWahrnehmung wird.

Aber diese Auffassung besteht eben nur für die Deutung des be urteilenden Normalsinnigen, nicht für das Bewußtsein des Halluzinierenden. Wäre dlas letytere der Fall, so würde der Kranke seinen in der Trugwahrnehmung aufgefaßten Bewußtscinsinhalt nicht in demselben Sinne als real begründet auffassen wie seine normalen Wahrnehmungen.

1) Wie es z. B. Griesinger getan hat in ,Pathologie u. Therapie der psychischen Krankheiten“4. 2, Aufl. 1867. 
Es gibt nun in der Tat für den Geisteskranken Vorstellungsinhalte, bei welchen er sich einer Projektion in die Außenwelt bewußt wird. Die Folge hiervon muß aber sein, daß der Kranke selbst diese Projektion als eine gegenstandslose auffaßt, daß er gewissermaßen zum Normalsinnigen gegenüber der betreffenden Bewußtseinslage wird. Er erkennt unmittelbar oder nachträglich, daß er projiziert hat. In solch einem Falle hat der Kranke Kritik für seine Halluzinationen.

Regelmäßig kommt diese Kritik bei der Genesung vor. Ja es ist das Prinzip, das eigentliche Kennzeichen der Genesung von der Psychose, daß der Geisteskranke Kritik für seine Halluzinationen bekommt, das Projektionsbewußtsein also in ihm auftaucht.

Umgekehrt kann man aber nicht sagen, daß der Geisteskranke, welcher Kritik für seine Halluzinationen hat, sich nun auch prinzipiell im Zustande der Genesung befindet. Denn neben seinen unkritisierten Halluzinationen kann der Geisteskranke auch kritisierte haben und dauernd behalten.

Hat das kranke Individuum nur kritisierte Halluzinationen, so ist es nicht geisteskrank im eigentlichen Sinne. Denn es läßt sich eben nicht durch seine Trugwahrnehmung, ,betrügen“. Regelmäßig kritisiert sind die Halluzinationen, die infolge von Erkrankungen der peripheren Sinnesflächen durch eine sekundäre Reizung der Hirnrinde hervorgerufen werden, es müßte denn zugleich Geisteskrankheit vorliegen.

Aber auch bei Geisteskrankheiten im engeren Sinne mögen in seltenen Fällen kritisierte Halluzinationen allein vorkommen. Soweit uns bekannt ist, scheint dazu jedoch bisher nur der von Probst veröffentlichte Fall zu gehören, und wie sich dieser weiter entwickelt hat, wissen wir nicht ${ }^{1}$ ). Immerhin mögen solche Fälle sich häufiger ereignen, als wir wissen. Wenn wir bedenken, wie beharrlich Paranoiker ihre Wahnideen zu dissimulieren verstehen, so werden wir es auch für möglich halten, daß jemand seine Halluzinationen für sich behält.

Nicht nur in der Genesung, sondern auch im Beginn der Psychose, solange noch der besonnene Kranke sich nicht wehrlos seinen Halluzinationen hingibt, werden wir hin und wieder Kritik erwarten können. Ein Schulfall für einen solchen, freilich nur vorübergehend gelungenen Versuch, über seine Halluzinationen zur Kritik zu gelangen, ist der häufig zitierte, von Binswanger ${ }^{2}$ ) berichtete Fall des paranoisch gewordenen Arztes, der auf den See hinausfährt, um zu erfahren, ob dort ebenfalls Halluzinationen auftreten. Er schloß ganz richtig, wenn auf dem See, wo menschliche Stimmen ihn nicht erreichen können, dennoch solche von ihm gehört werden, so muß es sich um eine Trugwahrnehmung handeln.

1) Probst, Über das Gedankenlautwerden und über Halluzinationen ohne Wahnideen. Monatsschr. f. Psych. u. Neurol. 13. 1903.

$\left.{ }^{2}\right)$ Binswanger usw. Lehrb. d. Psychiatrie. 
Er hörte eine Stimme und kritisierte sie richtig als Halluzination. Das hinderte ihn aber nicht, ans Land zurückgekehrt, neu auftretende Halluzinationen unkritisiert hinzunehmen oder doch seine Kritik von der Wucht der Leibhaftigkeit seiner Halluzinationen überwältigen zu lassen.

In allen diesen Fällen scheint es sich freilich zunächst um ein kritisches Urteil zu handeln, welches sich an die bereits stattgefundene Halluzination anschließt ${ }^{1}$ ). Es ist verständlich, daß ein solches nachträgliches Urteil über die Realität, mag es richtig orler falsch sein, bei Halluzinierenden nicht so selten auftreten wird. Denn in sehr vielen Fällen wird, wenn nicht die Besomnenbeit des Kranken bereits stärker beeinträchtigt ist, doch schon die Fremdartigkeit und die inhaltliche Besonderheit der Halluzination den Kranken zum Nachdenken über die vermeintliche Wahrnehmung und zum Vergleich mit dem tatsächlichen Wahrnehmungsfelde, von dem jene so häufig absticht, anregen.

Es kann aber nun die Frage aufgeworfen werden, ob ein solcher urteilsmäßig sich vollziehender, die Realität betreffender Bewußtseinsvorgang schon von vornherein im Halluzinationsakte unmittelbar, sei es in annehmendem oder ablehnenden Sinne, sich geltend macht.

Wir glaubten der Mitwirkung eines Urteilsaktes bei der normalen Wahrnehmung eine ausschlaggebende Rolle nicht zuerkennen zu sollen, und ebenso glaubten wir eine solche bei der ausgebildeten Trugwahrnehmung ausschließen zu müssen. Wir anerkannten aber die prinzipielle Möglirhkeit und das tatsächliche Vorkommen des Mitwirkens eines Realitätsurteils bei der normalen Wahrnehmung. Ebenso werden wir natürlich das tatsächliche Vorkommen eines Urteilsaktes bei der Trugwahrnehmung für möglich halten müssen. Ja, wir werden aus den oben angeführten Gründen das Mitwirken eines Urteilsaktes im Halluzinationsakt für viel häufiger halten mïssen als im Wahrnehmungsakt des Gesunden.

Daß Geisteskranke beim Ausfragen in ihrem Urteil schwanken, ob sie wirkliche Halluzinationen - in ihrem Bewußtsein Wahrnehmungen oder Eigenvorstellungen gehabt haben, kommt ja häufig genug vor. Vielleicht beurteilen sie selbst nicht einmal ihre Bewußtseinsakte richtig, verwechseln z. B. in manchen Fällen Pseudohalluzinationen mit echten. Hier würden wir mit Jaspers von dem Realitätsurteil das ps ychologische Urteil zu trennen haben, in welchem der Kranke über den Leibhaftigkeitscharakter seiner abnormen Bewußtseinsinhalte ein, sei es richtiges, sei es falsches Urteil abgibt.

Da nun die psychologische Möglichkeit besteht, daß Urteilsakte und Schlußfolgerungen von noch so komplizierter Form bei später auftretenden Wahrnehmungen unmittelbar mitwirken, so wird man die prin-

1) Bezügl. des Falles Binswangers s. jedoch weiter unten. 
zipielle Möglichkeit nicht bestreiten können, daß beim Halluzinationsakte selbst ein Urteilsakt in dem von Golds tein angenommenen Sinne wirksam ist. Es erscheint uns durchaus plausibel, daß die Kenntnisse und Urteile, welche wir im normalen Bewußtseinsleben aus der Gesamtheit unserer bisherigen Erfahrungen über Realität und Nichtrealität gewonnen haben, bei besonnenen Geisteskranken eine große Rolle spielen, und daß nur in den - allerdings wohl die Mehrzahl bildenden Fällen, in welchen die geistige Erkrankung bereits tiefer in die psychische Gesamtkonstitution eingegriffen hat oder schon von vornherein in akuter Form aufgetreten ist, eine Mitwirkung des Realitätsurteils ausbleibt.

Es würde also in solchen Halluzinationen jener Ausnahmefall verwirklicht sein, den wir zuweilen andeutungsweise in normalem Zustande erleben (entoptische und entotische Sensationen, Eigenerregungen der Haut), den wir besonders rein in den Experimenten $K \ddot{u} l p e s$, bei welchen wir das unmittelbare Nachwirken des aus früheren Wahrnehmungen gewonnenen Realitätsurteils glaubten annehmen zu sollen, künstlich hergestellt fanden.

Nur stellt die Natur bei den Halluzinationen das Experiment in umgekehrter Weise an wie der Experimentator in seinen Versuchen. Während bei den letzteren objektive Reize geboten werden, um sie auf die Möglichkeit der Verwechslung mit subjektiven, nämlich den entoptischen Phänomenen und den Eigenerregungen des Hautsinns zu prüfen, bietet die Natur in den Halluzinationen dem Subjekt rein subjektiv entstandene Vorstellungen, die nun das Individuum von Wahrnehmungsvorstellungen nicht mehr unterscheiden kann ${ }^{1}$ ).

In solchen Fällen wird die Apperzeption -- immer natürlich unter Voraussetzung einer gewissen Besonnenheit des Kranken - sicher alle Hilfen heranziehen, um den Unterschied zwischen Wahrnehmung und Vorstellung, zwischen Außenweltscharakter (Leibhaftigkeit) der ersteren und Subjektivität (Bildhaftigkeit) der letzteren dem Individuum zu ermöglichen. Und zwar werden diese Hilfen sich nicht erst der nachträglichen Reflexion zu Gebote stellen, sie werden sicherlich auch schon beim vermeintlichen Wahrnehmungsakte selbst mitwirken. Und diese Hilfen sind die Urteile über die Realität, welche wir im Anschluß an frühere Wahrnehmungen und Vorstellungen im praktischen Leben und in der wissenschaftlichen Betrachtung häufig genug zu fällen Gelegenheit hatten.

1) Es darf hier nur auf das Tertium comparationis, welches beide Male in dem Gegensatz zwischen Objektivität und Subjektivität liegt, geachtet werden. Im übrigen sind die entoptischen Phänomene nicht in jedem Sinne mitVorstellungen auf eine Stufe zu stellen. Die Auslösungsbedingungen der etoptischen Phänomene, etc. liegen nun einmal peripher, was bei den Vorstellungen im engeren Sinne nicht der Fall ist. 
Um die Möglichkeit der Mitwirkung früherer, à uf urteilsmäßigemWege gewonnener Frfahrungen im Apperzeptionsakte näher zu erkennen, wollen wir auf letztere mit einigen Worten eingehen.

In welchem Maße früher gewonnene Erfahrungen überhaupt im Wahrnchmungsakte mitwirken, das hat uns die Psychologie des 19. Jahrhunderts, im speziellen Herbart und seine Schule, ganz besonders aber die im Rahmen dieser schule betriebene Völkerpsychologie eines Lazarus und Steinthal kennen gelchrt. Die in der Wahrnehmung sich vollzichende Apporzeption - im Sime Herbarts, der in der modernen Psychologie noch im physiologischen Sinne ergänzt ist bedeutet dio Verschmolzung des in der augenblicklichen Wahrnehmung gobotenen Inhaltes mit den unter der BewuBtseinsschwella vorhandenen Residuen früherer Wahrnehmungen und Vorstellungen, damit aber auch aller, sci es in der Praxis, sei es in der wissenschaftlichen betrachtung früher gewonnener Urteile und. Schlüsse. Denn auch die auf diesem Wege gewonnenen Begriffe stellen sich von der psychologischen Seite als Vorstellungen oder Vorstellungsilerivate dar ${ }^{1}$ ).

Es weckt also die im Wahrnehmungsakte gebotene Perzeptionsmasse eines äuBeren (iegenstandes die unter der Schwelle des Bewußtseins ruhenden Residuen frïherer der Perzeptionsmasse verwandter Apperzeptionsmassen und verschmilzt mit diesen zu einer einheitlichen Erkenntnis ${ }^{2}$ ).

Um ein Beispiel anzuführen, so werden in dem Wahrnehmungsakte, in welchem der Naturmensch des Mondes ansichtig wird, nur diejenigen Residuen anklingen, die ihm von früheren Wahrnehmungen des Mondes, ev. auch ron abergläubischen Vorstellungen, die er und seine Volksgenossen sich über die Wirkung des Mondes gemacht hatten, geläufig sind. Betrachten wir den Mond, oder betrachtet gar der Astronom unserer Tage auf der Sternwarte den Mond, so wird der ganze in UnterbewuBtsein vorhandene, aus Erfahrung und Wissenschaft herrührende Niederschlag seiner Kenntnisse im Apperceptionsakte mitwirken, oder doch apperzeptionsbereit an der Schwolle des BewuBtseins verharren. Denn wenn der Astronom bei einem Abendspaziergange des Mondes ansichtig wird, während er seine gedankliche Intention vielleicht auf das die 'Tagesereignisse betreffende (respräch mit seinem Begleiter richtet, so braucht natülich der ganze Niederschlag seiner wissenschaftlichen Erfahrungen in der Wahrnehmung des Mondes nicht mitzuwirken. Er wird sich des Mondes in den meisten derartigen Fällen wohl nur so bewußt werden wie jeder Wahrnehmende überhaupt.

1) S. Anmerkurg auf folg. Seite.

2) B. Erdmann, Logik", Halle 1907. Ders. Zur Theorie d. Apperzeption. Vierteljahrssehr. f. wissen. Philosophie 10. 
Wir wollen noch ein anderes Beispiel wählen, bei welchem die Mannigfältigkeit des sinnlich dargebotenen Inhalts größer ist. Welch eine Summe von Vorstellungen können durch den Anblick eines Kunstwerks erweckt werden. Je länger ich das Gemälde betrachte, um so mehr ,spricht" es zu mir. Kein Urteilsakt, keine von der Wahrnehmung des Gemäldes selbst gesondert auftretende Vorstellung ist es oder braucht es doch nicht zu sein -- es ist immer dieselbe Wahrnehmungsvorstellung und doch nicht dieselbe, weil immer neue Apperzeptionsmassen, von denen die eine die andere nach sich zieht, ins Bewußtsein treten, um unmittelbar miteinander und dem betrachteten Gemälde zu einem einheitlichen Bewußtseinsgebilde zu verschmelzen.

Der Apperzeptionsakt ist ein Akt assoziativer Verschmelzung. Während beim Denken im engeren Sinne, d.h.im Gedankenverla uf, die einzelnen assioziativ geweckten Vorstellungen an Hand der Leitvorstellung gesondert ins Bewußtsein treten, verschmelzen im Apperzeptionsakte die Vorstellungen bzw. ihre Residuen mit der in der Wahrnehmung des äußeren Objektes gebotenen Perzeptionsmasse zu einem einheitlichen Gebilde ${ }^{1}$ ).

Wir haben nun allen Grund anzunehmen, daß bei Vorstellungen von bestimmtem Charakter, nämlich wenn sie mit besonderer Lebhaftigkeit und Dauerhaftigkeit sich vor das Bewußtsein stellen, sich ein ähnlicher Proze $\beta$ abspielen wird. Im allgemeinen zwar wird die Form des Reproduktionsvorganges wie beim Denken sein, $d . h$. es wird sich um einen Vorstellungsverla uf handeln. Vorstellungen jedoch, die ich im Gedankengange festzuhalten suche, weil ich sie zum Objekt meines praktischen oder wissenschaftlichen Nachdenkens mache, werden mit immer neuen aus den Tiefen des Unterbewußtseins herangezogenen Merkmalen behaftet sich vor mein inneres Auge stellen, d.h. es wird ein Apperzeptionsvorgang stattfinden wie bei der Wahrnehmung.

In noch viel höherem Maße wird das möglich sein bei jenen abnorm produzierten Vorstellungen, welche wir Pseudohalluzinationen nennen. Denn diese treten, wenn auch nicht mit dem Wirklichkeitscharakter behaftet, doch mit einer solchen Deutlichkeit und Lebendigkeit vor das Bewußtsein, daß ihr Träger sie, wenn es sich um Visionen handelt, wie ein leibhaftiges Objekt von allen Seiten beschauen kann.

Und bei den echten Halluzinationen? Nun, diese sind ja für den Kranken Wahrnehmungen. Sie stellen sich vor das Bewußtsein des

1) Man hat übrigens neuerdings nicht ganz mit Unrecht Protest dagegen erhoben, Gedanken ohne weiteres als Vorstellungen aufzufassen und überhaupt von einer Vorstellungshypertrophie im wissenschaftlichen Sprachgebrauch geredet. In der Tat ist im "Gedanken" das eigentlich Repräsentative, welches in der Vorstellung steckt, fast bis zur Unauffindbarkeit verflüchtigt. Trotzdem dürfen wir wohl der Einheitlichkeit wegen von Vorstellungen sprechen, weil die Gedanken ebenfalls ursprünglich aus Vorstellungen hervorgegangen sind. 
Kranken genau so wie die Gegenstände der Außenwelt. Er betrachtet sie, wenn es sich um Gesichtshalluzinationen handelt, ganz so, wie wir ein Gemälde betrachten. Aber dieses Gemälde bietet ihm, wenn er seine Besonnenheit gewahrt hat, besondere Eigentümlichkeiten, durch welche es aus dem Zusammenhange mit der wirklichen Wahrnehmungswelt herauszufallen droht, und diese Eigentümlichkeit muß die Apperzeption des kranken Individuums in eine ganz bestimmte Richtung lenken, nämlich in Richtung a uf das Merkmal der Realität.

Tritt nun die Verschmelaung mit dem aus früheren Urteilen stammenden Realitätscharakter tatsächlich ein, so hat das Bewußtseingebilde den Charakter der Realität (Leibhaftigkeit). Wird die Verschmelzung vom Bewußt. sein abgelehnt, so hat das Bew ultseinsgebildeden Charakter der Nichtrealität (Bildhaftigkeit). Oszilliert das Bewußt. sein resultatlos zwischen Verschmelzung und Nichtver. schmelzung, so hat das Bewußtseinsgebilde in bezug a uf das Realitätsmoment einen schwankenden Charakter.

Nachträglich kann dann natürlich in der Reflexion ein Urteil gemäß der stattgefundenen, nicht stattgefundenen oder zweifelhaft gebliebenen Verschmelzung des Bewußtseinsgebildes mit dem Realitätsfaktor abgegeben werden. In bezug auf stattgefundene oder nicht stattgefundene Verschmelzung wird das Urteil in kategorischer oder a podiktischer Form, in bezug auf die zweifelhaft gebliebene Verschmelzung in problematischer Form erfolgen ${ }^{1}$ ).

Dieses urteilsgemäß abgegebene oder gedachte Votum ist nur die prädikative Zerlegung des im Halluzinationsakte selbst schon implizite vorhandenen, aber noch nicht in der eigentlichen logischen Form zum Ausdruck gekommenen Erkenntnisvorganges in bezug auf die Realität.

Es gibt natürlich Utbergänge von der unmittelbaren Verschmelzung des Halluzinationsinhaltes mit dem Realitätsfaktor zu der nachträglichen Reflexion, ebenso wie es Ủbergänge gibt zwischen dem Gedankenverlauf und dem als einheitlichen Akt sich darstellenden Erkenntnisvorgang. Das eine Mal wird schon im Halluzinationsakte selbst - so, wie wir es beschrieben haben - die Verschmelzung stattfinden, das andre Mal wird vielleicht nur einfach ein abnormes BewuBtseinsgebilde (Halluzination) auftauchen und dieses erst nachträglich in der Reflexion mit dem

1) Hat sich das halluzinatorische Gebilde so einfach wie jede andere Wahrnehmung vor das Bewußtsein des Kranken gestellt, $d . h$. in jenem Sinne, in welchem ein differenziertes Realitätsbewußtsein wegen der Gewohnheit des Objekts sich überhaupt nicht bemerkbar macht, so wird es sich nur um jene einfachen assertorischen Urteile handeln, in welchen wir über irgendwelche Vorgänge der Außenwelt berichten.

z. f. d. g. Neur. u. Psych. O. XXIV. 
Realitätsfaktor urteilsmäßig in Verbindung gebracht werden; das dritte Mal wird der Apperzeptionsakt fließend in das nachfolgende Urteil über die Realität übergehen.

Aus dem Gesagten geht wohl hervor, daß es nicht angängig ist, die Auffassung Goldsteins über die Mitwirkung des Urteils bei der Halluzination in toto zu verwerfen. Sie hat nur keine Anwendung oder doch keine Bedeutung bei den unmittelbar mit dem unerschütterlichen Bewußtsein der Leibhaftigkeit auftretenden Wahrnehmungen und Halluzinationen. Ganz so häufig, wie man gewöhnlich glaubt, ist aber dieses unerschütterliche Realitätsbewußstsein bei den Halluzinationen der Geisteskranken keineswegs.

Selbst bei den völlig auf der Höhe ihrer Ausbildung stehenden Psychosen wird sicherlich nicht selten auf dem Wege über frühere Urteile das Realitätsbewußtsein bei den Halluzinationen zustande kommen. Denn bei manchen Psychosen erfahren wir in allen Stadien von den Kranken, daß sie in ihrem Urteil über die Externalität ihrer Halluzinationsinhalte schwanken. Wir haben keine Berechtigung, anzunel men, daß diese Unsicherheit des Urteils nur auf der Schwierigkeit beruht, über die eigenen Bewußtseinsinhalte richtig Auskunft zu geben (psychologisches Urteil von Jas pers), eine Schwierigkeit, die freilich auch der normalen Psychologie bei denjenigen Urteilen anhaftet, die wir über die nur auf introspektivem Wege zu erfahrenen Vorgänge des Bewußtseins gewinnen, sondern wir haben wohl als sicher zu betrachten, daß die Psyche des geistig Erkrankten ihre Bewußtseinsinhalte nicht immer in so deutlicher Form produziert, daß diese selbst jedesmal entweder den Charakter reiner Bildhaftigkeit (Vorstellungscharakter) oder reiner Leibhaftigkeit (Wahrnehmungscharakter) in voller Ausbildung an sich trügen, daß also bei den Halluzinationen häufig der von uns oben geschilderte dritte Fall realisiert sein wird, bei welchem das Bewußtsein zwischen Realitäts- und Nicht-Realitätsauffassung oszilliert und dementsprechend ein problematisches Urteil nach sich ziehen muß.

Apriori zu sagen, bei welchen psychischen Erkrankungen und welche bei diesen auftretenden Halluzinationen sich durch Vermittlung früherer Realitätsurteile, und welche unmittelbar ihren Leibhaftigkeitscharakter gewinnen, wird natürlich nicht durchweg möglich sein. Es muß der weiteren Forschung überlassen bleiben, Gesichtspunkte für die Entscheidung dieser Frage zu gewinnen. Wir können aber schon jetzt sagen, daß die unmittelbare Úberzeugung von der Realität manchmal vermißt wird bei den Erkrankenden und bei den Genesenden, bei vielen schizophrenen Zuständen, bei vielen Halluzinationen Deprimierter, besonders aber Hysterischer und Degenerierter. Bei allen diesen wird das frühere gewonnene Realitätsurteil zu unmittelbarer Mitwirkung im Apperzeptionsakte gelangen, und zwar um so eher, je besonnener der Kranke ist, je 
häufiger er bewußt kritisierte Halluzinationen oder Pseudohalluzinationen gehabt hat, und je mehr infolgedessen sein BewuBtscin darauf eingestellt ist, seine abnormen Bewubtseinsinhalte nicht ohne weiteres mit dem Leibhaftigkeitscharakter zu versehen.

In der Literatur finrlen sich eine Anzahl Falle, welche in diesem Sime zu deuten sind. So berichtet Baillargar) von einem Alkoholiker, der schon mehrere Male cin Delirium durchgemacht hatte, da $B$ er bei Beginn eines neuen Anfalles eine tüchtige Dosis Koloquintenwein zu sich nahm, weil er zufälligerweise die Beobachtung gemacht hatte, daß er dadurch seine Halluzinationen zum Schwinden bringen konnte.

Würde dieser Alkoholiker scine Halluzinationen nicht für das, was sie waren, cben für Trugwah rneh mung:n, gehalten haben, so würde er wohl nicht auf den Hinfall gekommen sein, sie clurch ein Heilmittel zu vertreiben. Bei der Massenhaftigkeit, mit welcher Halluzinationen im Delirium auftreten, ist auch als sicher an\%unehmen, daß, selbst wenn sich das Bewulistein der Lnwirklichkeit, also im obigen Falle das negative oder abweisende Realitïtsbewußtsein, bei den ersten Halluzinationen erst nachträglich im Urteil eingestellt haben sollte, doch gemäß unsorer obigen schilderung bei den folgenden unmittelbar im Halluzinationsakt selbst auf (irund der früle:en Urteile sich geltend gemacht haben wird.

Deshalb können wir auch nicht der Ansicht Heilbronners folgen, der bei einem ähnlichen Fall ${ }^{2}$ ) annimmt, daß das Realitätsbewußtsein sich erst nachträglich eingestellt hätte. Hcilbronner berichtet von einem Alkoholiker, der, weil er ebenfalls schon mehrere Male ein Delir durchgemacht hatte, beim Ausbruch eines neuen Delirs sich in der Nacht nach der Klinik aufgemacht habe. Schwere Angst habe er erst auf der Landstraße bekommen, da er hinter jedem Baume eine drohende Gestalt zu sehen glaubte. Das heilst aber nichts anderes, als daß er sich erst bei den später auftretenden Halluzinationen von deren Leibhaftigkeitscharakter hat überwältigen lassen.

Manche Intoxikationen scheinen überhaupt für die Erhaltung des Realitätsbewußtseins günstige Vorberlingungen zu schaffen. So berichten die Autoren, da B im Haschischrausch das RealitätsbewuBtsein nie getrübt ist. ,I Ias Bewußtsein, da $B$ man irre sieht und irre redet, ist da, und doch kann man es nicht ändern und nicht lassen." (Pick 1. c.)

Ähnlich liegen die Verhältnisse bei Atropin- und Belladonnavergiftungen.

Ein Beispiel für die Bemühung eines im Beginn seines Leirlens stehenden Geisteskranken auf Grund der Erfahrungen, die er in

1) Annales méd.-psych. 1, 4:34. 1881.

2) Heilbronner, C̈ber Krankheitseinsicht. Arehiv f. Prych. 58, 613 f. 1901. 
gesunden Tagen über die gegebene, in kranken Tagen über die vermeintliche Realität gewonnen hat, seinen abnormen Bewußtseinsinhalten unmittelbar den richtigen Stempel aufzudrücken, dürfte auch schon der oben zitierte Fall Binswa ngers von dem paranoisch gewordenen Arzte gerade dadurch liefern, daß dieser absichtlich auf den See hinausfährt, um zu erfahren, ob er dort ebenfalls Halluzinationen bekomme. Dieser Paranoiker stellt ein erkenntnispraktisches Experiment a uf Grund früher gewonnener Realitätsurteile an. Er rückt absichtlich die von den früher gewonnenen Realitätsurteilen in seinem Unterbewußtsein zurückgebliebenen Erkenntnisresiduen apperzeptionsbereit an die Schwelle seines Bewußtseins, damit sie sofort beim Auftreten der erwarteten, sei es tatsächlichen, sei es vermeintlichen Wahrnehmungsinhalte erweckt werden und diesen unmittelbar ihren wahren Charakter, Vorstellungs- oder Wahrnehmungscharakter, aufprägen möchten. Dieses auf Urteil sich stützende Apperzeptionsexperiment glückt auf dem See, auf dem Lande nicht.

Ein weiteres Beispiel für einen auf Urteile sich gründenden Apperzeptionsvorgang in Hinblick auf das Realitätsbewußtsein bietet der von Japers berichtete Fall einer Kranken, welche nach der Ansicht dieses Autors an Pseudohalluzinationen, nicht an echten Halluzinationen leidet $\left.{ }^{1}\right)$. Sie hat bereits Gehörshalluzinationen oder Pseudohalluzinationen gehabt, deren Realitätslosigkeit sie erkannt hatte. Als sie nun zu einer Zeit, in welcher so etwas nicht zu erwarten war, Glockenläuten hörte, geht sie ans Fenster, öffnet dieses, um weiter die Glocken zu hören. Sie hört aber nichts. Als sie nun eines Abends bei Tische auf einmal Musik hörte, fällte sie sofort das richtige - negative Realitätsurteil. Sie wußte ja vom Glockenläuten her, daß sie ,so etwas“ habe. Das heißt: die vermeintlich perzipierte Musik weckte sofort die Apperzeption ,Nichtwirklichkeit", welche sich auf frühere unmittelbare und urteilsmäßig gewonnene Erfahrungen über Realität und Nichtrealität aufbaute, und prägte dem abnormen Bewußtseinsvorgang den riehtigen Stempel, nämlich den des Vorstellungscharakters, auf.

Natürlich wird sich nach dem früher Gesagten nicht immer mit Sicherheit entscheiden lassen, ob die Kritik eine nachträgliche ist, oder ob sie sich im Halluzinationsakte selbst auf dem geschilderten Apperzeptionswege vollzieht. Es gibt hier sicher mannigfache Utbergänge.

Wenn Kranke, mögen sie an Halluzinationen oder Pseudohalluzinationen leiden, während ihres länger dauernden Leidens ihre Besonnenheit bewahren, so wird wohl stets auf Grund urteilsmäßig gewonnener Erfahrungen das Realitätsbewußtsein bei den abnormen Bewußtseinsinhalten zustande kommen.

1) L. c. S. 513 f. Wir glauben aus später zu erörternden Gründen, daß es sich vielleicht um echte Halluzinationen gehandelt haben wird. 
Ein Beispiel für das richtige negative Realitätsbewußtsein bietet in bezug auf Pseudohalluzinationen der von Goldstein zitierte Fall Tr. ${ }^{1}$ ), für Halluzinationen der von Probst berichtete Fall (l. c.).

Stets wird auf diese Weise das Realitätsbewußtsein sich ausbilden bei den auf Grund von Affektionen der peripheren Sinnesflächen an Halluzinationen leidenden Kranken, die ja nicht Geisteskranke im eigentlichen Sinne des Wortes sind, die deshalb auch ihre Besonnenheit stets bewahren, wenn nicht eben zugleich eine echte Psychose vorliegt. Hier wird sich wohl immer ein unmittelbares mit den Halluzinationen selbst gegebenes Bewußtsein ihrer Nichtrealität auf Grund früher gewonnener Urteile geltend machen, und sollte es bei den ersten Halluzinationen noch nicht vorhanden gewesen sein, sondern sich erst im nachträglichen Urteil eingestellt haben, bei den darauffolgenden ist es sicher, wie wir das selbst an einigen Fällen feststellen konnten, mit der Halluzination unmittelbar gegeben.

Indem wir so erkannt haben, daß im Halluzinationsakte in der Tat ein Urteilsakt über die Realität mitwirken kann und ohne Zweifel häufig mitwirkt, haben wir doch zugleich die Erkenntnis gewonnen, daß es keineswegs in jedem Falle sicher ist, zu welchem Resultat das Bewußtsein im halluzinatorischen Apperzeptionsakte gelangt. Es kann sich für oder gegen die Realität entscheiden, es kann aber auch unentschieden in der Schwebe bleiben.

Prinzipiell zu trennen von der Frage, ob im Halluzinationsakte selbst ein Urteil über die Realität seine Mitwirkung zum Zustandekommen des Realitätsbewußtseins entfaltet, ist die Frage, ob die durch die Geisteskrankheit verursachte intellektuelle Störung, also Urteilsstörung, zugleich auch die Ursache des fälschlichen Realitätsbewußtseins in der Halluzination ist.

Zur Entscheidung dieser Frage ist folgendes zu bedenken. Halluzinieren und zugleich den halluzinierten Gegenstand als einen wirklichen ebenso ansehen wie einen tatsächlich wahrgenommenen, kann unter allen Umständen nur derjenige, welcher das richtige Urteil über die Realität in bezug auf bestimmte Bewußtseinsinhalte verloren hat, $d$. h. also der Geisteskranke oder der Bewußtseinsgetrübte, etwa der Träumende.

Insofern könnte man den Verlust des richtigen Urteils über die Realität als die Vorbedingung für das fälschliche Realitätsbewußtsein des Halluzinierenden bezeichnen. Richtiger ist es aber wohl zu sagen, daß das fälschliche Realitätsbew ußtsein und das fälschliche Urteil über die Realität koordinierte Folgen der zugrunde liegenden Geisteskrankheit sind. Sahen wir doch das fälschliche Realitätsbewußtsein im Apperzeptionsakt des Halluzinierenden fließend in das nachfolgende Urteil über die Realität übergehen.

1) Archiv f. Psych. 44, 593. 
Zugleich erkennen wir, daß der Schluß, welchen Golds te in aus faIschen Prämissen zog, dennoch ganz richtig ist. Der Autor meint, Trugwahrnehmungen oder Vorstellungen können nicht im selben Raume erlebt werden, solange wir die Unterscheidung durchführen können, solange ein Urteil darüber möglich ist; die Vortäuschung des Eingeordnetseins der Trugwahınehmungen in den räumlichen Zusammenhang sei nur möglich, wenn das Crteil oder das Meinen des Individuums verändert ist, also bei Bewußtseinstrübung oder Einengung des Bewußtseins durch Wahnideen.

Von dem ,Nieinen“ wollen wir freilich absehen. Denn in der Funktionspsychologie, aus welcher dieser Begriff entnommen ist, bedeutet er die gleichbleibende, vor allem aber unmittelbare, also nicht auf einem Urteilsakt beruhende Auffassung des Dinges als einheitlichen Gegenstandes gegenüber dem mannigfachen Wechsel seiner Empfindungsqualitäten. Insofern wäre es natürlich eine Tautologie, wenn man sagen würde: das unmittelbare Realitätsbewußtsein ist verändert, wenn das Meinen der Realität verändert ist.

Dann möchten wir noch statt Wahnideen ganz allgemein Geisteskrankheit setzen. Denn halluziniert und zwar mit fälschlichem Realitätsbewußtsein halluziniert wird doch auch ohne Wahnideen. Wir beobachten ja häufig Kranke mit Halluzinationen, bei welchen wir nicht imstande sind, eine ausgesprochene oder auch nur angedeutete Wahnidee zu konstatieren. Zum Halluzinieren genügt eben Geisteskrankheit im weitesten Sinne.

Wenn wir also sagen: Trugwahrnehmungen werden in den wirklichen räumlichen Zusammenhang eingeordnet, wenn zugleich das Urteil über die Realität infolge Geisteskrankheit oder Bewußtseinstrübung verändert ist, so ist das eine Formulierung, gegen die schließlich niemand etwas wird einwenden können.

Möglicherweise hat sich Goldstein durch die unbezweifelbare Tatsache, daß man halluzinieren und zugleich fälschlich in den wirklichen räumlichen Zusammenhang einordnen nur auf Grund einer Urteilsveränderung über şlie Realität kann, zu der falschen Prämisse verleiten lassen, daß bei der normalen Wahrnehmung, in welcher ja die Dinge richtig in den räumlichen Zusammenhang eingeordnet werden, das richtige Urteil über die Realität die eigentliche Ursache dieser Einordnung ist. Zu welchen eigentïmlichen Konsequenzen diese Auffassung bezüglich des Tieres und des Kindes, welche doch auch Wahrnehmungen haben, $d$. h. richtig in den wirklichen räumlichen Zusammenhang einordnen, führen würde, haben wir ja gesehen, und zugleich erkannt, daß auch rom Standpunkt der Erkenntnistheorie diese Ansicht unhaltbar ist.

Daß aber in der Tat der Verlust des richtigen Urteils über die Realität eine notwendige Vorberlingung für die fälschliche Einordnung der Trug- 
wahrnehmungen in den wirklichen räumlichen Zusammenhang ist, dafür haben wir die Gegenprobe in denjenigen Fällen, in welchen echte Trugwahrnehmungen bestehen, diese aber nicht vom Bewulstsein ihres Trägers in den normalen Wahrnehmungszusammenhang eingeordnet werden, weil das Lrteil über die Realität eben nicht pathologisch verändert ist.

Das ist der Fall erstens bei den geistig Gesunden, die auf Grund von pathologischen Veränderungen in den peripheren Simnesorganen halluzinieren. Die Erregung der Hirnrinde, welche durch solche abnorme periphere Reize gesetzt werden, genügt wohl, um Halluzinationen hervorzurufen ${ }^{1}$ ), nicht aber um das Realitätsbewußtsein zu veränderm. Um letzteren Erfolg hervorzubringen, muß das Gehirn in seiner Substanz oder in seiner Funktion tiefer gestört sein, d. h. der Mensch muß geisteskrank sein.

Zweitens aber kommen auch bei sicher Geisteskranken Halluzinationen ohne positives Realititsbewußtsein vor, d. h. also Pseudowahrnehmungen, deren Inhalt nicht auf einen wirklich vorhandenen Außenreiz bezogen wird.

Ein Fall, bei dem sich rer Realitätscharakter auf Grund logischer Schlußfolgerungen überhaupt verlor, trotzdem es sich, wie auch Jaspars, der ja das Pseudohalluzinatorische rom echt Halluzinatorischen so grüncllich zu scheirlen weiß, anerkennt, um echte Halluzinationen handelt, ist der Fall Probstis (C. c.).

In der normalen Bewußtseinsbreite erleben wir Phänomene, die uns wohl den Bewul3tseinszustand Halluzinierender ohne positives Realitätsbewußtsein reranschaulichen können. So lokalisieren wir deutlich die Nachbilder nach Blendung im wirklichen Raum. Ja, diese Blendungsnachbilder verdecken wie echte Wahrnehmungsgegenstände und Trugwahrnehmungen andere Gegenstände. Aber ein positives Realitätsbewußtsein ist nie vorhanden.

Ist zur pathologisehen Veränderung des Realitätsbewußstseins Geisteskrankheit als Ursache jedenfalls unbedingt erforderlich, so gilt frejlich nicht das Umgekehrte: es mul. nicht jeder Geisteskranke halluzinieren. Gerade diejenige Art von Geisteskrankheit, die uns das Prototyp für lie pathologische Veränderung des Urteils in besonderer Reinheit zu bieten scheint, die man darum auch frïher als reine Verstandeskrankheit glaubte betrachten zu können, die Paranoia, zeigt uns Fälle, in welchen nie halluziniert wird.

1) Wir lassen es dahingestellt, ob bei genauer Analyse sich nicht der größte Teil dieser Halluzinationen als Pseudohalluzinationen herausstellen wird. Bei cinem augenblicklich von uns beokachteten Fall konnte der pseudohalluzinatorische ('harakter der Tonwahrnehnungen mit Sicherheit festgestellt werden. Als Begrïndung der Unwirklichkeit der Phoneme gab der Kranke an, daß er die Stimmen „,im Kopf" höre. 
Zur fälschlichen Einordnung in den wirklichen $Z$ usammenhang der Dinge gehört also zweierlei: erstens eine Halluzination und zweitens Geisteskrankheit. Eine Bedingung allein genügt nicht für das Individuum, um ein abnormes Bewußtseinsgebilde mit dem Kennzeichen der Realität zu verknüpfen. Sind beide Bedingungen erfültt, so werden die Trugwahrnehmungen in der Regel, wenn auch nicht immer, gleich den normalen Wahrnehmungen vom Bewußtsein des Kranken aufgefaßt. Wir müssen hier auch den Begriff der Geisteskrankheit in etwas weiterem Sinne fassen. Denn auch bei Hysterien und Psychopathien kommen echte Halluzinationen vor. (Einen Fall siehe weiter unten.)

Von ganz besonderer Beweiskraft für die Annahme, daß das fälschliche Realitätsbewußtsein lediglich durch den Verlust des richtigen Urteils über die Realität zustande kommt, könnten Fälle erscheinen, in welchen man direkt nachweisen kann, daß Pseudohalluzinationen, über deren Bildhaftigkeit das betreffende Individuum vor Ausbruch der eigentlichen Psychose nicht zweifelhaft war, durch diese und die damit einsetzendeTrübung des Urteils sofort Leibhaftigkeitscharakter annehmen.

Solche Fälle mögen nicht häufig vorkommen. Wir haben aber selbst einen solchen beobachtet. Ich führe nur den wesentlichen Kern des Falles an.

Es handelte sich um eine Dame der gebildeten Stände, eine Arztschwester, welche an Hysterie leidet und Pseudohalluzinationen auf dem Gebiete des Gesichts und Gehörs produziert. Sie war über die Bildhaftigkeit ihrer Bewußtseinsgebilde nie im Zweifel. Einmal bekam sie jedoch einen heftigen Erregungsanfall, der sich über mehrere Wochen erstreckte und ihrer Hysterie einen echt psychotischen Charakter aufdrückte. Während dieser Periode faßte sie genau dieselben Bewußtseinsinhalte, welche sie vor Ausbruch der Psychose als Pseudohalluzinationen erlebt hatte, nunmehr als echte Halluzinationen auf. Nachdem der Erregungszustand abgeklungen war, nahmen die Halluzinationen wieder pseudohalluzinatorischen Charakter an ${ }^{1}$ ).

So sicher nun freilich in diesem Falle der Verlust der Kritik, der des richtigen Urteils über die Realität, als die nächste Ursache des Utberganges der Pseudohalluzinationen in echte zu betrachten ist, so ist doch nach unseren früher dargelegten Anschauungen der Verlust des Urteils selbst in der Geisteskrankheit selbst zu suchen, welche anstatt der früheren Pseudohalluzinationen nunmehr Halluzinationen hervortrieb, die als solche sowohl unmittelbar wie im nachfolgenden Urteil externalisiert werden.

1) Finen Fall mit schwankendem Realitätsbewußtsein je nach der Einwirkung des Arztes beschreibt Goldstei n. Die Halluzination, ihre Ursache, ihre Entstehung und ihre Realität. Wiesbaden 1912, S. 66. 
Solche Fälle müssen übrigens auch in uns die Frage anregen, ob es Ubergänge zwischen echten Halluzinationen und Pseudohalluzinationen gibt. Störring und Jas pers verneinen diese Frage. Letzterer meint, daß zwischen beiden eine unüberbrückbare Kluft bestehe, während zwischen Vorstellungen und Pseurlohalluzinationen alle möglichen Úbergänge stattfinden sollen.

Zu dieser Ansicht ist wohl Jaspers auf Grund der Unterschiede gekommen, wie sie im normalen Leben sich zwisehen Vorstellungen und Wahrnehmungen ergeben. In der Tat scheidet die Bildhaftigkeit, welche jenen, und die Leibhaftigkeit, welche diesen anhaftet, beide Bewußtseinsgebilde in so fundamentaler Weise voneinander, daß ein Ubergang in der Regel als ausgeschlossen erscheinen muß. Die Pseudohalluzination erscheint nun zunächst als nichts anderes denn als eine Vorstellung von besonderer Lebhaftigkeit und Dauer. Es müßten deshalb, wie man zunächst annehmen köṇte, alle denkbaren Ubergänge zwischen diesen beiden (xebilden existieren.

In anderem Lichte jedoch mul3 uns dieses Problem schon in gewissen Ausnahmefällen erscheinen, die sich noch in normaler Breite abspielen, z. B. bei den entoptischen Phänomenen. Wir erinnern wieder an die Experimente $K u ̈ l p e s$ und an das von Helmholz angeführte Beispiel des Spazierganges im Dunklen, bei welchem im peripheren Gesichtsfelde ein schwacher Lichtschein auftaucht. Hier dürfte bereits der Unterschied zwischen. Vorstellung und Wahrnehmung nicht mehr den absoluten Charakter zeigen wie sonst gewöhnlich.

Wenn wir nun gar zu den Geisteskrankheiten übergehen, so dürften wir hier genügend Fälle finden, in welchen ein solcher Ubergang zwischen Pseudohalluzinationen und echten Halluzinationen gegeben ist, ohne daß wir berechtigt wären, in dem von Jaspers sogenannten psychologischen Urteil allein, d. h. also in der nachträglichen mangelhaften Beurteilung der abnormen Bewußtseinsphänomene durch den Kranken selbst, das eigentlich Schwankende zu finden.

Zunächst beobachteten wir selbst einige Fälle von Unfallhysterie, in deren einem sich die Neurose vorübergehend zur Psychose steigerte, in welcher die Kranken nicht immer mit Sicherheit angeben konnten, ob einige von den massenhaften Pseudohalluzinationen, an welchen diese Individuen litten, nicht echten Lebhaftigkeitscharakter annahmen.

1)amn möchten wir auf den von Goldstein veröffentlichten Fall Tr. hinweisen. Hier wird ganz deutlich geschildert: ,Wenn er sich einerseits auch bewußt ist, daß es seine Vorstellungen sind, so erscheinen sie ihm doch in gewissem Sinne unabhängig in der Außenwelt ${ }^{1}$."

1) Archiv f. Psych. 44. S. 524, 
Das will doch nichts anderes besagen, als daß das psychische Phänomen sich als Mittelding zwischen Halluzination und Pseudlohalluzination vor das Bewußtsein des Kranken stellte.

Auch Kandins $k y^{1}$ ) führte schon einen solchen Fall an. Er spricht direkt von einer Transformation der Pseudohalluzinationen. ,Zuweilen (bei gewissen Bedingungen) transformieren sich einzelne dieser Pseudohalluzinationen in wirkliche Halluzinationen; dann crhalten einige pseudohalluzinatorische Gebilde den Charakter der Objektivität, wenn man sich so ausdrücken darf, Fleisch und Blut, werden materialisiert."

Auch Döllke $\mathbf{n}^{2}$ ) berichtet über eine Anzahl derartiger Fälle, die freilich zum Teil durch Erkrankung der peripheren Sinnesorgane kompliziert waren, was aber zur Entscheidung der hier vorliegenden Frage nicht von Belang ist. Von einem Falle wird gesagt: , Es zeigte sich, daß die Halluzination mit dem wirklichen Geräusch eine Verschmelzung einging, so daß er sich nicht auseinander halten konnte." Uber den pseudohalluzinatorischen Charakter wurde sich der Kranke erst klar, wenn das wirkliche Geräusch aufhörte.

Von den beiden ersten geschilderten Fällen sagt Döllken: ,Je nachdem also ein bestimmter Gehörreiz angenähert oder entfernt wurde, erhielt die Halluzination objektiven Charakter oder nicht."

Mit Rücksicht auf diese Fälle erklärt Döllken, daß sie gegen die Ansicht Störrings sprächen, daß eine haarscharfe prinzipielle Unterscheidung zwischen Halluzinationen und Pseudohalluzinationen gemacht werden könne.

Wir möchten nun zwar glauben, daß eine prinzipielle Unterscheidung zwischen Halluzinationen und Pseudohalluzinationen nicht nur gemacht werden kann, sondern auch gemacht werden muß. Denn was jene von dieser ,,prinzipiell“" unterscheidet, das ist ja der Leibhaftigkeitscharakter, der Externalitätsfaktor, welcher den Halluzinationen anhaftet, den Pseudohalluzinationen aber, die im selben Bewuß3tseinsraume erlebt werden wie unsere Erinnerungsvorstellungen auch, fehlt. Dieser prinzipielle Unterschied hindert aber nicht, daß in manchen Fällen, vielleicht häufiger, als wir bisher angenommen haben, Ủbergänge zwischen beiden vorhanden sind. Utberall da besonders, wo Halluzinationen mit Kritik auftreten, wird ein Unterschied zwischen beiden sich nicht immer mit Sicherheit feststellen lassen.

1) Kandinsky, l. e. S. 64 .

2) Döllken, Über Halluzinationen und Gedanken lautwerden. Archiv f. Psych. 44, S. 425 f. Bei diesem Falle könnte freilich Jas pers dem dureh äußere Bedingungen irregeleiteten psychologischen Urteil die Schuld für den Übergang der Pseudohalluzinationen in Halluzinationen zuschreiben. Ausschlaggebend für die Beurteilung scheint mir aber doch das besonnene Bewußtscin selbst. Bezügl. der prinzipiellen Beurteilung der Phoneme als Halluzinationen oder Pseudohallu. zination s. weiter unten. 
Im übrigen werlen wir die hauptsächlichsten Resultate dieses Kapitels so zusammenfassen können:

1. Außer den Halluzinationen, gekennzeichnet durch den Wahrnehmungscharakter (Leibhaftigkeit), d. h. dadurch, daß ihr gegenständlicher Inhalt in dem äußeren Raume erlebt wird, gibt es Pseudohalluzinationen, welche sich durch ihren Vorstellungscharakter (Bildhaftigkeit), von jenen abheben, d. h. deren Inhalte im inneren, dem sogenannten Bewußseinsrame erlebt werden.

2. Fs gibt Ưbergänge zwischen Halluzinationen und Pseudohalluzinationen wie auch natürlich zwischen diesen und normalen Vorstellungen.

3. Die Pseudohalluzinationen werden nismals als Gegenstände der Außenwelt erlebt.

4. Auch mit den echten Halluzinationen ist ihrem Träger nicht unberlingt die Uberzeugung von der Realitat ihres Inhaltes gegeben. Beweis: Halluzinationen bei Geistesgesunden auf Grund von Erkrankungen der peripheren Sinnes organe und manche Halluzinationen bei Geisteskranken.

5. Die Einordnung des halluzinierten Inhaltes in den Wirklichkeitszusammenhang vollzicht sich in der Regel durch den Halluzinationsakt selbst unmittelbar, also ohne Mitwilkung eines Crteilsvorganges.

6. Es können jedoch durch einen Apperzeptionsakt im Hallurinationsvorgange selbst die früher gewonnenen $U_{r}$ teile über Realität und Nichtrealitä mit zur Bildung des unmittelbaren, sei es positiven, sei es negativen, sei es sohwankenden Realitätsbewußtseins verwendet werden.

7. Wa durch die Geisteskrankheit die Fähigkeit zur Erkenntnis der Nichtrealität des halluzinatorischen Inhaltes sowohl unmittelbar wie im nachfolgenden Urteil aufgehoben ist, muß man sagen, daß das fälschliche RealitätsbewuBtsein und das falsche Realitätsurteil koordinierte Folgen der zugrunde liegenden Geisteskrankheit sind.

3. Die psychologischen Morkmale der Halluzination.

Wir hätten nun darzulegen, durch welche psychologischen Merkmale sich die Halluzination von den als reine Vorstellungen von dem kranken und gesunden Individuum erfahrenen Bewußtseinsinhalten abhebt.

Als Hauptcharakteristicum der 'Trugwahmehmung hatten wir die im Fingang des vorigen Kapitels gokennzeichnete erkenntnispraktische Stellung des Individuums zu seinem fälschlich externali- 
sierten Bewußtseinsinhalt erkannt. Hat deshalb diese Externalisierung sich des Geisteskranken einmal bemächtigt, so scheint es kaum ein psychologisches Merkmal zu geben, welches, und mag es noch so kennzeichnend für den reinen Vorstellungscharakter der Halluzination sein, den Kranken veranlassen könnte, von der falschen Projizierung abzulassen. Je mehr freilich auch die psychologischen Kennzeichen der Halluzination denen der reinen Wahrnehmung gleichen, um so leichter werden die abnormen Bewußtseinsinhalte dem Kranken als echte Wahrnehmungen imponieren. Und das ist von besonderer Wichtigkeit für jene auf der Grenze zwischen Halluzination und Peudohalluzination stehenden Bewußtseinsvorgänge, über deren Realitätscharakter der Erkrankte selbst nicht zur Klarheit gelangen kann.

Stimmen auf der anderen Seite die psychologischen Merkmale eines Bewußtseinsinhaltes noch so sehr mit denen einer Wahrnehmung überein, so bra ucht das geistig erkrankte Individuum diesen Bewußtseinsinhalt nicht nach Art eines halluzinatorischen Inhaltes zu externalisieren. Denn neben seinen Halluzinationen kann eben der Kranke auch Pseudohalluzinationen haben, oder er hat nur letztere.

Gehen wir nun die einzelnen psychologischen Merkmale durch und versuchen wir deren Bedeutung für die Auffassung eines Bewußtseinsinhaltes als Halluzination zu erkennen!

$\mathrm{Da}$ ist zunächst die Qualität des Bewußtseinsinhaltes. Als Bild eines durch die Sinneswahrnehmung erfahrenen Gegenstandes der Außenwelt bedeutet sie die Reproduktion des Empfindungsbestandteils, wie er durch die Spezifität unserer Sinnesorgane bestimmt wird. Die Bedeutung dieses Momentes für die halluzinatorische Verarbeitung des Bewußtseinsinhaltes kommt rein für sich genommen kaum in Betracht. Denn ein prinzipieller Unterschied in der Qualität zwischen Wahrgenommenem und Reproduziertem ist wohl, wie wir sahen, schwer anzugeben. Was den psychologischen Unterschied unter normalen Bedingungen so unmittelbar hervortreten läßt, liegt wohl nicht auf der Qualitäts-, sondern auf der weiter unten zu besprechenden Intensitätsseite.

Von einer gewissen Bedeutung dürfte jedoch schon die Qualitätsseite als solche bei den niederen Sinnen, den Kontaktsinnen, sein. Denn im Bereich dieser wird wegen der mangelhaften Reproduktionsfähigkeit der durch sie gewonnenen Inhalte schon das Auftreten eines subjektiv erregten Bewußtseinsinhaltes als solches die halluzinatorische Verarbeitung sofort anregen. Und zwar wird diese besonders bei den Trugwahrnehmungen in der Geruchsphäre sich besonders leicht einstellen, weil schon bei den normalen Geruchswahrnehmungen der erregende Gegenstand der Kontrolle durch die übrigen Sinne häufig schwer oder gar nicht zugänglich ist. Gase sieht und tastet man nicht. Wenn ich aber etwas rieche und mag es von noch so geringer Intensität sein, 
so werde ich ohne weiteres annehmen dürfen, daß etwas da sein muß, was den Geruch hervorgerufen hat. Der Geisteskranke wird sich diesen berechtigten Schluß des Gesunden ganz besonders nutzbar machen.

Ähnlich steht es mit den Trugwahrnehmungen des Geschmacksinnes, die von den Halluzinierenden meist nicht auf eine Speise, so wie sie dem Auge und Tastsinn sich ohne weiteres darbietet, sondern auf einen in diese gemischten Inhalt, der dem normalen Auge und Getast nicht unmittelbar erkenntlich ist, bezogen wird.

Auch für die Trugwahrnehmung im Bereiche des Hautsinnes hat der Fortschritt der Technik die Unterlagen geschaffen, welche dem Kranken das Recht zu geben scheinen, schon das Auftreten von Empfindungen überhaupt auf die Außenwelt zu beziehen. Elektrische Ströme sieht und tastet man ebenfalls nicht. Im übrigen werden die Eigenerregungen, zu welchen die Haut ebenso fähig ist wie die Netzhaut, die halluzinatorische bzw. illusionistische Verarbeitung leicht anregen. Besonderen Anla $ß$ werden dazu die Psychalgien geben müssen, die schon im Bereich der funktionellen Neurosen eine so große Rolle spielen. Diese mögen wohl in jenen Fällen mitwirken, in welchen sich die Kranken auch in grob mechanischer Weise insultiert, mit Messern bearbeitet usw. fühlen. Unter solchen Umständen ist es freilich nicht mehr die Qualitätsseite allein, welche durch sich den halluzinatorischen oder illusionären Bewußtseinsvorgang anregt, sondern in hervorragendem Maße die mit ihr zugleich das Bewußtsein irritierende Intensitätsseite.

Betrachten wir nun die Intensität als solche! Jede Qualität tritt in der normalen Wahrnehmung mit einer Intensität behaftet auf, und diese Intensität finden wir, wie wir früher bei den höheren Sinnen sahen, nicht als solche auf der Vorstellungsseite wieder. Deshalb wird diese, sobald sie sich in der Eigenart, in welcher sie in der Wahrnehmung erscheint, in einem Bewußtseinsinhalt vorfindet, schon durch sich selbst die Externalisierung des supponierten Reizes zur Folge haben.

Immerhin bedarf diese Behauptung gewisser Einschränkungen, und zwar zunächst, wie auch bei der Qualität, in dem Maße, je höher wir in der Sinnenreihe aufsteigen. Im Bereich der aus den niederen Sinnen stammenden Reproduktionsinhalte wird zwar auch schon eine geringe Intensität unmittelbar das Externalitätsbewußtsein erwecken können. Denn wenn auch, besonders wegen der geringeren Reproduktionsfähigkeit im Bereiche der niederen Sinne, die Intensität der Vorstellungsinhalte derjenigen der Wahrnehmungsinhalte im allgemeinen ebenso wenig entsprechen wird wie im Gebiete der höheren Sinne, so wird doch wegen der leichten Eigenerregbarkeit der niederen Sinne sich dieser Unterschied leicht verwischen können. Es wird darum im allgemeinen mit steigender Intensität der Empfindungen im Gebiete der 
Kontaktrinne auch das Bewußtsein der Externalisierung an Sicherheit zunehmen müssen.

Anders auf dem Gebiete der Gesichtshalluzinationen. Wird auch hier die Intensität, mit welcher der qualitative Inhalt vor das Bewußtsein tritt, um so stärker die halluzinatorische Verarbeitung anregen, je stärker sie selbst ist, notwendig ist sie zur Hervorrufung der Halluzination nicht. Der Halluzinierende hat auch ganz blasse Visionen, ohne an ihrer Externalität zu zweifeln; und auf der anderen Seite braucht die lebhafteste Färbung des Bewußtseinsgebildes nicht ein Externalitätsbewußtsein zu erwecken. Der Kranke kann sich völlig der Abhängigkeit jener von seiner eigenen geistigen Produktion bewußt bleiben. Er hat dann eben Pseudohalluzinationen. Es ist hier also wesentlich die Einordnung des Bewußtseinsgebildes in den äußeren Sehraum, was den Visionen den Wahrnehmungscharakter verleiht.

Am schwierigsten liegen die Verhältnisse auf dem Gehörsgebiete. Einen primären Gehörsraum gibt es, wie wir erkannten, wohl nicht, weshalb ja auch die Lokalisation eine so unsichere ist. Hier ist es aber die Art der Intensität selbst, welche unter normalen Umständen dem Bewußtseinsvorgang den Wahrnehmungscharakter verleiht. Denn wir sahen, daß die reproduzierte Gehörsintensität mit der wahrgenommenen in ihrer Eigenart nicht vergleichbar ist, während auf dem Gesichtsgebiet reproduzierte Gebilde, soweit wenigstens die Farbensättigung - nicht die Lichtintensität - in Betracht kommt, unter Umständen die wahrgenommene an Intensität sogar übertreffen können.

Man könnte hiernach darum zunächst folgendes schließen: Hat der Kranke Gehörsreproduktionen, deren Intensität der Intensität wirklicher Gehörsreize entspricht, so hat er Halluzinationen. Gleichen sie in ihrer Eigenart der auch im normalen Bewußtseinsleben reprod uzierten Intensität, so hat er Pseudohalluzinationen.

Da wir nun das wesentliche Moment der Halluzination im Externalitätsbewußtsein erkannten, in der Anhaftung des Bewußtseinsinhaltes an einen Gegenstand der wirklichen Wahrnehmungswelt, so wird aber wohl die Entscheidung anders zu treffen sein: Die Gehörshalluzinationen werden immer dann als echte zu betrachten sein, wenn ein Externalitätsbewußtsein vorhanden ist, mag auch sonst die Intensität derjenigen eines reproduzierten Gehörsreizes gleichen.

$\mathrm{Zu}$ echten Halluzinationen, nicht zu Pseudohalluzinationen werden darum wohl auch die Gehörshalluzinationen zu rechnen sein, welche der Kranke in irgendeinen Teil seines Körpers verlegt. Nur wenn er sie ,in seinem Kopf“ lokalisiert oder wenn er von sog. inneren Stimmen spricht, wird es sich um Pseudohalluzinationen handeln, und dieser pseudohalluzinatorische Charakter wird selbst dann anzunehmen sein, 
wenn der Krrnke seine Gehörsphänomene in derselben Eigenart innerlich vernimmt wie einen wirklichen Gehörsreiz.

Die Entscheidung in der Praxis wird freilich auch nach diesen Kriterien nicht immer leicht fallen. Demn ist die Lokalisation der normalen Gehörsreize überhaupt schon schwierig, um wieviel mehr wird das bei den pathologischen Gehörsphänomen sein. In der Tat erhalten wir auch gerade auf dem (iebiete der Gehörshalluzinationen von den Kranken die unsichersten Angaben. Dabei werden wir, was mir besonders wichtig erscheint, zu bedenken haben, daß durch das Externalitätsbewußtsein als solches der Unterschied in den Intensitätscharakteren, welcher unter normalen Umständen zwischen gehörten und reproduzierten Gehörsreizen besteht, verwischt werden wird ${ }^{1}$ ).

Unbedingt wird also das Externalitätsbewußtsein geweckt durch das räumliche Moment, sofern eben dieses als Bestandteil eines tatsächlichen Raumes aufgefaßt wird. Mag die Qualität des Bewußstseinsinhaltes noch so wenig ausgebildet, die Intensitüt noch so gering sein, wiıd der Bewußtseinsinhalt in äußerem Raume lokalisiert vorgestellt, so ist die Halluzination da.

Wir erkennen zugleich weiter, daß es für das Zustandekommen des Externalitätsbewußtseins gleichgültig ist, ob der Bewußtseinsinhalt in denjenigen Raum lokalisiert wird, in welehem im betreffenden Moment des Halluzinierens die tatsïchlich wahrgenommenen Gegenstände lokalisiert werden oder ob der Bewußtseinsinhalt in einem re produzierten Raum lokalisiert wird, der selbst nun als externalisiert vorgestellt wird. Es wird dann eben der Raum mit halluziniert. Unbedingt tritt dieser

1) Aus allen angeführten (iründen möchten wir glauben, daß es sich in dem von Jas pers angeführten Fall der Frau, welche Gilockenläuten hört, wohl um Hallu zinationen gehandelt hat. Im anderen Falle erscheint es mir wenigstens kaum verständlich, warum die Frau die Fenster öfnet, um ihre Halluzinationen auf Realität zu prüfen. Das ist doch das Kennzeichen des Pseudohalluzinatorischen, daB das Individuum über die Abhängigkeit des Bewußtseinsinhaltes von der eigenen psychischen Produktion nicht im Zweifel ist.

Mit welcher Bestimntheit (iehörstäuschungen selbst von nicht eigentlich (ieisteskranken externalisiert werden, konnte ich noch in diesen Tagen an einer durchaus besonnenen Hysterica konstatieren, welche sowohl an Gehörs. wie an Gesichtstäuschungen leidet. Während sie die letzteren als pseudohalluzinatorisch erkennt, hält sie trotz eingehender Prüfung an der Externalität der ersteren fest. Als Grund für diese verschiedene Auffassung gibt sie an, daß, wenn sie genau nach der Stelle sah, wo sie ihre Visionen erblickte, diese verschwanden, man könne sich doch aber nicht tïuschen, wenn es klopfe. Sie habe es gehört und sei auch mit dem Licht die Treppe herauf- und heruntergegangen, um der Ursache des Klopfens nachzuspüren. Es wäre ja sehr naheliegend, aus der pseudohalluzinatorischen Form der Visionen auf die der Akoasmen zu schließen, zumal es sich ja um keine Geisteskranke handelte, und dem ,psychologischen Urteil" wieder die Schuld zuzuschieben. Wir glauben aber, die bestimmten Angaben der Pat. als Unterlage auch unserer Beurteilung machen zu müssen. 
Fall bei Gesichtshalluzinationen ein, wenn im Dunkeln oder mit geschlossenen Augen halluziniert wird (auch bei hypnagogen Halluzinationen und Träumen).

Ist das äußerlich räumliche Moment auch das wesentlichste Kennzeichen für den halluzinatorischen Charakter des Reproduktionsgebildes, so braucht dieses doch keineswegs die räumlichen Eigenschaften zu haben wie die vom normalen Bewußtsein wahrgenommenen Gestalten oder wie die wirklichen Raumgebilde, welche der Kranke ebensogut und mit denselben Raumqualitäten behaftet auffaßt wie jeder Normale. In bezug auf die räumliche Gestalt seiner Halluzinationen ist der Kranke sehr anspruchslos. Sie braucht nicht dreidimensional zu sein. Der Kranke sieht flächenhafte Gebilde, Schatten, Geister, Gemälde usw., ohne an deren Wirklichkeitscharakter zu zweifeln.

So sehen wir sogar bei dem wichtigsten Merkmal der Halluzination, daß nur das erkenntnispraktische Moment des im äußeren Raume Gegebenseins das Ausschlaggebende für den halluzinatorischen Charakter ist. Ob die Form dieses Äußerlichen den sonstigen Formen der Äußerlichkeit entspricht, ist prinzipiell nebensächlich, wenn auch vielleicht nicht immer belanglos für das kritische Bewußtsein des Kranken.

Das äußerlich-räumlich Vorgestellte, mit Qualität und Intensität Behaftete, ist nun das Ding, welches Beziehungen zu anderen Dingen und zu unserer eigenen Person hat. Diese beiden Beziehungen, besonders aber die letztere, sind nun von besonderer psychologischer Bedeutung für das Zustandekommen des Externalitätsbewußtseins. Je besser sich das Bewußtseinsgebilde in den Wirklichkeitszusammenhang einordnen läßt, um so eher wird es schon durch dieses äußere Moment das Externalitätsbewußtsein wecken. Sahen wir doch im vorigen Kapitel dieses Moment bei der Bedeutung des Urteils für das Externalitätsbewußtsein eine so große Rolle spielen. Die Kranke von Jaspers öffnet die Fenster und lauscht, ob die Glocken noch weiterklingen. Der Kranke Goldsteins Tr., zu welchem wir selbst viele Pendants beobachtet haben, ist wegen ihrer Sonderbarkeit nie über die Subjektivität seiner abnormen Bewußtseinsgebilde im Zweifel. Es kommt hier das von letzterem Autor mit Recht hervorgehobene Moment der inhaltlichen Inkongruenz für die Ablehnung der Realität durch das Bewußtsein zur Geltung.

Eine noch größere Bedeutung für das Zustandekommen des Realitätsbewußtseins haben die inneren Beziehungen des abnormen Bewußtseinsinhaltes zur Persönlichkeit des Kranken. Ja diese inneren Beziehungen sind von so fundamentaler Bedeutung, daß sie nicht nur das Realitätsbewußtsein, welches die Halluzination begleitet, sondern diese selbst schafft. Denn diese inneren Beziehungen bedeuten ja einen integrierenden Teil der abnormen Geisteskonstitution, aus welcher die 
Halluzination herauswächst. Wir werden daräber im nächsten Kapitel zu handeln haben.

Wir kommen nun zu denjenigen Kennzeichen der Halluzination, welche nicht sowohl ihre gesamte Gegenständlichkeit mit ihren äußeren und inneren Beziehungen betrifft als ihre Verlaufsart. Wir hatten an der Vorstellung erkannt, daß sie unbeständig, schwer festzuhalten ist, zerflattert, ja daß, je abstrakter sie ist, ein der Wahrnehmung analoger sinnlicher Reproduktionsbestandteil an ihr nicht nachweisbar ist. Die Halluzination und auch die Pseudohalluzination hat gegenüber der Vorstellung eine viel ausgesprochenere Konsistenz und Beständigkeit. Aus diesem Grunde wird sie der Wahrnehmung so ähnlich. Aber selbst die Abstraktheit hindert den abnormen Bewußtseinsinhalt nicht, sich mit dem Halluzinationscharakter zu bekleiden. Jene A p parzeptions halluzinationen Kraepclins - wir möchten sie lieber Gedankenhalluzinationen nennen - sind solche halluzinatorisch gewordene Denkinhalte. Sie sind nicht zu verwechseln mit dem (xedankenlautwerden selbst, bei welchem der sprachliche Ausdruck der Gedanken, also die Klangbilder zu Gehörshalluzinationen werden, wenn auch wohl manche Utbergänge vorkommen mögen.

Wenn nun auch die Halluzinationen und Pseudohalluzinationen viel beständiger sind oder doch sein können als die Vorstellungen, so werden sie selbstverständlich nie die Beständigkeit eines (Kegenstandes des wirklichen uns umgebenden Wahrnehmungsfeldes annehmen. Aber das Charakteristische ist, daß für das Bewußtsein des Kranken der halluzinatorische Inhalt so in das wirkliche Wahrnehmungsfeld eingeordnet ist, da $B$ er auf Befragen, manchmal vielleicht erst nach einigem Zögern, behauptet, da B auch andere seine Halluzinationsgebilde hätten wahrnehmen können.

Wenn also auch die Halluzinationen in der Regel lange nicht so unbeständig sind wie die normalen Vorstellungsgebilde, so teilen sie doch mit diesen die relativeUnbeständigkeit gegenüber den Wahrnehmungsinhalten. Sie haben auch mit den Vorstellungen gemein, daß sie im Gegensatz zu den Wahrnehmungsinhalten sich meist auf eine $m$ Sinnesgebiet abspielen.

Häufig genug aber breiten sie sich über mehrere Sinnesgebiete aus. Gesichts- und Gehörshalluzinationen vereinigen sich so häufig zu einer „,komplexen“ Halluzination. Aber auch Gehörs-, Tast- und Bewegungsempfindungshalluzinationen verknïpfen sich häufig zu einem komplexen Gebilde. Da die Produktionen der Sprache in der Norm diese komplexe Form haben, so werden sie bei ihrer Umsetzung in dic halluzinatorische Bewußtseinsform die Komplexität beibehalten. Zugleich können sie sich mit Gesichtshalluzinationen verbinden, die dem Sohriftoder Druckbilde entsprechen ${ }^{1}$ ).

1) Über diese komplizierten Halluzinationsformen s. bei Goldstein l. c. und neuerdings bei P'fersdorf (s. weiter unten). 
Bei Taubstummen können Halluzinationen reiner Bewegungsempfindungen, nämlich der Zeiche machenden Hände, an die Stelle der Klanghalluzinationen treten. Das wird in der Regel dann zu erwarten sein, wenn der Kranke in so frühem Alter und so stark ertaubt war, daß er nicht in die Lage kam, Gehörswahrnehmungen überhaupt zu machen. Er entbehrt darum der Gehörsvorstellungen, die er in halluzinatorischer Form umsetzen könnte. Cramer ${ }^{1}$ ) hat bekanntlich zuerst derartige hochinteressante Fälle mitgeteilt.

Indem nun die Halluzinationen gleich den wirklichen Wahrnehmungsinhalten als Bestandteile der Außenwelt aufgefaßt werden, erhalten sie zugleich im Bewußtsein des Kranken das Merkmal der Unabhängigkeit ihres inhaltlichen Materials vom Bewußtsein selbst. Während wir uns bei den Vorstellungen bewußt sind oder doch jeden Augenblick bewußt werden können, daß sie abhängig sind von einem produzierenden Ich, so haben im Gegenteil die Halluzinationen das Characteristicum an sich, daß sie für das Bewußtsein des Kranken ganz ohne das Zutun des Subjektes zustande zu kommen scheinen. Ja das macht, wie ohne weiteres erkenntlich ist, das Wesen der Halluzinationen aus und stellt sie erst für das Bewußtsein des Kranken auf dieselbe Stufe, auf welcher für das Bewußtsein des Gesunden die Wahrnehmungen stehen.

Aber beim normalen Individuum bleibt doch noch bei den Wahrnehmungen ein ganz bestimmtes Bewußtsein der Abhängigkeit dieser von gewissen psychophysiologischen Vorbedingungen bestehen. Wir wissen, da $\beta$ wir unsere Sinne offenhalten müssen, um Wahrnehmungen erleben zu können. Schließen wir unsere Augen, so nehmen wir durch den Gesichtssinn jedenfalls nichts von der Welt wahr. Für den Kranken fällt oder kann doch prinzipiell selbst dieses Abhängigkeitsbewußtsein wegfallen. Er halluziniert auch mit geschlossenen Augen und kann die auf diesem Wege gewonnenen gegenständlichen Inhalte mit demselben ausgebildeten Charakter der Realität versehen, wie die mit offenen Augen erlebten.

Genau so steht es auch mit den von Bleuler sog. extrakampinen Halluzinationen. Auch bei diesen kann das fälschliche Realitätsbewußtsein nur durch den Fortfall des Abhängigkeitsbewußtseins von bestimmten psycho-physiologischen Vorbedingungen, die für alles normale Wahrnehmen gelten, zustande kommen.

Es ist demgegenüber ein psychologisches Kennzeichen der Pseudohalluzinationen, daß deren Abhängigkeit von der eigenen Produktionstätigkeit dem Subjekt stets bewußt ist.

1) Cramer, A., Über Sinnestäuschungen bei geisteskranken Taubstummen. Arch. f. Psych. 28. 
Ja, während wir bei den Vorstellungen meistens gar nicht auf deren Beziehung zu unserem Ich achten, sondern unsere Aufmerksamkeit nur auf den Inhalt richten, bringt es die Auffälligkeit der Pseudohalluzinationen für das erlebende Bewußtsein mit sich, daß deren Träger sich wohl stets deren Abhängigkeit von seinem Ich vor die Seele rufen wirci.

Ein anderes Moment aber haben im allgemeinen die Pseudohalluzinationen wieder mit den Halluzinationen gegenüber den gewöhnlichen Vorstellungen gemeinsam. Mit der Abhängigkeit vom Ich wird bei den gewöhnlichen Vorstellungen zugleich deren Abhängigkeit von der subjektiven Willenstätigkeit bewußt. Zwar ist diese Abhängigkeit, wie wir erkannten, keine absolute. Auch Vorstellungen steigen häufig ohne meine Willenstätigkeit im Bewußtsein auf, manchmal sogar gegen meine Willenstätigkeit. Dieses nicht gewollte Aufsteigen der Vorstellungen kann sich bekanntlich bei psychopathischer Veranlagung bis zur Zwangsmäßigkeit steigern. Im allgemeinen unterliegt aber die Vorstellungstätigkeit der Willensintention. Durch eine darauf gerichtete Absicht rufe ich die Vorstellung auf die Bühne des Bewußtseins und schicke sie wieder ins Unterbewußtsein zurück. Diese Abhängigkeit von der subjektiven Willenstitigkeit ist bei den Pseudohalluzinationen im allgemeinen aufgehoben.

Halluzinationen, Pseudohalluzinationen und eben auch Zwangsvorstellungen haben also gemein, daß sie ganz unabhängig von der Willensintention sich dem Bewußtsein präsentieren.

Freilich erleben wir es manchmal bei Halluzinanten - es wird auch von Pseudohalluzinanten berichtet -, daß sie durch eine darauf gerichtete Intention jene pathopsychischen Phänomene ins Bewußtsein zu rufen imstande sind. Das wird wohl auch bei den Zwangsvorstellungen möglich sein. Nur daß dann das Individuum die Geister, die es rief, nicht mehr los wird oder doch besonderer Kunstgriffe - angestrengte Ablenkung - benötigt, um sie wie auch die durch normale Assoziationstätigkeit erweckten Vorstellungen wieder unter der Schwelle des Bewußtseins verschwinden zu lassen.

Die Begriffe der Aktivität und Passivität, welche sich als durchgreifende Kriterien zur Unterscheidung der Wahrnehmung von der Vorstellung nicht verwenden ließen, dürften für die Unterscheidung der Halluzinationen und Pseudohalluzinationen einerseits von Wahrnehmung und Vorstellung andererseits größere Bedeutung haben. Denn durch das Auffallende, welches die Pseudohalluzinationen und durch das - freilich nicht immer - Erschütternde, welches Halluzinationen für das erlebende Bewußtsein haben, wird sich dieses seinen abnormen psychischen Gebilden gegenüber wohl meist im Gefühle der Passivität befinden. 
Mit Rücksicht auf die psychophysischen Unterlagen der normalen Wahrnehmung ergeben sich noch einige weitere psychologische Kennzeichen der Halluzination.

Da die Funktion der Kontaktsinne stets mit Organempfindungen verknüpft ist, so müssen auch die Halluzinationen in diesen Bereichen zusammen mit Organempfindungen auftreten. Ja, diese Organempfindungen machen hier das Wesentliche der Halluzination aus.

Anders auf dem Gebiete der höheren Sinne, der Sinne der Ferne. Da die Funktion dieser bei mittlerer Reizstärke keine Organempfindungen oder doch nur in unbeträchtlicher und von der Aufmerksamkeit vernachlässigter Intensität auslöst, so spielen sie auch bei Halluzinationen auf diesem Gebiete keine Rolle. Die älteren Psychiater legten noch großes Gewicht auf die Erregung eines supponierten „,Organempfindungszentrums".

Wie unwesentlich aber die Organempfindungen, an deren Bedeutung für die Entstehung der Halluzination trotz Fallenlassen eines Organempfindungszentrums noch heute von manchen Forschern festgehalten wird, für das Zustandekommen der Halluzination ist, ersehen wir daraus, daß die Kranken häufig angeben, daß sie ihre Visionen überhaupt nicht mit leiblichen Augen wahrnehmen. Hier wird sich also der Kranke selbst der Unabhängigkeit der Visionen von der Mitwirkung seiner peripheren Aufnahmeapparate bewußt, was wohl nicht möglich wäre, wenn irgendwelche Organempfindungen bei solchen Halluzinationen eine Rolle spielen würden. Trotzdem zweifelt oder braucht doch nicht der Kranke an der Leibhaftigkeit seiner Halluzinationen zu zweifeln. Wir haben jedenfalls nicht das Recht, in solchen Fällen stets das Vorhandensein von Pseudohalluzinationen, und nicht von echten. anzunehmen.

Von etwas größerer psychologischer Bedeutung für den Halluzinationsakt, und zwar auch für die Gesichtshalluzinationen, mögen die Muskel- und Bewegungsempfindungen sein. Wir wiesen früher darauf hin, daß diesen Empfindungen auf dem Gebiete der höheren Sinne wohl nicht die grundlegende Bedeutung zukommt, die ihnen häufig vindiziert wird. Sie spielen beim normalen Sehakt wohl nur eine unterstützende Rolle. Größer mag aber deren Bedeutung für die Halluzination sein. Denn das Bewußtsein, mit den Augenbewegungen eine Vision in ihren Umrissen und ihren Bewegungen verfolgen zu können, wird natürlich auch dem fälschlichen Realitätsbewußtsein neue Nahrung zuführen. Es wird sogar auf die Visionen akkommodiert, wie wenigstens einige Autoren angeben.

Zugleich mit diesen Muskel- und Bewegungsempfindungen sind dann auch jene Spannungsempfindungen gegeben, die man, wie wir sahen, fälschlich als Innervationsempfindungen auffaßt. Auch diesen 
Spannungsempfindungen wird man eine unterstützende Rolle dür das Realitätsbewulstsein, wenn auch nur in geringem (xrade, zusprechen können. Sie werden ja wohl auch bei den Pseudohalluzinationen angedeutet sein. Sogar bei den normalen Vorstellungen erleben wir gewisse Spannungsempfindungen, die bei größeren geistigen Anstrengungen sogar in unlustbetonte und schmerzhafte Sensationen übergehen können (,,Kopfschmerzen").

Eine größere Rolle spielen die Śpannungsempfindungen, taktilen Empfindungen und vielleicht auch Empfindungen auf Grund leichter, tatsächlich zustandekommender Bewegungsempfindungen im Gebiete, der Sprechhalluzinationen, wie aus dem oben Gesagten bereits hervorgeht.

Daß Nachbilder bei Halluzinationen sich ebensowenig finden wie bei Vorstellungen, ist als sicher zu betrachten.

Ein Mitwandern der optischen Halluzinationen bei Augenbewegungen scheint manchmal stattzufinden. Darin würde sie also ebenfalls den normalen Vorstellungen und Pseudohalluzinationen gleichen. Meist aber hat wohl die Halluzination einen festen Ort, und gerade hierdurch imponiert sie dem Bewußtsein als äußeres Objekt.

Was über Vergrößerung und Verkleinerung der halluzinatorisch wahrgenommenem Objekte - es kommen hier nur die Visionen in Betracht - mit der Entfernung und Annäherung, über deren Verdoppelung durch Prismen usw. berichtet wird, ist jedenfalls auf Rechnung des Mitwirkens suggestiver Momente zu setzen. Denn es fehlt ja das äußere Objekt, welches imstande wäre, nach physikalischen Gesetzen seine Wirkung auf das Wahrnehmungsorgan zu entfalten ${ }^{1}$ ).

Sehr charakteristisch für den Einfluß der Suggestion ist die Mitteilung Bernheims, nach welcher die betreffende Patientin die Verdoppelung ihrer freilich suggerierten Vision durch das vor das Auge gesetzte Prisma nur dann wahrnahm. wenn sie zugleich wirkliche Gegenstände durch das Prisma verdoppelt sah. Fehlten solche im Gesichtsfelde, so sah sie auch ihre Vision einfach. Hier ist deutlich zu erkennen, wie die Kranke durch Ubertragung der Verdoppelung der wirklich gesehenen Gegenstände auf die Vision auch die Verdoppelung der letzteren auf autosuggestivem Wege bewerkstelligte.

Uber die sonstigen physiologischen Begleiterscheinungen ist schon im vorigen gesprochen worden. Wir werden uns dahin zusammenfassen können, daß keiner von diesen eine wesentliche Bedeutung für das Zustandekommen der Halluzinationen zugesprochen werden darf.

1) Bei den Halluzinationen bzw. Illusionen, welche sich an Skotomen ansetzen, kommt freilich ein physikalisches Moment, das vergrößernd zu wirken imstande ist, in Betracht. Dieses liegt aber im positiven Skotom selbst, das mit der Entfernung an (iröße wächst. 
Wir müssen jedoch der häufig gemachten Beobachtung Erwähnung tun, nach welcher, besonders im Beginn der Psychose, von den Kranken eine große Empfindlichkeit ihrer peripheren Aufnahmeapparate berichtet wird. Es kommen hier hauptsächlich Auge und Ohr in Betracht. Die Kranken fühlen sich durch die gewöhnlichen Reize der Außenwelt, welche sie im normalen Zustande ohne irgendwelche irritierende Wirkung ertragen haben, stark belästigt.

Die Erklärung hierfür liegt ziemlich nahe. Es ist verständlich, daß die krankhafte Erregung des Gehirns, die wir als materielles Korrelat der ausbrechenden Psychose zu betrachten haben, eine große Empfindlichkeit der mit dem Zentrum also in Verbindung stehenden seuriblen Sphäre hervorrufen wird. Die Empfindlichkeit wird nach den Gesetzen der Projektion in die Aufnahmeapparate verlegt. Ähnliche Erscheinungen beobachten wir bereits in der normalen Breite. Wir wissen, wie empfindlich wir gegen stärkere Gesichts- und besonders Gehörseindrücke im Zustande der Ermüdung sind. Bei Neurasthenikern steigert sich diese Empfindlichkeit bekanntlich schon zu pathologischen Graden.

Es könnte darum sogar verwunderlich erscheinen, warum von den psychisch Erkrankten über Empfindlichkeit der Sinnesapparate verhältnismäßig selten geklagt wird. Es ist anzunehmen, daß die Aufmerksamkeit der Kranken viel zu sehr vom Inhalte ihrer Halluzinationen und anderer pathologischer Bewußtseinsvorgänge in Anspruch genommen wird, als daß sie jenen peripherischen Sensationen größere Beachtung schenken könnten. Aber es wäre nach dem früher Gesagten falsch, aus der im Anfang der Psychose manchmal geklagten, viel häufiger wohl noch vorkommenden Empfindlichkeit der peripheren Aufnahmeapparate auf eine wesentliche Mitwirkung dieser oder der Organempfindungen beim Zustandekommen der Halluzination zu schließen.

Wir haben schließlich noch das Verhalten der Halluzination bei Erkrankungen der peripheren Sinnesorgane kurz zu besprechen.

Daß durch Funktionsanomalien im Bereiche der peripheren Sinnesorgane Halluzinationen ausgelöst werden können, haben wir bereits erfahren. Häufig geben sie nur zu den sogenannten elementaren Halluzinationen Anlaß, einfachen Geräuschen, Sausen, Pfeifen usw. auf dem Gehörsgebiete, Licht- und Farbenerscheinungen im Sehfelde. Kommt es jedoch aus Anlaß dieser peripherischen Erregungen im Zentrum zu tieferen Erregungen, so treten zusammengesetzte Halluzinationen auf, wie auch bei den Psychosen. Wir wiesen schon darauf hin, daß in solchen Fällen immer noch eine zentrale Disposition angenommen werden muß, weil sonst nicht verständlich wäre, warum im Verhältnis zur ungeheuren Häufigkeit von Erkrankungen der peripheren Sinnesorgane Halluzinationen bei diesen so selten sind. Und 
zweitens ist es prinzipiell nicht $\mathrm{zu}$ verstehen, wie gegenständliche Inhalte infolge peripherer Reizung der Sinnesorgane allein halluziniert werden könnten ${ }^{1}$ ). Schließlich ist es, wie wir noch näher erkennen werden, das gesamte Gehirn, welches auf den peripheren Reiz reagiert, wenn auch die zentrale Sinnesstätte die zuerst von dem Reiz betroffene Stelle ist. Es entstehen also - je nach der Individualität - ähnliche Halluzinationen und Pseudohalluzinationen wie bei Psychosen und Neurosen auch, nur daß die Erhaltung der Urteilsfähigkeit die Einordnung der halluzinierten Inhalte in die Wirklichkeit nicht gestattet.

Dann gibt es noch einige Modifikationen im Verhalten der Halluzinationen echt Geisteskranker bei Defekten ron Sinnesorganen. Man wird nach dem eben Gesagten annehmen dürfen, daß die Halluzination mit besonderer Vorliebe auf das Gebiet des erkrankten Organs bezogen wird, da dieses ja dem Abfluß der zentralen Erregung die Richtung geben wird. Immerhin scheint auch das Umgekehrte vorzukommen, daß nämlich der Halluzinierende seine Trugwahrnehmungen im Bereich des normal funktionierenden Organs in intensiverer Weise erlebt als im Bereich des kranken. So beobachteten wir eine Melancholische, welche auf der Hornhaut des einen Auges einen Pannus hatte und darum mit diesen die Teufelserscheinungen, von denen sie geängstigt wurde, nicht so deutlich sah wie mit dem gesunden Auge. Ob es sich bei dieser Lokalisation um psychogene Momente handelte, möchten wir freilich nicht mit Sicherheit entscheiden. Utbrigens scheint auch bei Hemianopischen das Verhalten der Halluzinationen nicht eindeutig zu sein. Die Halluzination wird nicht immer in die defekte Gesichtshälfte verlegt, kann auch von der einen in die andere übergreifen ${ }^{2}$ ).

Daß es sich in vielen Fällen peripher ausgelöster pathopsychischer Phänomene eigentlich nicht um echte Halluzinationen handelt, sei nur kurz erwähnt. Mit Recht wird von vielen Autoren darauf hingewiesen, daß wir es in solchen Fällen mit illusionär verarbeiteten peripherischen Reizen zu tun haben.

Wenn wir nun noch einmal die psychologischen Merkmale, welche wir an der Halluzination konstatieren können, uns ins Gedächtnis zurückrufen, so werden wir wohl die zu Beginn dieses Kapitels aufgestellte Behauptung als begründet erkennen, daß nämlich keines von ihnen als absolut kennzeichnend für das Wesen der Trugwahrnehmung betrachtet werden kann, sondern daß eben nur die erkenntnispraktische Beziehung auf die Außenwelt das ausschlaggebende Kriterum für den echt halluzinatorischen Charakter eines Bewußtseinsgebildes ist. Alle psychologischen Merkmale sind von sekundärer Bedeutung.

1) Siehe das Nähere bei Goldstein l. c.

2) Siehe Uhthoff l. c. 
Es muß das eigentlich als ein selbstverständliches, wenn darum auch nicht minder bemerkenswertes Resultat erscheinen. Denn während viele psychologischen Eigenschaften der Wahrnehmung, z. B. die Intensität, für diese so charakteristisch sind, daß sie allein genügen würden, um sie von der Vorstellung unterscheiden zu lassen, verlieren für den echt halluzinatorischen Charakter die psychologischen Merkmale eigentlich ihre prinzipielle Bedeutung ${ }^{1}$ ).

Gewiß wird das Bewußtseinsgebilde um so eher dem Kranken als Trugwahrnehmung imponieren, je mehr auch die psychologischen Merkmale dieser sich derjenigen einer normalen Wahrnehmung nähern, aber von durchschlagender Bedeutung sind sie nicht. Das durchgreifende Kriterium zur Kennzeichnung der echten Halluzination, ihrer Unterseheidung von Pseudohalluzinationen und von normalen Reproduktionsgebilden liegt überhaupt nicht a uf psychologischem, sondern a uf erkenntnistheoretischem Gebiet. Denn es handelt sich bei der echten Halluzination um jene unmittelbare Beziehung des Bewußt. seins a uf die Wirklichkeit, die wir auch bei der Wahrnehmung als ein der psychologischen Charakterisierung unzugängliches Erkenntniselement konstatieren konnten.

Zugleich erkennen wir wieder, daß in der Psychose der ga n ze Geist nach allen seinen Richtungen affiziert wird, und daß es neben der Erkrankung der intellektuellen Sphäre (Demenz), der psychologischen Sphäre (Hemmung, Ideenflucht usw.), der affektiven, ethischen Sphäre etc. auch eine Erkrankung der Erkenntnissphäre gibt, und daß diese pathologische Veränderung des Geistes gerade das grundlegende pathopsychische Erkenntnisphänomen, die Halluzination an sich hervortreibt.

Wir hätten nun im vorigen auch die hauptsächlichsten psychologischen Merkmale der Halluzination gekennzeichnet. Es wäre nur noch hinzuzufügen, daß mit den Halluzinationen ebenso wie mit den normalen Empfindungen und Wahrnehmungen ein Gefühl verknüpft ist, meistens der Unlust, manchmal auch der Lust. Zuweilen steht auch der Kranke seinen Trugwahrnehmungen gleichgültig gegenüber.

Von besonderer Bedeutung für die Trugwahrnehmung sind nun nicht sowohl die primären Gefühlstöne, wie sie mit den elementaren

1) Das Bemerkenswerteste an Resultat liegt eigentlich nicht auf psychiatrischer, sondern auf theoretisch-philosophischer Seite und soll deshalb hier nur angedeutet werden. Während nämlich vom philosophischen Standpunkt das Erkenntnistheoretische unbedingt das Prius vor dem Psychologischen beansprucht, erweist sich hier das Psychologische bzw. Psychopathologische - nämlich dic pathologische Cemuitsveränderung, wie wir noch näher erkennen werden - als das Prius, und zwar als das kausal bewirkende Prius für das Erkenntnistheoretische, nâher für die pathologische Erkenntnis einer äußeren Schcinwelt. 
Empfindungen verknüpft auftreten. sondern die sekundären, durch Assoziation ausgelösten Gemütsgefühle und die sich aus diesen entwickelnden Affekte. Indem diese durch ihre pathologische Steigerung oder Umwandlung bei den Psychosen zur ursprünglichen Ursache der Halluzination wurden, gewinnen wir den Ủbergang zum kausalgenetischen Gesichtspunkt, von dem aus wir das Halluzinationsproblem noch zu betrachten haben.

\section{Die Entstehungsbedingungen der Halluzination.}

\section{Die psychopathologischen Entstehungsbedingungen der Halluzination.}

Wir haben hier einige Bemerkungen methodologischer Natur vorauszuschicken. Sie werden uns nahegelegt durch die besonderen Schwierigkeiten, welche dem Psychiater daraus erwachsen, daß er, wenn wir rom Philosophen absehen, der einzige Forscher ist, dessen Arbeitsgebiet auf die beiden großen Erscheinungsreihen, in welche wir die Weltvorgänge einteilen können, übergreift. Alle anderen Wissenschaften bewegen sich immer nur in einer der beiden Sphären. Zwar spielen stets Elemente der einen Sphäre in die der anderen hinein, sind sogar nicht selten ein wesentliches Element für die Betätigung des wissenschaftlichen Arbeiters, aber das Endziel der Forschungsrichtung liegt bei allen anderen Wissenschaften auf der einen oder der anderen Seite, nie auf beiden zugleich $\mathbf{1}$ ).

Entsprechend jenen beiden großen Sphären, der Welt der körperlichen und der Welt der geistigen Vorgänge, von denen man die ersteren meistens zum Naturbereich im engeren Sinne zählt, hat man auch die Wissenschaften eingeteilt in Naturwissenschaften und Geisteswissenschaften. Indem man sich aber klar wurde, daß das eigentliche Wesen des Forschers nicht sowohl durch das Forschungsmaterial als das Forschungsprinzip bestimmt werde, daß ferner die geistigen Vorgänge vom Bereiche der Natur nicht gut ausgeschlossen werden können, hat man die Wissenschaften neuerdings eingeteilt in Natur- und Kultur. wissenschaften (Rickert, Windelband).

Das Forschungsprinzip nun, auf Grund dessen diese Zweiteilung der gesamten Wissenschaftssphäre sich vollzieht, ergibt sich durch die beiden Gesichtspunkte, von welchen aus man die Grundabsicht jeder Forschung überhaupt betrachten kann. Diese Grundabsicht geht, nachdem die Sammlung, Analyse und Systematisierung des speziellen Forschungsmaterials, mit welchem sich der betreffende wissenschaft-

1) Man könnte dic physiologische Psychologie in Parallele zur Psychiatrie setzen. Das wäre begreiflicherweise entschieden richtig. Der Physiologe ist aber nicht berufsmäßiger Psychologe und der Psychologe noch weniger berufsmäßiger Physiologe. 
liche Arbeiter beschäftigt, vollzogen ist, aufs Erklären. Dieses aber teilt sich, je nachdem ich es unter dem Gesichtspunkt des Kausalprinzips oder des teleologischen Prinzips betrachte, in das Erklären im engeren Sinne, d. h. in das Begreifen aus Ursache und Wirkung, und in das Verstehen, das ist das Begreifen unter Zugrundelegung des Zweckbegriffes ${ }^{1}$ ).

Die Psychiatrie ist eine kausale, erklärende Wissenschaft und fällt damit unter den Bereich der Naturwissenschaften, trotzdem ihr Forschungsgebiet auf beiden Seiten des Weltgeschehens sich bewegt.

Der Begriff des kausalen Erklärens findet nun nicht nur seine Anwendung auf die Zusammenhänge zwischen den Vorgängen, die sich im Bereiche jeder der beiden großen Gebiete der Weltvorgänge für sich abspielen, sondern er greift auch auf die Zusammenhänge über, wie sie sich in der empirischen Betrachtung zwischen den Vorgängen beider Sphären untereinander darbieten. So „erkläre“ ich die Demenz, an sich ein rein psychisches Ausfallssymptom, aus der Störung der materiellen oder funktionellen Gehirntätigkeit, also aus einem materiellen Vorgang.

Während nun diese Richtung der erklärenden Betrachtungsweise bei dem Naturforscher kaum einen Anstoß, ja ungeteilte Billigung finden wird ${ }^{2}$ ), scheint sie doch viel mehr Bedenken zu erregen bei ihrer Anwendung auf die intrapsychischen Vorgänge selbst. Der Psychiater, dessen Bestreben sich gleich den Forschern auf den medizinischen Schwestergebieten allein auf die materielle Fundierung seines Wissensgebiets richtet, fühlt sich so lange unbefriedigt, als es ihm nicht gelingt, irgendein in sein Bereich fallendes Symptom körperlich zu erklären. Geisteskrankheiten sind Gehirnkrankheiten, wird erklärt. Die Geisteskrankheit muß also materiell, nämlich aus anatomischen oder funktionellen Störungen des Gehirns restlos erklärt werden können, wenn dem wissenschaftlichen Erklärungsbedürfnis selbst Genüge geschehen soll.

Der Vordersatz - Geisteskrankheiten sind Gehirnkrankheiten ist nicht unrichtig, wenn er auch nicht die ganze Wahrheit wiedergibt. Der Nachsatz ist falsch.

1) Vgl. hierzu die methodologischen Betrachtungen von K. Jas pers: Kausale und verständliche Zusammenhänge zwischen Schicksal und Psychose bei der Dementia praecox. Zeitschr. f. d. ges. Psych. u. Neur. 14, 159f. und J as pers Psychopathologie 1913. Die scharfsinnigen Ausführungen J as pers gehen z. T. in eine andere Richtung.

2) Die schwerwiegenden Gründe, welche vom philosophischen Standpunkt gegen die Anwendung des Kausalitätsbegriffs auf den Zusammenhang zwischen körperlichen und geistigen Vorgängen aufgeführt werden können, müssen wir in dieser auf die Erforschung empirischer Vorgänge gerichteten methodologischen Betrachtung außer acht lassen. 
Das Bestreben des Psychiaters, nur in der materiellen Sphäre den letzten Stützpunkt für sein Erklärungsbedürfnis zu suchen, zieht seine Nahrung vornehmlich aus zwei Gründen. Der erste liegt in einer für die Empirie unbrauchbaren Beschränkung der Anwendungssphäre des Kausalbegriffs, der zweite beruht auf einer letzten Grundes aus einer bestimmten philosophischen Weltanschauung zu erklärenden Beschränkung seines Forschungsprinzips, wie sie dem Psychiater als Naturforscher freilich recht nahe liegt. Beide Gründe greifen ineinander über.

Um auf den zweiten Punkt zunächst ganz kurz einzugehen, so ist es ja verständlich, wenn der Naturforscher in derjenigen der beiden großen Weltsphären seinen letzten Stützpunkt sucht, der nicht nur sinnlich greifbar vor unseren Augen liegt, der ihm nicht nur das eigentliche Material für seine Forschung liefert, sondern auf den auch der Begriff des kausalen Erklärens erst seine Anwendung in vollem Maße finden kann. Und dieses volle Maß liegt in der Äquivalenzbeziehung zwischen Ursache und Wirkung, welche dem Kausalbegriff erst das feste Gerippe gegeben hat, welche ihn erst zu dem mächtigen Hilfsmittel ausgestaltet hat, durch das die moderne Naturwissenschaft und die ganze technische Kultur unserer Tage fast wie aus einem Nichts hervorgezaubert wurden.

Wir haben hier keine Weltanschauungsfragen auszutragen. Wir haben aber vom psychiatrischen Standpunkt diePflicht, uns zu überlegen, welchen Nutzen wir aus einer naturwissenschaftlichen Anschauung, welche die letzten Erklärungsgründe auf der materiellen Seite der Welterscheinungen sucht, für unser eigenes Erklärungsgebiet erwarten können.

Die Beantwortung dieser Frage hängt davon ab, was wir überhaupt von der Erklärung geistiger Vorgänge aus materiellen, aus Gehirnvorgängen zu erwarten haben. Können wir z. B. die normalen geistigen Vorgänge in eine derartige kausale Beziehung zu Gehirnvorgängen bringen, da $\beta$ wir jene aus diesen im eigentlichen Sinne des Wortes als erklärt betrachten könnten - wie etwa den Rauch aus dem Feuer, die Galle aus der Leber -, so wäre die Richtung, in welcher sich das psychiatrische Erklärungsbestreben allein zu bewegen hätte, ohne weiteres gegeben.

Nun, es ist leicht einzusehen, daß, wie man sich auch zur materialistischen oder auch energetischen Betrachtungsweise stellen mag, von einer Erklärung der geistigen Vorgänge aus Gehirnvorgängen in diesem Sinne nicht gesprochen werden kann. Selbst wenn wir das letzte Ziel des gehirnanatomischen, -physiologischen und -pathologischen Strebens erreicht hätten, d. h. genau die Gehirnveränderung angeben könnten, welche einem bestimmten psychischen Vorgang entsprechen, ,erklärt" hätten wir diesen weder seinem Wesen nach, noch im Sinne 
jener Äquivalenzbeziehung, welche erst den vollen Sinn des Erklärens ausmacht. Wir können deshalb auch irgendeinen psychopathologischen Vorgang, etwa eine Wahridee, eine Halluzination, nicht im eigentlichen Sinne des Wortes aus einem pathologischen Gehirnvorgang ,,erklären“.

Von all den schon so häufig dargelegten Gründen, welche gegen ein übertriebenes Lokalisationsbestreben der komplexen psychischen Vorgänge sprechen, sehen wir dabei überhaupt ab. Der Wunsch etwa, einen logischen Schluß oder den Eifersuchtswahn auf eine lokalisierte Gehirnveränderung anatomischer oder funktioneller Natur zurückzuführen, dürfte sich als eine der wissenschaftlichen Widerlegung kaum mehr bedürftige Utopie erweisen.

Ergibt sich so die Unmöglichkeit, psychische Vorgänge, normale oder pathologische, im Sinne der auf den übrigen Gebieten der Naturforschung betriebenen Erklärungsweise auf rein materielle oder energetische Veränderungen kausal — im vollen Sinne dieses Wortes zu beziehen, so erweist sich auch sofort für das psychiatrische Bedürfnis die Beschränkung des Kausalbegriffs auf die materiellen Vorgänge und die Abhängigkeit geistiger Vorgänge von materiellen als unzulänglich. Es ist also notwendig, wenn anders wir nicht auf Erklärung im eigentlichen Sinne des Wortes verzichten wollen, auch eine intrapsychische Kausalität zu statuieren.

Geisteskrankheiten sind Gehirnkrankheiten. Wir haben also selbstverständlich die wissenschaftliche Pflicht, für alle Störungen auf geistigem Gebiet Störungen auf der materiellen Seite des Gehirns anzunehmen. Und diese Pflicht, deren Erfüllung der Psychiatrie so große Erfolge gebracht hat, wird weiter ausgeübt werden müssen, wenn wir nicht unsere wissenschaftliche Pflicht überhaupt versäumen wollen.

Aber Geisteskrankheiten sind, wie der Name besagt, eben Krankheiten des Geistes, der im letzten Grunde nicht aus materiellen Vorgängen ,erklärt" werden kann. Wir haben deshalb ebenso die wissenschaftliche Pflicht, pathologisch-psychische Phänomene aus pathologischen Veränderungen des Geistes selbst in vollem Sinne des Wortes zu erklären.

Es ist hierbei natürlich ganz gleichgültig, ob wir den Geist selbst substantiell oder, wie es meist die moderne Psychologie tut, funktionell fassen. Auch wir werden uns mit der letzteren Fassung begnügen, da wir ja empirisch auf psychischem Gebiete es nur mit Vorgängen zu tun haben. Aber die Beziehung dieser psychischen Funktion auf das Gehirn als deren substantielle „Ursache“ im eigentlichen Sinne des Wortes mïssen wir ablehnen.

Wir kommen darum zu dem Schluß: Geisteskrankheiten sind a uch Gehirnkrankheiten. Ist, wie selbstverständlich, die gehimanatomische, -physiologische und -pathologische Forschung ein Grundpfeiler der 
Psychiatrie, ohne welchen sie als Wissenschaft einen großen Teil ihres Wertes sicherlich verlieren würde, so ist die psychologische und psychopathologische Forschung der andere Grundpfeiler, ohne welchen sie nicht minder als Wissensehaft in sich zusammenfallen würde.

Auf welches Ursachengebiet man bei der Erforschung der psychischen Krankheiten sein Hauptaugenmerk richtet, hängt ganz von dem Fall ab. Bei den exogenen Psychosen, der progressiven Paralyse z. B., wird man auf die anatomische, bei den ,endogenen" Psychosen, den hysterischen z. B., auf die psychologische Seite a potiori rekurrieren. Vernachlässigen darf man keine der beiden Seiten, da wir aus hier nicht weiter zu erörternden Gründen als sicher annehmen, daß jeder psychische Vorgang sein materielles Korrelat hat.

Bei der Erforschung der pathopsychischen Symptome wird sich jedoch prinzipiell zunächst in der psychologischen bzw. psychopathologischen Sphäre das Erklärungsbestreben bewegen müssen, da sich das Symptom als solches zunächst als Erscheinung eben der Sphäre erweist, aus welcher es seine Daseinsform bezieht ${ }^{1}$ ).

Wenn wir uns nach diesen methodologischen Vorbemerkungen, die sich freilich auf das Notwendigste beschränken mußten, der Frage nach der Entstehung der Halluzinationen zuwenden, so haben wir also die Erklärung dieses eigenartigen Phänomens zunächst auf der pathopsychischen oder psychopathologischen Seite zu suchen. Wir haben darum zu fragen: Wolche Veränderungen müssen in der Psyche vor sich gehen, damit eine Halluzination zustande kommt?

Indem wir die Psyche als Funktion fassen, die psychischen Vorgänge aber ganz allgemein in drei große (Aruppen zerfallen, in Willens-, Vorstellungs- und Gefühlsvorgänge, spezialisiert sich unsere Frage sofort dahin: Welche dieser drei Sphären muß eine pathologische Veränderung erfahren haben, und worin besteht im speziellen die Veränderung, aus welcher die Halluzination hervorgeht?

Zunächst also: Haben wir die Entstehung der Halluzination in der Veränderung der Willens-, Vorstellungs-oder Gefühlssphäre zu suchen?

Mit der Willenssphäre können wir uns leicht abfinden. Einen Willen als solchen, reine Intention, gibt es überhaupt nicht. Der Wille ist immer auf etwas gerichtet, führt also immer eine Vorstellung mit sich. Man kann nicht einfach wollen, man kanm nur etwas wollen, und mag dieses „Etwas" noch so unbestimmt sein, wie in jenen Bewußtseinszuständen, in welchen wir nicht recht wissen, was wir wollen. Würde also die

1) Das gilt freilich nicht für bestimmte A usfallssymptome, wie \%. B. die A phasice. Hier kamn nur auf der materiellen Seite die eigentliche Frklärung gesucht werden. 
Willenssphäre bei der Entstehung der Halluzination, deren Inhalt doch ein Etwas, eine Vorstellung - eine für Wahrnehmung gehaltene Vorstellung - ist, wirksam sein, so kann er jedenfalls nicht allein bei der Entstehung der Halluzination eine Rolle spielen.

Schließlich finden wir auch in denjenigen psychopathologischen Veränderungen, in welchen die Willensseite krankhaft affiziert erscheint, nichts, was uns zur Annahme berechtigte, daß der Wille bei der Entstehung der Trugwahrnehmung irgendeine Rolle spielen könnte. Denn die krankhaften Abschwächungen der Willensseite, Abulie, Hemmungen, könnten nur zur Herabsetzung der Vorstellungstätigkeit führen. Dadurch werden sie aber geradezu hemmend auf die Entstehung von Halluzinationen wirken müssen. Auf der anderen Seite kann die Steigerung der Willenstätigkeit sich nur in motorischen Entladungen und in größerer Energie der Vorstellungsproduktion als solcher aussprechen, wie sie z. B. ihren Ausdruck im motorischen Rededrang findet. Daß diese Lebhaftigkeit der Vorstellungsproduktion zur Entstehung von Halluzinationen führen sollte, ist ebenfalls nicht einzusehen und nicht beobachtet worden.

Sind aber einmal Halluzinationen da, so kann die Willensintention unter Umständen sehr wohl die Halluzination ins Bewußtsein rufen. Die absichtliche Hervorrufung von Halluzinationen bei manchen Geisteskranken ist eine bekannte Erscheinung. Aber hier ist die Willensintention natürlich nur der gelegentlich, nicht der ursächlich auslösende Faktor. Die Willensseite kann also für die Entstehung der Halluzination ausscheiden.

Viel schwieriger liegen die Verhältnisse auf dem Gebiete des Vorstellungslebens. Daß eine Halluzination nicht ohne ein vorstellendes Element zustande kommen kann, ist selbstverständlich. Denn die Halluzination ist selbst eine Vorstellung. Anders steht die Frage, ob die ursächlichen Bedingungen für die Entstehung der Halluzination auf dem Gebiete unseres Vorstellungslebens aufzusuchen sind.

Betrachten wir zunächst das Vorstellungsleben von der intellektuellen Seite!

Psychopathologische Veränderungen des Intellekts als solchen stellen sich uns in auffallender Weise zunächst von der negativen Seite, als Ausfallssymptome dar. Es kommt hier im wesentlichen die Demenz in Frage. Diese kann aber natürlich unter keiner Bedingung in ursächlicher Beziehung zur Halluzination stehen. Zwar beobachten wir bei Psychosen, die mit dementen Erscheinungen einhergehen, häufig genug Halluzinationen, wir haben aber nicht den geringsten Grund, hier die Demenz selbst als Ursache der Halluzination zu betrachten.

Der Verringerung der intellektuellen Seite, wie sie sich uns als primär oder sekundär entstandene Demenz darstellt, steht auf der anderen Seite eine Steigerung des intellektuellen Lebens gegenüber. Diese hat 
aber überhaupt keine psychopathologisehe Bedeutung. Sie führt in ihrer höchsten Form zur genialen Veranlagung. Mögen nun die Äußerungen des Genies manche Beziehungen zu psychopathologischen Phänomenen zeigen, ja sogar Halluzinationen uns von überragenden historischen Persönlichkeiten berichtet werden, so haben wir doch allen Grund zur Annahme, daß jene vereinzelt vorkommenden pathopsychischen Bewußtseinsäußerungen bei ihnen nicht in der Betätigung des intellektuellen Lebens selbst, sondern in ganz anderen psychischen Sphären, in deren Diensten die intellektuelle Betätigung stand, zu suchen sind, in jener psychischen Sphäre, aus deren pathologischer Steigerung oder Umbildung wir weiter unten die Halluzination werden hervorgehen sehen.

Insofern sich schließlich die gesteigerte intellektuelle Tätigkeit auf abstrakten Gebieten bewegt, wie beim Gelehrten, ist sie der Entstehung von anschaulichen Phantasiegebilden überhaupt abträglich. Je abstrakter das Denken, um so mehr verblaßt der sinnliche Anteil des Vorstellungslebens.

Können wir auf der intellektuellen Seite des Vorstellungslebens keinen Grund für die Entstehung der Halluzination finden, so doch vielleicht auf der psychologischen Seite, d. h. in der Form der Vorstellung oder in gewissen Arten des Vorstellungsverlaufs.

Was zunächst die Form der Vorstellung anbetrifft, so wollen wir darunter nicht nur etwa die räumliche Gestalt verstehen, unter welcher sich die Erinnerungs- und Phantasievorstellungen in unserem Bewußtsein darstellen, sondern zugleich die Gesamtheit der Merkmale, aus welchen irgendein repräsentatives Bewußtseinsgebilde besteht.

Es liegt ja nun die Annahme sehr nahe, daß eine Vorstellung um so eher die Möglichkeit zum Utbergang in halluzinatorische Form bieten mag, je lebhafter sich die Merkmale, aus welchen sie besteht, die räumliche Gestalt oder der qualitativ-intensive Anteil, in unserem Bewußtseinsraum darstellen wird. Man sollte Individuen mit lebhafter Phantasie, mit der Fähigkeit großer Erinnerungstreue, für besonders geeignete Subjekte halten, um an ihnen den U'bergang der Vorstellung in Halluzinationen zu studieren. Man spielt dabei meistens auf die Künstler an, von denen ja einige Beispiele mit halluzinationsähnlicher Erinnerungsfähigkeit berichtet werden. Wir möchten einen Beruf nennen, deren Ausüber wohl mindestens in demselben Maße zur räumlichen Reproduzierung der Objekte ihres Denkens und Schaffens genötigt sind. Das sind die Techniker. Man bedenke, mit welcher Energie der reproduktiven Tätigkeit sich der Ingenieur die Teile einer komplizierten Maschine im Raume angeordnet vorstellen muß, damit das Produkt seines Schaffens genau dem geforderten Effekt entspricht. Die kleinste Raumverschiebung eines Rädchens, die geringste falsche Biegung eines Hebels 
würde sein Vorstellungsgebilde zur Umsetzung in die Realität ungeeignet machen.

Zunächst ist nun überhaupt nicht bekannt, es ist nur eine Annahme, daß Künstler und Techniker die Fähigkeit zur Reproduktion sinnlicher oder räumlicher Merkmale durchschnittlich in hervorragenderem Maße besitzen als andere Individuen. Das, was den Künstler, besonders den Plastiker, vom Kunstanschauenden oder auch vom Kunstverächter unterscheidet, ist nicht im Prinzip die Verschiedenheit in der Lebhaftigkeit der Phantasietätigkeit - diese kann bei allen dreien genau dieselbe sein - sondern die Verschiedenheit in der Fähigkeit der Realisierung des Vorgestellten. Der Plastiker kann Plastiken schaffen, und das können die anderen nicht, mag im übrigen ihre Phantasietätigkeit, wie man das häufig bei unbegabten, aber nervös labilen Individuen findet, noch so lebhaft sein. Wenn man freilich die Fähigkeit der Raumgestaltung im tatsächlichen Kunstschaffen der Reproduktionsfähigkeit in der Phantasie, welche der Realisierung des Kunstobjekts vorangehen muß, substituiert, so kann leicht die Annahme entstehen, als ob die Phantasiegebilde selbst sich den Eigentümlichkeiten eines tatsächlich externalisierten Objekts, einer Wahrnehmung oder einer Halluzination, näherten.

Wir erkennen jedenfalls, daß die Vorstellungstätigkeit als solche trotz noch so gesteigerter Fähigkeit des Individuums, sie mit aller Greifbarkeit ins Bewußtsein zu rufen, doch durch sich niemals imstande ist, jene Umwandlung oder Externalisierung hervorzurufen, welche ihr den Charakter einer Pseudowahrnehmung verleihen könnte.

Aber trotzdem ist es richtig, daß bei exzessiver Phantasietätigkeit, mag diese nun einem Künstler eignen oder einem unbegabten Individuum, die Vorstellungen einen pseudohalluzinatorischen oder gar halluzinatorischen Charakter annehmen können. Und zwar kommt das vor bei Psychopathien, bei Hysterien. Sehr häufig findet man halluzinatorische Bewußtseinsäußerungen bei leicht erregbaren Kindern. Aber es ist klar, daß die Ursachen für diese abnormen Bewußtseinsphänomene nicht auf der Vorstellungsseite selbst zu suchen sind. Schon der Begriff der Erregbarkeit in diesem Zusammenhange schließt das aus.

Wir wissen auch, daß die Psychopathie letzten Grundes nicht auf einer Anomalie der Vorstellungstätigkeit, sondern des Charakters beruht. Die eigentümlichen Reaktionsformen der Psychopathen und auch der Hysterischen spielen sich auf dem Grunde eines abnorm gestalteten Gemütslebens ab. Die Vorstellungsanomalien sind als sekundäre Äußerungen zu betrachten. Wir werden darum nicht fehlgehen, wenn wir auch jene Kunstschaffenden, von denen die Fähigkeit eines exzessiven, pseudohalluzinatorischen Erinnerungsvermögens berichtet wird, ebenfalls für psychopathisch veranlagt halten - eine Annahme, welche in Anbetracht der leichten Gefühlserregbarkeit des Künstlers nahe genug liegt. 
So werden wir auch von dieser Seite darauf hingewiesen, daß wir die eigentliche Ursache der Pseudohalluzinationen und Halluzinationen nicht auf der Vorstellungsseite, sondern in einer ganz anderen Sphäre des psychischen Lebens zu suchen haben.

Ist es nun nicht die Form der Vorstellung, so könnte doch schließlich die Art des Vorstellungsverlaufs uns Anhaltspunkte für die Entstehung der Halluzination aus der Sphäre des Vorstellungslebens selbst bieten. Wir brauchen da nur an die Energie zu denken, mit welcher sich überwertige Ideen und Zwangsvorstellungen dem Bewußtsein aufdrängén. Aber zunächst kommt es nur selten vor, da $B$ ein an Zwangsvorstellungen Leidender eine echte Psychose mit Halluzinationen bekommt, und zweitens haben wir zu bedenken, daß die Zwangsvorstellungen selbst ihre Ursache letzten Grundes ebenfalls gar nicht in einer Störung des Vorstellungslebens haben. Auch sie etablieren sich meist auf dem Grunde einer psychopathischen Veranlagung, also eines durch degenerative Momente schon in seinem Grundaufbau gestörten Gefühlslebens. So werden wir auch hier wieder auf die emotionelle Seite des Seelenlebens als die eigentliche Ursache der zur Wahrnehmungsähnlichkeit gesteigerten Reproduktionsbilder geführt.

Man könnte uns noch auf ein halluzinatorisches oder halluzinationsähnliches Phänomen hinweisen, das jerler Gesunde zuzeiten erlebt, die Träume. Aber zunächst handelt es sich bei diesen Phänomenen um Erscheinungen eines veränderten Bewußtseinslebens. Die Psychosen sind aber nicht Bewußtseins-, sondern Geisteskrankheiten, wenn auch letztere mit Bewußtseinsveränderungen einhergehen können, die dem Schlaf ähnlich sind, und in denen auch lebhaft halluziniert werden kann -Dämmerzustände. Sofern uns aber die Träume ein Hilfsmittel zum Verständnis des Auslösungsmechanismus für halluzinationsähnliche Bewußtseinsgebilde liefern können - und das werden sie in der Tat tun -, werden wir sie ebenfalls durch ihre Beziehung zur emotionellen Seite des Seelenlebens eine solche Handhabe bieten sehen.

Doch gehen wir endlich zu den emotionellen Äußerungen der Psyche, auf die wir so deutlich von allen Seiten hingewiesen werden, selbst über! Was wissen wir zunächst von den Beziehungen unseres Vorstellungslebens zum Gefühls- und dem sich darauf aufbauenden Affektleben in der Gesundheitsbreite?

Nun, zunächst ist es sehr wahrscheinlich, daß von der psychischen Seite betrachtet, nicht nur das Vorstellungsleben, sondern überhaupt alle tierischen und menschlichen Bewußtseinsäußerungen ursprünglich aus Gefühls- bzw. Affektreaktionen hervorgegangen sind. Alle Grundäußerungen des tierisch-menschlichen Lebens stellen sich psychisch zunächst in Gefühlen und Affekten dar. Diese assoziieren sich mit Vorstellungen, die in den Dienst jener Gefühle treten. Der Selbsterhaltungs- 
trieb und der Gattungserhaltungstrieb äußern sich psychisch in den mächtigen Gefühlen des Hungers, des Durstes, des Schmerzes, der geschlechtlichen Erregungen usw. und treiben die Vorstellungen ins Bewußtsein, welche die Objekte zur Befriedigung jener Gefühle bildmäßig enthalten. Instinkt und Trieb sind nichts als die Äußerungen jener emotionalen Grundaffekte, in welchen die elementaren Lebensbedürfnisse zuerst psychisches Leben gewinnen. Sie treiben auch die gefühlsmäßig motivierten Vorstellungen und Strebungen hervor, vermittelst deren alles Lebende das Objekt zur Befriedigung seiner Grundbedürfnisse bewußtseinsmäßig mehr oder minder klar darzustellen sucht, u m es dann in der Tatsächlichkeit zu erreichen. Die Erkenntnis dieser Zusammenhänge hat dann auch zu jener Theorie des Affektualismus oder Emotionalismus geführt, in welcher das Gefühls- bzw. affektive Element als Grundlage aller seelischen Äußerungen anerkannt wird. Es ist auch nicht schwierig nachzuweisen, daß selbst die höchsten Bewußtseinsäußerungen des Menschen in mehr oder minder vermitteltem Zusammenhange mit den Grundgefühlen des Lebens stehen.

Es ist nur eine Konsequenz dieser Motivierung der Vorstellungen durch die Gefühle, daß, je mächtiger diese sind, mit um so größerer Lebhaftigkeit und Beständigkeit jene sich im Bewußtsein darstellen. Je stärker das Hungergefühl ist, um so lebhafter die Vorstellung des $\mathrm{Ob}$ jekts, das zu seiner Befriedigung führt. Je stärker die erotische Erregung ist, in um so ,greifbarerer" Gestalt steigt das begehrte Objekt im Bewußtsein auf. Und -- um von der positiven Seite der Gefühle zur negativen überzugehen - je größer die Angst, um so lebhafter und hartnäckiger drängt sich dem Bewußtsein das Angstobjekt auf. Je stärker das Mißtrauen, um so weniger können wir von unserem Bewußtsein die Vorstellungen der Personen und ihrer Handlungen fernhalten, auf die sich unser Mißtrauen bezieht.

Alle diese gefühlsmäßig motivierten Vorstellungen sind nun freilich zunächst bewußtseinsimmanent und steigern sich höchstens vorübergehend zu pseudohalluzinatorischer Lebhaftigkeit. Wie leicht wir aber geneigt sind, diese bewußtseinsimmanenten Vorstellungen zu externalisieren, drückt schon die Umgangssprache aus, welche den Ängstlichen und Mißtrauischen überall Feinde, ,sehen" läßt.

Das sind alles bekannte, fast triviale und auch häufig in mehr oder minder deutlicher Form zur Erklärung der Halluzinationen verwertete Erfahrungen. Wir haben sie nur in die richtige wissenschaftliche Form umzusetzen. Und diese ergibt sich, wenn wir systematisch unsere normalpsychologischen Kenntnisse von den Gefühlen und Affekten auf die psychopathologischen Gefühls- und Affekterscheinungen anwenden, wenn wir die Einsicht in die gesetzmäßigen Abhängigkeitsbeziehungen gewinnen, welche zwischen dem normalen Denken und Wahrnehmen 
vom nornalen Fühlen auf der einen Seite und zwisehen dem pathologischen Denken (Wahn) und Wahrnehmen (Halluzinationen) vom pathologischen Fühlen auf der anderen Seite besteht, und wenn wir schließlich die Halluzination in Beziehung zu jener triebmäßigen Motivierung bringen, durch welche wir die rein erkenntnispraktische Tatsache der Außenwelt sich für das assimilationsbedürftige Individuum in einen biologischen Wert umsetzen sahen.

Wir hatten schon am Schlusse des vorigen Kapitels auf die engen Beziehungen des Wahrnehmungs- und Vorstellungslebens zu den Gefühlen aufmerksam gemacht und gefunden, daß nicht nur die Wahrnehmungen stets mit einem Gefühlston verknüpft, sondern auch die Vorstellungen mit den höheren Gemütsgefühlen eng assoziiert sind.

Die beiden polaren Gegensätze, zwischen welchen überhaupt alle Gefühlsvorgänge schwanken, sind nun das Lust- und Unlustgefühl. Unser ganzes normales Seelenleben besteht von der Gefühlsseite im Schwanken zwischen diesen beiden Polen und in dem Bestreben, einen Ausgleich zwischen beiden zu finden. Wird dieser Ausgleich in so erheblicher Weise gestört, daß eine Rückkehr in das normale Gleichgewicht nicht möglich ist, so haben wir einen pathologischen Seelenzustand vor uns. Herrseht in diesem die positive Komponente vor, so handelt es sich um das manische Irresein, schlägt dagegen die negative Komponente vor, so handelt es sich um das melancholische Irresein, findet in mehr oder minder großen Zwischenräumen eine Abwechslung zwischen beiden abnormen Gefühlszuständen statt, so handelt es sich um das sog. manisch -de pressive Irresein mit seinen verschiedenen Arten.

Daß nun der Wahn und die Halluzination in diesen sogenannten Affektpsychosen in vollkommen einseitig bestimmter Abhängigkeits bezieh ung von dem dauernd der Krankheit zugrunde liegenden bzw. zurzeit gerade vorherrschenden Affektzustande sich befinden, ist selbstverständlich und auch wohl noch von niemandem bezweifelt worden. Wohl aber scheint von manchen bezweifelt zu werden, da $\beta$ aus diesem Grunde der pathologische Affekt im vollen Sinne des Wortes als Ursache, Wahn und Halluzination als Wirkung bezeichnet werden dürfen.

Wir können hier nur auf die vorangegangenen und noch folgenden Auseinandersetzungen hinweisen. Nach diesen liegen weder allgemeine methodologische Hinderungsgründe vor, psychische Phänomene in der auch sonst in den Naturwissenschaften gebräuchlichen Weise in kausale Beziehung zueinander zu setzen, noch ergeben sich beachtliche Einwände gegen die spezielle Anwendung einer solchen Kausalfolge auf die Beziehung von Wahn und Halluzination zum pathologisch veränderten Gemütszustand. Wer das leugnet, muß in den pathologischen Ver- 
änderungen der Psyche überhaupt etwas Unerklärliches sehen, zumal ja die Konstruktion einer Kausalbeziehung der pathologischen Seeleninhalte zu materiellen Gehirnveränderungen, selbst wenn wir diese in jedem Falle genau kennen würden, ausgeschlossen wäre ${ }^{1}$ ).

Es hieße wohl allen Erscheinungen, die wir im normalen Gefühlsleben antreffen, und den Ủbergängen zu den pathologischen Gefühlsveränderungen, welchen wir in so mannigfachen Abstufungen begegnen, Gewalt antun, wenn wir leugnen wollten, daß die Wahn- und Halluzinationsinhalte zum pathologischen Gefühlszustande in voll begreiflicher ursächlicher Beziehung stehen. Werden wir doch später Phänomene aus dem rein normalen Seelenleben antreffen, in welchen wir alle diese ursächliche Beziehung selbst erleben (Träume). Wir können also den Widerspruch gegen die Konstruktion einer kausalen Beziehung zwischen pathologischem Gemütszustande einerseits, Halluzination und Wahn anderseits wohl als gegenstandslos betrachten. Wir konstatieren einfach:

Der Größenwahn und die ihm entsprechenden Halluzinationen beim manischen Irresein sind vom psychopathologischen Standpunkte als die Wirkung des pathologisch gesteigerten positiven Affekts zu betrachten. Eben weil in der Manie das Lust- und Kraftgefühl zu pathologischer Höhe gesteigert ist, deshalb wähnt der Kranke, Kaiser und König zu sein, Reichtümer zu besitzen, mit Prinzessinnen zu verkehren usw., und aus diesem Grunde hat er die Halluzinationen, welche in inhaltlicher Beziehung zu diesen Wahnideen stehen. Sofern wir also überhaupt in der früher dargelegten Weise auf psychischem Gebiet von Kausalbeziehungen $\mathrm{zu}$ sprechen berechtigt sind, so ist unzweifelhaft der pathologisch gesteigerte Affekt als Ursache, der Wahn und die Halluzination als Wirkung zu betrachten.

Ganz genau dieselben t'berlegungen ergeben sich natürlich für die Abhängigkeit des Wahns und der Halluzination von der pathologisch gesteigerten negativen Gefühlsseite in der depressiven Psychose. Der traurige Affekt ist als die Ursache, die Versündigungs-, Verarmungs-, Verschuldungsideen usw. auf der einen, die Halluzinationen, die dem

1) Trotzdem kann man natürlich eine nachgewiesene oder mit Grund vermutete Gehirnveränderung als die Ursache der Geisteskrankheit selbst bezeichnen. Wir konstatieren dann eine empirische Kausalfolge in einer anderen Richtung.

Es wäre hier auch zu bemerken, daß der Naturforscher sich mit Recht prin. zipiell dagegen sträuben muB, wollte man seinem kausalen Forschungsbedürfnis in der Erklärung abnormer Vorgänge irgend wie eine Grenze setzen. So zweifelt z. B. der Mediziner, um bei diesen zu bleiben, nicht daran, darf die krankhaften Veränderungen des Körpers, etwa der Niere bei der Nephritis doch ebenso unter die Naturgesetze fallen und sich deshalb kausal arklären lassen müssen wir die gesunden. So sind wir auch nicht berechtigt, der intrapsychischen Erklärung abnormer Seelenerscheinungen eine Schranke zu ziehen, wir müssen sie vielmehr unter dem Gesichtspunkt allgemein giltiger seclischer Gesetze $\mathrm{zu}$ verstehen suchen. 
Inhalte dieser Ideen entsprechen, auf der anderen Seite, sind als Wirkung z u betrachten.

Außer den Affektpsychosen gibt es nun noch die sogenannten Intelligenzpsychosen, die paranoischen und paranoiden Zustände. Daß es sich bei diesen um eine primäre Störung der Intelligenz handeln sollte, ist in der neuseten Phase der psychiatrischen Forschung immer mehr und mit immer berechtigteren Gründen bezweifelt worden. Und in der Tat, wenn wir uns die Art der Urteilsstörung, welche das Wesen der ,,Verrücktheit" ausmacht, und besonders den Inhalt der Halluzinationen bei den paranoischen Psychosen nur einmal andeutungsweise systematisch $\mathrm{zu}$ ordnen und ihre Beziehung zum Seelenleben zu erwägen versuchen, mag uns sofort die Einsicht in die Haltlosigkeit, ja völlige Unmöglichkeit der Anschauung, welche die paranoischen und paranoiden Psychosen und alle ihre Symptome, sowohl die Trteilsstörung wie die Halluzinationen, auf eine primäre Intelligenzstörung zurückzuführen sucht, aufgehen.

Der Intellekt besteht, wenn wir uns zunächst an die Kantsche Definition halten, in der Fähigkeit, zu urteilen. Diese Fähigkeit macht das Wesen ressen aus, was wir Verstand nennen. Nun, die formale Urteilsfähigkeit ist bei der Paranoia nicht gestört. Es müßte sich ja dann um eine Demenz handeln. Halluzinationen können ein dementes Gepräge zeigen, wenn nämlich zugleich eine Demen\% vorliegt, sie brauchen es aber prinzipiell nicht und tun es auch nicht bei den rein paranoischen und paranoiden Zuständen. I) formale Urteilsfähigkeit als solche ist bei der Paranoia ebenso vorhanden wie beim normaisinnigen Individuum. Paranoische und paranoirle Individuen können sogar, wie wir wissen, außerordentlich scharfsinnig, d. h. in formaler Beziehung urteilskräftig sein. Das beweisen sie gerarle in der Begründung der Wahnideen, welche ihre vermeintliche Verstanderkrankung ausmachen sollen.

Die intellektuelle 'Tätigkeit beschäftigt sich nun mit der verstandesoder urteilsmäßigen Verarbeitung der Inhalte, die uns aus der Erfahrung zufließen. Betrachten wir also den Intellekt von der Inhaltsseite und fragen wir uns, was wir aus der Betrachtung dieser für die Entstehung des Wahns und der Halluzinationen bei der Paranoia für einen Gewinn ziehen können.

Die Inhalte, welche die Erfahrung dem Intellekt zur weiteren Verarbeitung darbietet, erstrecken sich auf die Gesamtheit der sinnlich erfahrbaren Gegenstände überhaupt. Und die Halluzinationen bei der Paranoia? Erstrecken sich diese auch auf das Gesamtheitsgebiet der Erfahrung? Wird jeder beliebige Inhalt in gleichmäßiger Weise zum Gegenstand halluzinatorischer Bewußtseinsdarstellung? Sind es Streichholzkästchen, Stiefelknechte, Pfeffernüsse oder sonst irgendwelche nütz- 
lichen Gebrauchs- und Genußgegenstände, welche den Inhalt der Halluzinationen bei der Paranoia darstellen? Es wäre lächerlich und entspricht auch nicht der psychiatrischen Erfahrung, eine solche Ausnahme zu machen.

Hier nähern wir uns wieder der eigentlichen Ursache für die Entstehung der Halluzinationen in den Geisteskrankheiten überhaupt. Denn auch auf dem Gebiete der Paranoia treffen wir als halluzinatorische Inhalte im allgemeinen nur solche, welche in Beziehung zu den für unsere Lebenserhaltung und Lebensbeziehungen wesentlichsten Gemütsgefühlen stehen.

Insbesondere sind es solche halluzinatorischen Inhalte, welche der pathologischen Steigerung oder Umwandlung der im früheren kurz berührten Persönlichkeitsgefühle oder der Eigengefühle, wie sie in der Psychologie genannt werden, entsprechen. Diese Persönlichkeitsgefühle, deren Pflege wir uns, soweit sie unser Selbstgefühl zu heben imstande sind, so angelegen sein lassen, und deren Steigerung wir uns, sofern sie unser Selbstgefühl zu beeinträchtigen vermögen, so wenig erwehren können, sind es hauptsächlich, welche in ihrer pathologischen Potenzierung und Transformierung den Inhalt für all das liefern, was die im Sinne dieser pathologischen Gemütsveränderung pathologisch affizierte Assoziations- und Reproduktionstätigkeit als halluzinatorische Gebilde vor das Bewußtsein ruft.

Zur näheren Erkenntnis des eigentlichen Wesens der paranoischen Umwandlung des Individuums hat man neuerdings versucht, die ersten Erscheinungen, welche sich bei dieser zeigen, ja schon die vorparanoischen Veränderungen des Individuums, deutlicher ans Licht zu ziehen. Was man da gefunden hat, ist niemals eine Veränderung der formalen Urteilsfähigkeit gewesen. Es waren Veränderungen eben jener Persönlichkeit, deren eigentliches Wesen in der besonderen Gemütsveranlagung, in der eigentümlichen zuständlichen Reaktionsweise des seelischen Gesamtzustandes auf äußere Eindrücke, besonders im $Z$ usammenhange der sozialen Beziehungen beruht. Reizbarkeit, Leidenschaftlichkeit, hochfahrendes Wesen, Stolz, Eigendünkel, Glaube an einen höheren Beruf, Dünkelhaftigkeit auf der einen Seite, Kleinmut, Verzagtheit, Ängstlichkeit, übertriebene Gewissenhaftigkeit, Unsicherheit des Wesens, vergesellschaftet mit hypochondrischer und verzagter Niedergeschlagenheit auf der andern Seite - das sind die psychischen Potenzen, aus welchen das paranoische Wesen mit seiner auf der einen Seite expansiv, auf der anderen Seite depressiv gerichteten pathologischen Assoziations- und Reproduktionstätigkeit hervorwächst. Alle diese psychischen Potenzen 
haben in ihrer pathologischen Steigerung wohl eine Störung der Urteilsfähigkeit zur Folge, aber nicht zur Ursache. Und die Folge ist auch nicht eine Störung der formalen Urteilsfähigkeit, sondern der Urteilsrichtung, des beurteilten Inhaltes. Nicht das Urteilen, sondern die Beurteilung, und $\mathrm{zwar}$ eines ganz bestimmten Ideenkreises, ist gestört, und diese Störung ist das eigentlicheMoment der Intelligenzveränderung, welche wir bei der Paranoia und den paranoiden Psychosen vorfinden und ebenso als Wirkung der zugrunde liegenden Gemütsveränderung zu betrachten haben wie die Halluzination selbst.

Indem wir die paranoische und paranoide Seelenveränderung ebenso im letzten Grunde auf eine pathologische Affektion des Gefühlslebens zurückführen, wie die in den Affektpsychosen sich kundgebende, brauchen wir jedoch keineswegs zu fürchten, die Scheidewand zwischen beiden einzureißen, wie das z. B. Specht getan hat. Denn es bleibt der prinzipielle Unterschied bestehen, daß bei der Affektpsychose es sich nur um eine pathologische und meist vorübergehende Steigerung der beiden Grundmodifikationen der Gefühls- bzw. Affektseite handelt. Das Wesen der Paranoia und der paranoiden Umwandlung besteht aber in der Änderung der die Persönlichkeit konstituierenden höheren Gemütsgefühle, die selbst schon eine verwickelte Psychogenese haben, im Gegensatz zu den einfachen, allem psychischem Leben, auch dem der Tiere zukommenden Grundmodifikationen des Gefühls überhaupt. $\mathrm{Ob}$ es infolge der einheitlichen psychologisehen Basis, auf der schließlich alle Gefühle stehen, Ǔbergänge zwischen Affekt- und paranoischen Psychosen gibt, haben wir an dieser Stelle nicht weiter zu untersuchen.

Wohl aber haben wir die Konsequenzen zu ziehen aus der Erkenntnis, daß die grundlegende pathologische Umwandlung bei den paranoischen und paranoiden Psychosen genau so die Gefühlsseite betrifft wie bei den Affektpsychosen. Und diese Konsequenzen können für die Entstehung der Halluzinationen natürlich nur die sein, daß auch bei den ersteren die pathologische Veränderung des Gefühls als die eigentliche Ursache der Halluzination zu betrachten ist. Unterlag es bisher nicht dem geringsten Zweifel und hat wohl auch noch niemand die auf der Hand liegende und aus der psychiatrischen Erfahrung sich unmittelbar ergebende Erkenntnis bestritten, daß bei den Affektpsychosen die Halluzination herauswächst aus der pathologisch gesteigerten (expansiven) oder gedrückten (depressiven) Gemütslage, und daß die Halluzinationen auch einen dementsprechenden Inhalt haben, so wird wohl auch, wenn einmal die pathologische Umwandlung der die Persönlichkeit zusammensetzenden höheren Gemütsgefühle als der Kern der paranoischen und paranoiden Geisteserkrankung erkannt worden ist, niemand dagegen Bedenken erheben können, daß die Halluzination bei diesen Psychosen 
ebenfalls als die unmittelbare Wirkung jener Gemütsveränderung zu betrachten ist. Entspricht doch ihr Inhalt genau so wie bei den Halluzinationen der Affektpsychosen prinzipiell durchaus der bestimmten Gemütslage, welche dem paranoischen und paranoiden Wesen selbst zugrunde liegt.

Zugleich ergeben sich aus den gewonnenen Resultaten die Schlüsse, welche wir über die inneren Beziehungen der Halluzination zum Wahn zu ziehen haben. Die Frage nach diesen Beziehungen ist ja stets ein Problem für die Psychiatrie gewesen und auch noch heute nicht in allgemein anerkannter Weise zum Abschluß gebracht worden.

Ausgehend von der Erfahrungstatsache, daß sehr häufig im Beginn der Psychose eine Wahnbildung nicht konstatiert werden kann, sondern daß diese erst auf Grund der Halluzinationen zustande kommt, daß erst aus der wahnhaften Verarbeitung dieser allmählich das Wahnsystem als sekundäres Gebilde entsteht, hat man in diesen Fällen meistens keinen Anstand genommen, die Halluzination als Ursache des Wahns $\mathrm{zu}$ betrachten.

In neuester Zeit hat man jedoch mit Recht Bedenken gegen diese Auffassung erhoben. So behauptet Ziehen, daß selbst in den Fällen, in welchen die Halluzination der bewußten Wahnvorstellung vorausgeht, die latente Disposition eben schon bei der speziellen Gestaltung der Halluzination mitgewirkt hat ${ }^{1}$ ).

In ähnlichem Sinne erklärt sich Krae pelin. Es ist ihm augenscheinlich, daß in den Fällen, in welchen Wahnbildungen an Sinnestäuschungen oder auch an wirkliche Wahrnehmungen angeknüpft werden, doch der Ursprung der Wahnbildung aus den inneren Zuständen des Individuums abzuleiten ist ${ }^{2}$ ).

Während nach der Ansicht dieser beiden Autoren die Halluzination als die Folge des Wahns oder doch der den Wahn schon latent in sich tragenden psychischen Veränderung des Individuums aufzufassen wäre, koordiniert Ble uler einfach beide Symptome und meint, es ginge nicht an, die Wahnideen sekundär aus Halluzinationen und Illusionen der Sinne und des Gedächtnisses abzuleiten. Es handle sich um koordinierte Symptome, die alle der Ausilruck der nämlichen Wirklichkeitsfälschung $\left.\operatorname{seien}^{3}\right)$.

Und die Wirklichkeitsfälschung? Diese werden wir wohl sicherlich als die unmittelbare Folge jener pathologischen Seelenveränderung, die sich uns als eine pathologische Veränderung des Gemütslebens darstellt, aufzufassen haben. Diese Veränderung ist die Psychose selbst. Sie

1) Ziehen, Lehrbuch der Psychiatrie.

2) Krae pelin, Lehrbuch der Psychiatrie.

3) Bleuler in Aschaffenburgs Handbuch der Psychiatrie. Dementia praecox oder Gruppe der Schizophrenien. 
kann zuerst den Wahn und dann die Halluzination, oder zuerst diese und dann jene, oder auch beide zugleich an die Bewußtseinsoberfläche treiben. Der sog. sekundäre Wahn ist dann aber nur die durch die Halluzinationen vermittelte gedankliche Bewußtseinswirkung der psychischen Erkrankung selbst.

So ist also im letzten Grunde niemals die Halluzination, sondern die diecer zugrunde liegende psychische Erkrankung die eigentliche Ursache des Wahns. Der beste Beweis dafür ist, daß Halluzinationen, welche etwa auf Grund einer peripheren Erkrankung der Sinnesorgane produziert werden, ohne daß gleichzeitig eine Psychose besteht, niemals wahnhaft verarbeitet werden ${ }^{1}$.

Die K'ordination von Wahn und Halluzination ist nur der Ausdruck des einhe,tlichen Geistes, in dessen normaler Konstitution Sinn und Gedanke unbeschadet der Aktivierung des Sinnes durch eine von ihm unabhängige Außenwelt ebenfalls nur die verschiedenartigen Bewußtseinsdarstellungen eben desselben einheitlichen psychischen Substrats bedeuten. Was jetzt als Wahrnehmung mein Bewußtsein erfüllt, kann später als gedankliches Produkt in demselben auftreten. Sa kann bei der Psychose die Gemütsveränderung, welche etwa in einem pathologisch gesteigerten Mißtrauen besteht, sowohl in der gedanklichen Form des Verfolgungswahns wie in der sensoriellen Form trügerisch wahrgenommener Verfolger sich äußern. Tritt die Trugwahrnehmung zuerst auf und wirl diese zum Wahn verarbeitet, so ist der letztere dennoch im letzten Grunde die Wirkung eben jener pathologischen Gemütsveränderung, welche zeitlich zuerst den Verfolgungswahn als abnormes Bewußtseinsprodukt hervorgebracht hat.

Indem wir die Halluzination sowohl bei den Affekt- wie bei den paranoischen und paranoiden Psychosen aus der pathologischen Steigerung bzw. Umwandlung des Gefühlslebens erklärten, haben wir die einheitliche Basis für die psychopathologische Erklärung der Halluzination überha u pt gewonnen.

Diese psychopathologische Erklärung ist zugleich eine pathopsychische. Sie findet ihre letzte Begründung in jener zu Anfang unserer Betrachtungen geschilderten Beziehungen des affektiv-motivierten Triebes zur Wahrnehmung und Vorstellung. Sowie durch den normalen Trieb die in der Wahrnehmung

1) Einen sehr instruktiven Fall, welcher dic aus der Koordination von Wahn und Trugwahrnehmung sich ergebende relative Unabhängigkeit beider voneinander beweist, führt neuerdings $\mathrm{R}$. Schneider an. (Zur Frage der chronischen Morphinpsychose und des Zusammenhangs von Sinnestäuschungen und Wahnideen. Zeitschr. f. d. ges. Neur. u. Psych. 19, 1913.) Bei diesem Fall, der auch noch aus anderen Gründen interessant ist, traten zuerst die Halluzinationen und Wahnideen zusimmen auf. Später verschwanden die Wahnideen, und es blieben nur die Halluzinationen. 
sich vollziehende Anerkennung der Außenwelt zum biologischen Wert gestempelt wird, so wird durch die krankhafte Steigerung oder Umwandlung der Affektivität eine neue triebmäßige Motivierung geschaffen. Sie richtet sich auf jene Vorstellungsbilder, welche bei normalem Trieb- und Instinktleben als die bewußtseinsimmanenten Antizipationen jener später im tatsächlichen Wahrnehmungsfelde zu realisierenden, anzueignenden oder abzuwehrenden Gegenständlichkeiten angetroffen werden. Der pathologisehe Trieb und Instinkt ist eben jene pathologische Affektivität selbst, durch welche wir die reine Bewußtseinsimmanenz eines mit dem Affekt oder Gefühl assoziierten Vorstellungsbildes sich in die trügerische Bewußtseinstranszendenz eines scheinbaren Wahrnehmungsgegenstandes umsetzen sahen.

So sehen wir denn auch auf den Höhepunkten der pathologischen Affektivität und Persönlichkeitsumbildung das geisteskranke Individuum rein triebhaft auf seinen Wahn und seine Halluzination reagieren. Mit einer nur der triebmäßigen Motivierung zukommenden unwiderstehlichen. Gewalt stürzt sich der Paranoische auf die gesehenen Verfolger, um sie zu vernichten, wähnt und sieht der Manische all das realisiert, was seine pathologisch gesteigerte Expansivität ihm vor das glückserfüllte Bewußtsein ruft.

Indem wir sowohl die in Affekt- wie in paranoischen Psychosen vorkommenden Halluzinationen auf die einheitliche Basis einer pathologischen Gefühlsveränderung zurückführten, haben wir zugleich auch die in irgendwelchen Geisteskrankheiten vorkommenden Halluzinationen auf dieselbe Grundlage gestellt. Denn im wesentlichen sind diese bei irgendwelchen Psychosen vorkommenden Halluzinationen, wenn es sich nicht um reine Affekt- oder reine paranoische und paranoide Psychosen handelt, doch aus pathologischen affektiven und paranoischen Komponenten, die diesen Psychosen eignen, zu erklären.

Trotzdem wird es natürlich nicht möglich sein, nun jede Halluzination im Sinne der von uns gegebenen pathopsychischen Erklärungsweise restlos aus affektiven und paranoischen Komponenten abzuleiten. Das Gebiet der Sinnestäuschungen, meint Pfersdorff, verleitet wie kein anderes den Psychiater auch bei der Beschreibung der pathologischen Symptome oder bei ihrer theoretischen Würdigung Resultate zu verwerten, welche die Psychologie des Gesunden uns liefert. Aber der Autor anerkennt doch in seiner eben erschienenen Arbeit ${ }^{1}$ ) das Verdienst von Jas pers auf diesem Gebiet, besonders in der Beurteilung der Stellungnahme des Kranken zu seinen Halluzinationen mit Zuhilfenahme

1) Pfersd orff, Zur Kenntnis der'T'ugwahrnehmungen (und der Lesestörungen). Zcitschr. f. d. ges. Neur. u. Psych. 19, 122 f. 1913. 
wissenschaftlicher Psychologie Klarheit geschaffen zu haben. ${ }^{1}$ ) So darf auch die wissenschaftliche Psychologie uns die Handhabe liefern, um in parallelem Gange zu ihr eine kausale Psychopathologie aufzubauen, in welcher wir die einzelnen Symptome auseinander ableiten.

Gewiß wird es uns also nicht möglich sein, jene komplizierten, zum Teil mit motorischen Komponenten verknüpften Halluzinationen, die Pfersdorff zum Gegenstand seiner eingehenden Analyse macht, völlig auf dem oben bezeichneten Wege aufzuklären. Wir müssen uns genügen, für die Haupterscheinungen eine brauchbare Grundlage zu schaffen. Im übrigen müssen wir es der fortschreitenden Wissenschaft überlassen, auch die ferner liegenden und komplizierteren Symptome mit ihr in Einklang zu bringen.

Wir möchten aber doch kurz andeuten, daß gerade für das komplizierte Gebiet des Gedankenlautwerdens und der mit diesen so eng verknüpften pathologischen Symptome auf motorischem Gebiet (des Sprechens, Lesens, Schreibens usw.) die allgemeine affektive Grundlage bekannt ist. Wir wissen ja, daß die Sprache ursprünglich aus Affektreaktionen hervorgegangen ist. $\mathrm{Da} \beta$ nun bei einer tiefer eingreifenden geistigen Störung gerade dieses bedeutungsvolle Gebiet mit allen seinen Komponenten in halluzinatorischer Weise bewußt werden und auch motorische Eigenerregungen nach sich ziehen wird, erscheint deshalb psychopathologisch ebenfalls verständlich, wenn es auch hier schwerer möglich sein wird, diese im einzelnen kausal zu begreifen oder gar in „kausale" und ,verständliche“" Zusammenhänge einzuordnen. Zum Teil handelt es sich hier aber wohl um Störungen der Hirnmechanik, die nicht mehr in das Problem der Halluzination im engeren Sinne ge-

1) An der Jasperschen Methodik gemessen würde wohl nach unseren Ausführungen nie die Halluzination sondern stets die Geisteskrankheit selbst das letzte „Unverständliche“ sein. Im übrigen würde es wohl zu weit führen, wenn wir die Jas persschen Unterscheidungen der verständlichen und kausalen Erklärung in dieser Arbeit, die sich nur mit der kausalen Erklärung beschäftigt, mit brücksichtigen würden. Wir glauben ebenfalls, daß die Unterscheidungen Jaspers' einen Sinn haben und methodologisch fruchtbar sind, möchten aber annehmen, daß auch die verständ. lichen Zusammenhänge sich schließlich mit allen möglichen Übergängen in das kausale Getriebe verlieren, wie es ja auch mannigfache Übergänge zwischen gesunder und kranker Psyche gibt. Auf der anderen Seite sind, wie auch Pfersd orff nicht im Unrecht bemerkt, beinahe alle durch Affeksstörungen bedingten Verfälschungen des Bewußtseinsinhalts verständlich, aber nichts desto weniger krankhaft. Dic Formel für die Lösung dieser schwierigen methodologischen Probleme ist wohl die, daß kausale und verstehende Betrachtungsweise sich auf dem Gesamtge. biete des Psychischen, Normalpsychischen und Pathopsychischen, nirgend anschließen, sondern uiberall ergänzen. Nur geht in den Naturwissenschaften, wie wir auseinandergesetzt haben, die Forschungsabsicht auf die kausale Erklärung. Die vorstehende Betrachtungsweise kann also in der Psychiatrie, sofern wir diese als Naturwissenschaft behandeln, nur als Durchgangspunkt, als Mittel zum Zweck (nämlich der kausalen Erklärung) eine Stätte finden. 
hören. Vielleicht kommen hier auch zum Teil aphasische Störungen in Betracht, wie sie neuerdings $\mathrm{K}$ leist beschrieben hat ${ }^{1}$ ).

Bezüglich der von Pfersdorff beschriebenen,,motorischen Halluzinationen" mit dem Gefolge reaktiver Eigenleistungen wäre zu bemerken, daß auch diese in ihrer Grundlage einer psychopathologischen Erklärung zugänglich sind. Denn auch die Körperbewegungen sind ursprünglich affektiv motiviert. Im übrigen spielen hier katatone Erscheinungen mit, die ebenfalls aus dem Gebiet der Halluzinationen im engeren Sinne herausfallen.

2. Die gehirnpathologischen Entstehungsbedingungen der Halluzination.

Als einer der bedeutungsvollsten Fortschritte auf dem Gebiete gehirnphysiologischer Forschung wird wohl stets die Auffindung jener Rindenzentren erscheinen, in welchen wir auf Grund von Experiment und pathologischen Befunden die organischen Korrelate der motorischen Impulse und der uns aus der Sinneswahrnehmung zufließenden primären Erkenntnisbilder und der Erinnerungsvorstellungen materiell realisiert zu denken haben.

Jeder Fortschritt, welcher unsere bisherige Erkenntnis grundlegend umzuändern imstande ist, bringt nun freilich auch eine gewisse Gefahr mit sich. Denn er eröffnet Perspektiven, in deren Richtung das Erklärungsbedürfnis sich zunächst allzuweit vorwagt. Erst allmählich beschränkt sich der nüchterne wissenschaftliche Blick auf die Grenzen, welche ihm durch die Natur des Objektes und den wahren Geltungsbereich des Forschungsmaterials gezogen wird.

Wir werden es nicht leugnen können, daß die Auffindung jener Rindenzentren zuerst die Hoffnungen des hirnphysiologischen Deutungsbedürfnisses allzu sehr beflügelt hat. Erst allmählich verloren die dem Wesen des Geistigen unangemessenen und zu weitgehenden Lokalisationsbestrebungen an Geltung.

Es ist verständlich, wenn gerade zur Erklärung der Halluzination in solchen Lokalisationsversuchen zu weit gegangen wird. Wenn nachgewiesen ist, daß in bestimmten Rindenzentren die materiellen Korrelate der Erregungen lagern, welche ihnen von den peripheren Sinnesflächen zugeführt werden, da muß es freilich zunächst wie selbstverständlich erscheinen, daß die Halluzination einfach aus einer Erweckung dieser Korrelate zu neuem Leben zu erklären ist, daß also eine lokale Reizung bzw. Erregung der betreffenden Hirnregion als letzte Ursache der Halluzination angenommen wird. Bestärkt werden könnten wir dieser Annahme noch, wenn wir beobachten, da $\beta$ durch

1) Kleist, Aphasie und Geisteskrankheit. Münchn. med. Wochenschr. Nr. 1. 1904. 
Reize, welche ron krankhaft veränderten peripheren Sinnesflächen ausgehen, in der Tat Halluzinationen ausgelöst werden. Hier scheint es ja auf der Hand zu liegen, daß ein lokaler von der Peripherie ausgehender Reiz im betreffenden Sinneszentrum die Erweckung der Vorstellungsresiduen zu halluzinatorischer Höhe anfacht.

Als einfache Konsequenz aus diesem peripheren Entstehungsmodus dieser Halluzinationen ergibt sich dann die Annahme, daß bei Ceisteskrankheiten die Halluzinationen durch eine Reizung der Sinneszentren von einer zentralen Stelle aus entstehen. Eine,,rückläufige Welle“ strömt, so meint man, von einem zentralen Hirngebiet, etwa einem „,Begriffszentrum“, nach dem Sinneszentrum. Kahlba u m nannte diesen Vorgang „,Reperzeption." Und von diesem Begriff der Reperzeption wird auch noch heute zur Erklärung der Halluzination weitgehender Gebrauch gemacht.

So viel wird freilich wohl allgemein zugestanden werden müssen, daß ein reperzeptorischer Vorgang, wie ihn die älteren Psychiater konstruierten, nicht gut als Ursache der Halluzination angenommen werden kann. Wernicke nahm neben einem ,Erinnerungszentrum" noch ein „Organempfindungszentrum" an. Die Reperzeption sollte in einer rückläufigen Welle bestehen, welche von jenem Zentrum zu diesem fließt. Hierdurch sollte die Halluzination erweckt werden. Wird das Erinnerungszentrum allein erregt, so sollten nur Erinnerungsvorstellungen reproduziert werden.

Wir haben nun freilich schon früher gesehen, daß beim normalenWahrnehmungsvorgang, wie er sich auf dem Gebiete der höheren Sinnesorgane abspielt - und diese geben ja das hauptsächlichste und bedeutungsvollste Material für Erinnerungsvorstellungen und Halluzinationen von Organempfindungen überhaupt kaum gesprochen werden kann. Bei mittlerer Reizstärke, bei welcher wir die meisten Wahrnehmungen durch Auge und Ohr in uns aufnehmen, ist eine Organempfindung gar nicht zu konstatieren. Wir empfinden nicht Auge und Ohr beim Sehen und Hören, sondern Farbe und Töne.

Freilich kann auch bei Fallenlassen eines ,Organempfindungszentrums" von einer Reperzeption gesprochen werden, und das geschieht ja auch noch heute von seiten vieler Psychiater. Aber es wird jetzt, wie leicht einzusehen ist, außerordentlich schwierig, diesem Begriff eine richtige Deutung, ja überhaupt eine Bedeutung zu verleihen. Denn man hat zu bedenken, daß es außer Halluzinationen auch Pseudohalluzinationen gibt. Diese Pseudohalluzinationen im Sinne Kandinskys, oder ,psychische Halluzinationen" im Sinne Beillargers orler Apperzeptionshalluzinationen im Sinne Kahlba ums haben, wie wir früher erkannten, die Eigentümlichkeit, daß sie mit derselben sinnlichen Deutlichkeit wie Halluzinationen vor das Bewußtsein des Kranken treten, 
wobei sich das Individuum auch wie bei den Halluzinationen im Gefühl der Rezeptivität befindet, nur daß die Pseudohalluzinationen eben nicht den Externalitätsfaktor an sich tragen, wie die, sei es mit, sei es ohne Kritik sich vor das Bewußtsein stellenden echten Halluzinationen.

Nun werden wir doch nicht zweifeln, daß bei den Pseudohalluzinationen ebenfalls eine Reizung oder Erregung der zentralen Sinnesflächen stattfindet, und zwar prinzipiell wohl noch in höherem Grade wie bei den echten Halluzinationen. Denn bei den letzteren ist es nicht sowohl die sinnliche Deutlichkeit - Halluzinationen können sehr undeutlich sein - sondern eben der Externalitätsfaktor, welcher dem abnormen Bewußtseinsgebilde den Wahrnehmungscharakter aufprägt.

Wir werden auch allen Grund zur Annahme haben, daß bei der Auslösung der Pseudohalluzinationen zentralere Gebiete ebenfalls eine Rolle spielen. Kommen sie doch in der Regel ebenfalls nur bei seelisch abnormen Individuen vor, also solchen, bei welchen wir eine, wenn auch nur funktionelle Abweichung der gesamten Hirnrinde von der Norm anzunehmen haben. Wir müßten also für die Entstehung der Pseudohalluzination ebenfalls einen „,reperzeptorischen“ Vorgang annehmen. Würden wir aber auf einen solchen verzichten, so wäre nicht einzusehen, warum wir an ihm bei der echten Halluzination prinzipiell festhalten sollten, da sich gerade doch deren Inhalt dem Bewußtsein häufig so fremd gegenüberstellt, als ob ,zentralere“ Seelenvorgänge gar keinen Anteil an ihrer Entstehung hätten.

Wann löst denn nun aber die Reperzeption in der zentralen Sinnesfläche Halluzinationen und wann Pseudohalluzinationen aus?

Kraepelin meint, es bestünde ein bestimmtes Verhältnis zwischen Reizbarkeit der Sinnesflächen und Reperzeption. Je stärker jene, um so schwächer diese und umgekehrt. Dieses bestimmte Verhältnis sei die Ursache für die Entstehung von Halluzinationen oder Pseudohalluzinationen. Bei der Entstehung der Halluzinationen sei die Reperzeption schwach und die Reizbarkeit der Sinnesflächen stark, bei den Halluzinationen sei dagegen die letztere schwach und die erstere stark.

Sollte nun nicht, wenn überhaupt eine Reperzeption bei der Erweckung der abnormen Bewußtseinsgebilde in den Sinnesstätten eine Rolle spielen würde, der umgekehrte Schluß viel näher liegen? Wir sehen $\mathrm{ja}$, und es ist jedem Psychiater bekannt, daß für den halluzinatorischen Charakter eines Bewußtseinsgebildes die sinnliche Deutlichkeit keine prinzipielle Rolle spielt. Und anderseits haben wir doch allen Grund zur Annahme, daß der Grad der sinnlichen Deutlichkeit offenbar abhängig ist von der Stärke der Erregung, die sich in den Sinneszentren selbst abspielt. Jede andere Annahme müßte doch unnatürlich erscheinen. Wir würden also offenbar umgekehrt schließen müssen wie Kraepelin. Ist die Reperzeption stark, dann entsteht eine Halluzi- 
nation, gleichgültig, ob die Erregung in den Sinnesstätten selbst schwach oder stark ist. Im ersteren Falle gibt es eine undeutliche, im letzteren Falle eine deutliche Halluzination. Ist aber die Reperzeption schwach und die Erregung in den Sinnesstätten stark, dann kommt es zu Pseudohalluzinationen.

Der Kraepelinsehen Erklärung ähnlich ist die von Grashe ${ }^{1}$ ). Dieser Autor verlangt für das Zustandekommen von Halluzinationen außer der Steigerung der Erregung in den corticalen Sinneszentren einen pathologischen Reiz in den Sinneszentren selbst. Dadurch würde die Unabhängigkeit vori zentraleren Stellen, also auch das Unabhängigkeitsbewußtsein bei der Halluzinationen selbst verbürgt. Kommt aber die Erregung in den Zentren durch Reize zustande, die auf den Asso. ziationsbahnen verlaufen, so ist die Verbindung mit zentraleren Stellen hergestellt und das psychische Korrelat ist ein Abhängigkeitsbewußtsein der entstandenen Pseudohalluzinationen.

Wir haben aber soeben gesehen, daß gerade bei Pseudohalluzinationen eine besonders starke Erregung der Sinnesstätten angenommen werden muß, und daß bei Halluzinationen ebenso und noch mehr wie bei Pseudohalluzinationen ein enger assoziativer Connex mit zentraleren Stellen angenommen werden muß, daran kann schon aus allgemein psychopathologischen Gründen ein Zweifel nicht existieren.

Die Annahme, daß die Stärke der Reperzeption - immer unter Voraussetzung der Anwendbarkeit dieses Begriffes überhaupt — ausschlaggebend für den echt halluzinatorischen Charakter des Bewußtseinsgebildes sei, lag freilich um so näher, als früher und von mancher Seite auch noch heute angenommen wird, dal3 zur Entstehung der Halluzination ein Zurückfliel3en der Erregungswelle durch den Sinnesnerv bis zur peripheren Sinnesflüche nötig sei. Diese Annahme wie überhaupt jeder Erklärungsversuch, der eine periphere oder auch nur subcortical supponierte Reizstelle mit in Rechnung zieht, hat nun freilich dadurch immer mehr an Kredit verloren daß man einsah, daß zur Entstehung der Halluzination die Mitwirkung peripherer oder subcorticaler Reize gar nicht nötig ist. Man kann optische Halluzinationen auch nach Enucleierung des Auges, auch nach vollständiger Atrophie der Sehnerven, sogar bei Degeneration der subcorticalen Gehirnabschnitte produzieren.

Wie wenig mit dem Begriff der Reperzeption anzufangen ist, möchten wir noch an einem anderen Autor beweisen, der sich sehr um die Klärung des Halluzinationsproblems bemüht und dabei vom Reperzeptionsbegriff die ausgiebigste Anwendung gemacht hat. Berze sagt wörtlich so: Tritt zunächst die rein intellektuelle Komponente auf und gesellt sich dadurch, daß die Aufmerksamkeit auf sie gerichtet wird,

1) Grashey, Über Halluzinationen. Münchn. med. Wochenschr.. 1893. 
die sinnliche Komponente hinzu, so haben wir eine - sinnlich betonte - Vorstellung; tritt die sinnliche Komponente ohne Willensbetätigung des Individuums, bei sozusagen passivem Verhalten desselben, zugleich mit der intellektuellen Komponente ins Bewußtsein, so handelt es sich entweder um eine Wahrnehmung - wenn die Quelle der Erregung durch ein Objekt gegeben ist - oder um eine Halluzination wenn die Quelle der Erregung in pathologischen Umänderungen der psychischen Tätigkeit zu suchen ist ${ }^{1}$ ).

Zunächst könnte im letzten Falle die Halluzination aber auch auftreten, wenn die Quelle der Erregung in pathologischen Veränderungen der peripheren Sinnesflächen läge und von hier aus aufs Zentrum wirkte. Sodann ist nicht einzusehen, warum nicht in diesem Falle auch eine Pseudohalluzination auftreten sollte, da bei dieser doch das Verhalten des Individuums ebenfalls ein passives ist und aller Grund zur Annahme wäre, daß die primäre Erregung sich in den Sinnesstätten abspiele. Und warum sollte im ersteren von Berze angeführten Falle nicht eine Halluzination auftreten, besonders wenn wir an den Bewußtseinszustand des Paranoikers denken, bei dem doch aus dem wahnhaften Komplexe die Halluzinationen hervorzugehen scheinen! Sogar eine Pseudohalluzination müssen wir aus früher erörterten Gründen in diesem Falle erwarten können. Und schließlich sehen wir gar, daß durch die Willensintention des Kranken Individuums, durch Lenkung der Aufmerksamkeit, d. h. also einen zentral ausgelösten Erregungsvorgang unter Umständen Halluzinationen und Pseudohalluzinationen ins Bewußtsein gerufen werden können.

Berze glaubt den Begriff der Reperzeption nicht entbehren zu können. Wir glauben mit ihm nichts anfangen zu können, da wir mit ihm alles erklären können.

Jendrassik ${ }^{2}$ ) hält sogar schon aus leitungsphysiologischen Gründen das Vorhandensein einer zentrifugal gerichteten Erregung für unmöglich. Die Perzeptionszellen seien entsprechend ihrer Funktion als Aufnahmeapparate nur für die von der Peripherie zufließenden Reize gebaut. Sie könnten deshalb sogar schon aus anatomischen Gründen gar nicht für Reize von einer zentraleren Stelle empfänglich sein.

Nun möchten wir zwar annehmen, daß prinzipiell eine jede Rindenzelle von der anderen, sei es direkt, sei es indirekt, Erregungen erhalten kann $^{3}$ ). Nur insoweit wird man Jendrassik recht geben müssen, als

1) Berze, Bemerkung zur Theorie der Halluzinationen. Archiv f. Psych. 46. 1013.1910.

2) Jendrassik, Über die Entstehung der Halluzinationen und des Wahns. Neur. Zentralbl. S. 1089 f. 1905.

3) Das nahm offenbar auch Pa r i sh (Über die Trugwahrnehmung, Leipzig 1894) an. Er meinte aber, daß der über die Assoziationsfasern zufließende Reiz wieder 
der physiologische Wert der intracerebralen, sei es zentrifugalen oder zentripetalen, Erregungen sich nicht gut vergleichen läßt mit dem physiologischen Wert eines von der Sinnesperipherie an das (Kehirn herantretenden Nervenstromes. Aber mit Rücksicht auf die bis auf den Externalitätsfaktor bestehende Gleichheit zwischen Halluzinationen und Pseudohalluzinationen erscheint es zunächst unmöglich, mit leitungsphysiologischen Betrachtungen den Fntstehungsbedingungen beider auf den Grund zu kommen.

Um gehirnphysiologische Hypothesen über Halluzinationen aufzustellen, braucht man nun freilich einen Reperzeptionsvorgang nicht hinzuziehen. Aber die Ansichten, bei deren Begründung von einem solchen abgesehen wird, können uns wohl noch weniger befriedigen.

Da kommt zunächst die von Jendrassik selbst in seiner kleinen geistreichen Abhandlung (1. c.) aufgestellte Hypothese in Betracht. Dieser Autor, der von vornherin nicht nur die Idee einer immateriellen Seele abweist, sondern auch von einer solchen als seelischer Funktion im Gegensatz zu der Funktion der nervösen Zellelemente nichts wissen will ${ }^{1}$ ), behauptet, daß nicht ein lokalisierter krankhafter Reiz die Ursache des Wahns, der Halluzination sei, sondern eine Idee, die sich auf vorbereitetem Terrain festsetze. Letzteres aber sucht er in einem hereditären mangelhaften Entwicklungszustande des Nervensystems, der seinerseits wieder in unternormaler Größe, unvollendeter Form, vielleicht unvollkommener chemischer Konstitution oder ungenügender Isolierung der Zellen und ihrer Ausläufer beruhen soll. Sowie bei einer (Orgel eine Taste stecken geblieben ist, so soll im Paranoikergehirn eine Assoziation offenstehen. Dort ist ein Ventil, hier das anatomische Substrat einer Assoziation insuffizient. Es läßt dauernd Erregungen durch wie die insuffiziente Klappe Blut im Herzen. Befindet sich diese insuffizient gewordene Assoziation auf sensorischem Gebiet, so hat der Kranke Halluzinationen, hingegen einen Wahn, wenn sie im motorischen Lager der Wortbilder entstanden ist.

Soweit uns die Literatur bekannt ist, hat man nicht versucht, zu dieser Theorie im einzelnen Stellung zu nehmen. In der Tat dürfte das auch sehr schwierig sein. Denn man kann wohl von ihr sagen: Soviel Worte, soviel Hypothesen. Man kann mit dieser Theorie um so weniger etwas anfangen, als sich in ihr wohl dieselbe unkritische Vermischung naturwissenschaftlicher und philosophischer (besser gesagt ideeller) Gesichtspunkte findet, welche der Autor gleich am Eingang seiner Betrachtungen einem großen Teil der bisherigen Theorien über

abfließt, um die nächste Vorstellung zu erwecken. Er fordert deshalb zur Realisierung der Halluzinationen eine Verstopfung der Ableitung. Die Gründe, auf welche er diese Verstopfung stützt, wiederlegt treffend Sẗ̈rring (l. c. S. 75.)

1) Man kann beide anerkennen, ohne sie in Gegensatz zucinander zu stellen. 
die Halluzination vorwerfen zu müssen glaubt. Denn was man sich unter einer Idee vorstellen soll, die an einer insuffizient gewordenen Stelle des Hirns, etwa an einer infolge mangelhafter Ausläufer isolierten Zelle, stecken geblieben ist, wird sich wohl nicht gut explizieren lassen.

Viel konsequenter, bis ins einzelne fein durchdacht, ist die komplizierte Theorie, welche neuerdings Goldstein über den hirnphysiologischen Vorgang aufgestellt hat, welcher dem Wahn und der Halluzination zugrunde liegen soll.

Der Autor geht von der durch Psychologie und Psychopathologie erhärteten Erfahrung aus, daß begriffliches Denken und Vorstellen in einem gewissen Gegensatze zueinander stehen. Je stärker jenes ausgebildet ist, um so schwächer dieses. Wer viel abstrakt zu denken gewohnt ist, dessen Vorstellungen entbehren der sinnlichen Lebhaftigkeit. Zwangsvorstellungen führen gewöhnlich nicht zu Halluzinationen trotz starker Erregung des nichtsinnlichen Anteils der Vorstellung. Wo haben wir also den Grund jener Erregung im Sinnesfelde, welche zur Halluzination führt, zu suchen?

Der Autor macht folgendes Bild: Stellen wir uns die Gehirnerregung, welche wir als materielles Korrelat des geistigen Lebens zu betrachten haben, in Wellenbewegungen vor, deren Form das Qualitative, deren Amplitude die Stärke der Erregung ausmacht, so haben wir uns offenbar die Wellenbewegungen im Sinneszentrum und im einheitlichen „Begriffsfeld" zur Erregungseinheit verbunden zu denken, was z. B. die Einheit der Erinnerungsbilder, die sog. Merksysteme Hirts, beweisen sollen. Nun bewirkt eine Erregung des sinnlichen Anteils auch eine Erregung des nichtsinnlichen Anteils der Vorstellung. (Das ist ja der gewöhnliche Weg des durch Wahrnehmung und Vorstellung in Bewegung gesetzten begrifflichen Denkens.) Der umgekehrte Weg ist aber, wie wir soeben sahen, nur bis zu einem gewissen Grade möglich, da ja abstraktes Denken der sinnlichen Lebhaftigkeit der Vorstellungen abträglich ist. Durch verschiedenen Leistungswiderstand in den verschiedenen Richtungen wäre das nicht zu erklären; denn da wir im Sinneszentrum und im Begriffszentrum ihrer Eigenart entsprechend spezifische Erregungsformen, Wellenformen, annehmen müssen, so könne von einer direkten Krregung beider Zentren durcheinander überhaupt nicht die Rede sein. Es könne sich nur um die vermittelte Auslösung einer Erregung durch die andere handeln. Und wie kommt diese Auslösung zustande? Durch die Abhängigkeit beider Erregungen von der ,nutritiven“ Erregung, die im ganzen konstant ist. Je größer die Erregung im Begriffsfelde ist, um so geringer muß sie im Sinnesfelde sein, und umgekehrt; und dieser umgekehrte Fall, bei welchem also die Erregung im Sinnesfelde groß, im Begriffsfelde gering ist, liegt der Wahrnehmung einerseits und der Halluzination andererseits zugrunde. 
Wenn wir nun diese Theorie auf die Entstehung der Halluzinationen anwenden wollten, so wäre wohl die nächste Voraussetzung, daß bei diesen die Erregung im Begriffsfelde, wenn wir nun einmal zunächst ein solches im Gegensatz zur Sinnesstätte annehmen wollen, herabgesetzt ist. Das könnte doch aber nur heißen, daß der Halluzinant ganz allgemein eine Abschwächung im Bereich der begrifflichen Sphäre aufweist. Sofern man nun überhaupt vor einer Intensität im begrifflichen Denken sprechen kann, wird davon allgemein bei den Psychosen keine Rede sein können. Mit welchem Aufwande von Denkenergie der Paranoiker die vermeintliche Realität seiner Halluzinationen wie seines Wahnsystems überhaupt zu begründen und verteidigen vermag, ist ja bekannt.

Goldstein führt nun als Beweis für die Richtigkeit seiner Behauptungen die Fieberdelirien an, bei welchen ja die Sinnesstätten offenbar in starker Erregung sich befinden. Den sehr nahe liegenden Einwand, daß bei diesen Delirien wie bei den Delirien überhaupt, die ganze Hirnrinde in starker Erregung ist, übersieht freilich der Autor nicht. Aber als Zeichen für eine Herabsetzung der Erregung des Begriffsfeldes im Verhältnis zur Sinnesstätte sieht er die mangelhafte Auffassung und Verwirrtheit an, welche wir ständig bei Deliranten finden, ja das eigentliche Kennzeichen des Deliriums ist.

Hier zeigt sich noch deutlicher die Unhaltbarkeit der Voraussetzung, auf welcher der Autor seine Schlüsse aufbaut. Denn es wird Stärke der Erregung des Begriffsfeldes als materielles Korrelat eines begrifflich klaren Denkens angenommen.

Läßt man nun unbefangen die psychischen Phänomene, welche uns im Zustande des Gesunden und Deliranten entgegentreten, auf sich wirken, so wird man wohl den umgekehrten Schluß machen müssen. Man wird sagen müssen, daß gerade die übermäßige Stärke der Erregung im Begriffsfelde das klare Denken und die Aufrechterhaltung eines ungetrübten Bewußtseinszustandes verhindert. Nur bei normaler Erregung ist es dem Individuum möglich, das zum begrifflich klaren Denken erforderliche mäßige Tempo in der Vorstellungs- und Gedankenproduktion einzuhalten und die Verwirrung des Bewußtseins zu verhindern, welche sich als Folge einer übermäßig starken Erregung der Hirnrinde und der daraus resultierenden abnorm schnellen Produktion der in inhaltliche Beziehungen zueinander nicht mehr zu bringenden Masse von Vorstellungen ergibt. Es kann also von einer relativen Herabsetzung der Erregung des Begriffszentrums im Gegensatz zur Erregung in der Sinnesstätte nicht die Rede sein.

Warum denn aber überhaupt die Annahme einer Vermittlung der beiden Erregungsstätten durch die ,nutritive " Erregung? Wir wiesen schon oben darauf hin, daß wir zunächsț alle Zellen der Hirnrinde mit- 
einander in Verbindung stehend zu denken haben. Es liegt doch für die durch Hypothesen nicht voreingenommene Betrachtungsweise gar kein Grund vor, der gegenseitigen Beeinflussung der im allgemeinen biologisch gleichwertigen Ganglienzellen durcheinander nach der einen Richtung eine größere Schranke zu setzen wie nach der anderen, ja überhaupt eine prinzipielle Schranke anzunehmen.

Von weiteren Einwendungen, welche sich gegen die Verwendung des Begriffes der nutritiven Erregung in seiner Beziehung zu den psychischen Funktionen in der Darstellung des Autors aufdrängen, wollen wir absehen. Wir wollen nur noch den Kern der ganzen Hypothese kurz auf seine Haltbarkeit prüfen.

Welcher Grund liegt denn überhaupt vor, bei der Erklärung der Halluzination von der Beziehung des begrifflichen Denkens zur sinnlichen Lebhaftigkeit der Vorstellungen auszugehen? Die Halluzination ist ja uberhaupt nicht in genetische Beziehung zum begrifflichen Denken zu bringen. Nicht die krankhafte Veränderung der Denk-, sondern der Gefühlssphäre erkannten wir als psychopathologische Ursache der Halluzination. Und Goldstein selbst ist dieser Annahme sehr nahegekommen, wenn er z. B. auf die ursächliche Beziehung des Mißtrauens, welches doch ein Gefühl ist, zur veränderten Auffassung der Umgebung hinweist. Es müßte also zunächst das materielle Korrelat der Gefühlssphäre lokalisatorisch oder funktionell abgegrenzt werden, um Hypothesen über die Beziehung dieser zur Sinnesstätte aufzubauen. Daß eine solche Abgrenzung noch mehr in der Luft schweben würde wie die Abgrenzung eines Begriffsfeldes, darüber ist wohl kein Wort weiter zu verlieren.

Und wo bleiben die Pseudohalluzinationen, die - nebenbei gesagt in der Theorie Jendrassiks und vieler anderer Autoren überhaupt keine Stätte finden? Von diesen sagt Goldstein ganz kurz, daß sie sich wohl durch Erregung anderer Hirnstätten werden erklären lassen als derjenigen, welche bei der Erklärung der Halluzination in Frage kommen.

Wir wollen diese Andeutung weiter ausführen, um zu zeigen, daß auch dieser Weg ungangbar ist.

Da der Unterschied zwischen Halluzination und Pseudohalluzination im Externalitätsfaktor, d. h. darin liegt, daß jene im äußeren Raum objektiviert werden, diese jedoch im sog. Bewußtseinsraum erscheinen, in welchem uns die Erinnerungsvorstellungen vor das ,innere Auge" treten, so liegt zunächst die Annahme nahe, da $B$ im ersteren Falle die Zellen des von vielen Autoren supponierten „Perzeptionszentrums", im zweiten Falle diejenigen des „Erinnerungszentrums" in lirregung gesetzt werden.

Für diese Annahme scheinen die Unterlagen gegeben zu sein in 
den Erfahrungen, welche man einerseits auf dem (iebiete der Aphasie, andererseits in dem Vorkommen der sog. Seelenblindheit und Seelentaubheit gemacht hat. Sie scheinen uns zu lehren, daß einerseits Wahrnehmungen gemacht werden können, während die Erinnerungsvorstellungen ausgefallen sind, und anderseits letztere wohl vorhanden sein können, ohne da 3 die Möglichkeit für erstere besteht. Im ersten Falle sieht und hört man, ohne das Gesehene und Gehörte agnostizieren zu können, im zweiten ist von Sehen und Hören keine Rede, aber die ,gnostischen" Fähigkeiten sind vorhanden, wie uns das ungestörte Denken, Sprechen und Handeln beweist.

Nun wird es freilich niemand für möglich halten, die Halluzinationen einfach auf reiner Erregung der Perzeptionszellen, die Pseudohalluzinationen auf eine solche der Erinnerungszellen zurückzuführen. Denn bei den Halluzinationen müssen ja doch auch die Erinnerungszellen eine Rolle spielen, weil sonst gar keine Trugwahrnehmungen zustande kommen könnten. Ebenso wie die normale Wahrnehmung ist auch die Trugwahrnehmung subjektiv ein Erkenntnis-, ein Apperzeptionsvorgang, bei welchem also stets eine Frweckung der Vorstellungsresiduen stattfinden muß. Auf der anderen Seite scheint doch die sinnliche Lebhaftigkeit der Pseudohalluzinationen unbedingt auch eine Erregung der Perzeptionszellen zu verlangen.

Vielleicht findet sich aber jemand befriedigt durch die Annahme, daß bei den Halluzinationen die sog. Perzeptionszellen, bei den Pseudohalluzinationen die sog. Erinnerungszellen im stärkeren Maße in Erregung geraten. Eigentümlich wäre nur, daß in vielen Fällen die Pseudo halluzinationen an sinnlich lebhafter Färbung die Halluzinationen übertreffen, also eine stärkere Erregung der Perzeptionszellen zu verlangen scheinen. Eigentümlich wäre ferner, da $\beta$ halluzinierende Individluen, welche an Hemianopsie leiden, ihre Visionen meistens in die ausgefallene Gesichtshälfte verlegen. Auf der anderen Seite müßte man verlangen, daß Individuen, welche an zentraler Taubheit oder Blindheit (doppelseitiger Hemianopsie) leiden, wemn sie geistig erkranken, überhaupt nicht mehr halluzinieren, sondern nur noch pseudohalluzinieren können. ()b die bisherigen Beobachtungen, sofern solche überhaupt an geistig erkrankten Individuen mit zentraler Blindheit und Taubheit gemacht werden konnten, mit diesen Voraussetzungen übereinstimmen? Von den Einwendungen, welche von vornherein gegen die scharfe Trennung eines Perzeptionszentrums von einem Erinnerungszentrum gemacht werden können, sehen wir dabei völlig ab.

Man könnte vielleicht noch eine andere Hypothese konstruieren. Man könnte annehmen, daß bei den Pseurlohalluzinationen überhaupt zentralere Gebiete, etwa das sog. Begriffsfeld, das ja ebenfalls sein Material bei den Apperzeptionsvorgängen liefern muß, in größere Er- 
regung geriete, bei den Halluzinationen aber die Sinnesstätte (Perzeptions- + Erinnerungszellen) stärker gereizt wird. Wenn nur auch diese Hypothese sich irgendwie durchführen ließe!

Angesichts der Unmöglichkeit, eine irgendwie befriedigende hirnphysiologische Hypothese zur Erklärung der Halluzination und Pseudohalluzination durchzuführen, erscheint es wohl geraten, zunächst von der Konstruktion solcher Hypothesen, die uns aus bald zu erörternden Gründen prinzipiell nie zum Ziele führen können, abzusehen. Vielmehr scheint es erforderlich, sich zunächst ein Bild von den Gehirnvorgängen, welche den normalen Bewußtseinsäußerungen zugrunde liegen, zu machen, um dann zu fragen, ob wir irgendeinen Grund haben, einen veränderten Leitungsvorgang oder eine besondere lokalisatorisch $a b$ grenzbare Erregung als Ursache des Wahns und der Halluzination anzuschuldigen.

Wir wollen die erste Frage gleich dahin spezifizieren, ob und inwieweit wir bei den normalen Bewußtseinsvorgängen zu lokalisatorischen Annahmen in bezug auf die zugrunde liegenden Hirnprozesse berechtigt sind.

Da werden wir zu bedenken haben, daß schon bei denjenigen gehirnphysiologischen Vorgängen, welche wir auf Grund der Auffindung der Rindenzentra bis zu einem gewissen Grade lokalisiert zu denken haben, dennoch, wie sich mit einiger Ubberlegung nachweisen läßt, immer die ganze Hirnrinde in Erregung sich befindet. Wir dürfen nämlich nicht vergessen, daß jeder Perzeptionsvorgang zugleich, wie früher ausführlich erläutert, ein Apperzeptionsvorgang ist, daß in jeder Wahrnehmung die Residuen all der früheren Erfahrungen, die wir auf sämtlichen Sinnesgebieten an dem betreffenden Gegenstand und der ihm ähnlichen und mit ihm in irgendeiner Beziehung stehenden Gegenständen gemacht haben, mit anklingen, daß zugleich in der Apperzeption das Resultat all der mannigfaltigen Denkprozesse, welche sich auf Grund der betreffenden Erfahrungen in unserem Geiste abgespielt haben, in Wirksamkeit tritt, daß auch all die Gefühlstöne, sei es die primären mit den Empfindungselementen gegebenen, sei es die sekundären, durch die Assoziation angeregten Gemütsgefühle durch den Apperzeptionsvorgang in mehr oder minder intensivem Grade zu neuem Leben erweckt werden, daß schließlich der Niederschlag aller unserer Wollungen, unserer Instinkte und Triebe durch den Apperzeptionsvorgang mehr oder minder deutlich über die Schwelle des Bewußtseins nachgezogen wird oder doch werden kann.

Wer sich das alles nach seiner ganzen Weite und Tiefe vergegenwärtigt, dem ist es sofort klar, daß schon im Wahrnehmungsvorgang keineswegs ein lokalisiertes Rindenzentrum, sondern die gesamte Hirnrinde tätig ist. 
Auf die Erfahrungen, welche uns die neuesten Fortschritte der Aphasielehre gebracht haben, wollen wir nur hindeuten. Denn auch diese scheinen immer mehr von der Annahme einer streng lokalisierten Hirnfunktion abzuführen, vielmehr immer deutlicher zu beweisen, daß3 der Begriff der Rinden,,zentra" nur in relativem Sinne zu nehmen ist, daß wir diese Zentra nur als besonders ausgebildete Durchgangs- und Knotenpunkte für bestimmte Erregungen zu betrachten haben.

Was von der Wahrnehmung gilt, ist in noch viel höherem Grade von dem Vorstellungsleben anzuerkennen. Wir denken mit der gesamten Hirnrinde, oder um die eine materialistische Auffassung präsumierende Ausdrucksweise zu vermeiden: unsere gesamte Hirnrinde ist in Tätigkeit, wenn wir denken. Ein besonderes Zentrum für das Denken anzunehmen, welches in jedem einzelnen Denkvorgange ebenfalls das Resultat aller früheren Sinneserfahrungen, aller früheren Denkprozesse und der mit diesen verknüpften Wollungen und Gefühle mit verwertet, ist schon kaum mehr als naiv, ist als eine vollkommene Verkennung des Wesens des Denkprozesses zu bezeichnen.

Im Denkvorgange, der seinen Inhalt aus dem Erfahrungsmaterial nimmt, welches uns ursprünglich die Sinnesorgane zugeführt haben, werden nun die Vorstellungsresiduen, die den spezifischen Wahrnehmungsfunktionen entsprechen, wieder in mehr oder minder starkem Grade neu erweckt. Es findet ein stetes "Mithalluzinieren“ der Sinne statt, wio sich Griesinger ausdrückte. Dieses Mithalluzinieren ist aber nach dem Vorhergesagten nun nicht als zustande gekommen durch einen Reperzeptionsvorgang zu denken, sondern als ein mehr oder minder starkes Erregtwerden gewisser Rindenstellen bei dem im übrigen a die gesamte Hirnrinde sich erstreckenden Er. regungsvorgange.

In derselben Weise haben wir uns den Erregungsvorgang über die gesamte Hirnrinde, nur mit Bevorzugung bestimmter Hirnabschnitte, ausgebreitet zu denken, wenn wir von dem logischen Prozeß, in welchem sich beim Menschen das Denken in engerem Sinne abspielt, absehen, wenn wir nur auf das in einem assoziativen Zusammenhang stehende Spiel der Vorstellungen reflektieren, das wir z. B. bei den Tieren, bei welchen es ein Denken im spezifisch logisch-menschlichen Sinne wohl nicht gibt, als allein vorhanden ansehen müssen. Denn auch die Vorstellungen als solche stehen in einem inneren Zusammenhange, der bestehen bleibt, selbst wenn wir von dem Denken im eigentlichen Sinne des Wortes abstrahieren.

Das wird uns besonders deutlich, wenn wir schließlich das gesamte Gefühlsleben, die Affekte, Wollungen, Instinkte und Triebe berücksichtigen, mit welchen die Vorstellungen aufs engste vorknüpft sind. welche sogar im allgemeinen als das Motiv für die eimzelne im BewuBt- 
sein auftretende Vorstellung anzusehen sind. Für diese Wollungen, Gefühle, Instinkte und Triebe aber ein lokalisatorisch abgrenzbares Rindenzentrum anzunehmen, muß ebenfalls als ohne weiteres indiskutabel bezeichnet werden.

Wenn schließlich in unserem Bewußtsein manchmal eine sinnlich betonte Vorstellung, Gehörs-, Geruchs-, Gesichts- usw. -Vorstellung auftaucht, für die wir im Augenblick einen Zusammenhang mit anderen Vorstellungen, mit dem jeweiligen Denkprozeß, mit unserer augenblicklichen Stimmungslage usw. nicht aufzuweisen vermögen, so ist das natürlich nur ein Beweis dafür, daß ein solcher Zusammenhang im augenblicklichen Bewußtseinszsutand nicht aufzufinden ist ${ }^{1}$ ), aber nicht dafür, daß ein solcher Zusammenhang überhaupt nicht vorhanden ist. Denn die unter- und außerbewußten Verbindungen entziehen sich bei der ungeheueren Kompliziertheit des seelisch-geistigen Lebens in vielen Fällen unserer Kenntnis.

Aus alledem geht hervor, daß beim normalen Vorstellen jedenfalls von einem Reperzeptionsvorgang nicht die Rede sein kann, sondern nur von einem über die gesamte Hirnrinde sich erstreckenden Assoziationsvorgange, bei welchem bestimmte Assoziationsglieder - sinnliche Vorstellungsresiduen - mit erweckt werden. Die Modalität dieser zu einer Bewußtheit erweckten Residuen hängt von der Denk- und Aufmerksamkeitsrichtung, der Grad ihrer sinnlichen Deutlichkeit einmal von der Stärke der Aufmerksamkeit und zweitens von der individuellen Anlage ab. Der eine ist imstande, mehr seine optischen, der andere mehr seine akustischen, motorischen usw. Vorstellungsresiduen zu größerer Lebhaftigkeit anzuregen.

Haben wir nun irgendwelchen Grund zur Annahme, daß die allgemeinen Leitungsbedingungen für die Erweckung von Halluzinationen bei Geisteskrankheiten andere sind als die oben gekennzeichneten? Wir meinen, nicht den geringsten. Warum sollte sich denn der Leitungsvorgang als solcher anders verhalten? Welche Eigentümlichkeiten des pathologischen Denkens, Fühlens und Wollens erfordern das? Der Umstand, daß bei Geisteskrankheiten das häufig als Halluzination erscheint, was unter normalen Umständen sich in unserer Phantasie vielleicht nur als eine lebhaft sinnlich betonte Wunsch-oder Abwehrvorstellung kundgibt, kann doch nun unmöglich auf einmal den Leitungsvorgang im Gehirn prinzipiell umwandeln. Und selbst wenn das geschehen könnte, so wäre noch immer nicht einzusehen, wie diese Umwandlung eine Halluzination hervorrufen sollte.

Auf die von der Peripherie ausgelösten Halluzinationen bei Frkrankungen von $\mathrm{Ohr}$ und Auge werden wir uns aber nicht berufen können.

1) Nur in diesem sinne nehmen wir auch ein ,freies Aufsteigen“ der Vorstellungen, von dem wir früher sprachen, an. 
Denn erstlich trifft hier der Reiz die zentrale Sinnesstätte auf demjenigen Wege, auf welchem auch unter normalen Umständen das mit dem Wahrnehmungscharakter ausgestattete Bewußtseinsgebilde erweckt wird. Zweitens aber haben wir gesehen, daß auch bei den auf diese Weise zustande kommenden Halluzinationen eine neuropathische Prädisposition, d. h. abnorme Erregbarkeit der gesamten Hirnrinde, angenommen werden muß. Denn die Halluzinationen, welche auf diesem Wege ausgelöst werden, sind, abgesehen von elementaren Sensationen, komplizierte Gebilde, welche zudem ihren Zusammenhang mit gewissen Gefühlskomplexen ebenso verraten wie die Halluzinationen der Geisteskranken. Dabei ist es dann auch ganz gleichgültig, ob die Halluzinationen nur so lange vorhanden sind wie der äußere Reiz ${ }^{1}$ ).

Zugleich fällt mit der Annahme eines veränderten Leitungsvorganges auch die Annahme einer besonderen lokalen Reizung und Erregung, von welcher $\mathrm{Heveroch}^{2}$ ) mit Recht urteilt, daß sie viel zu plump sei, um die Entstehung der Halluzination zu erklären. Das Wesentliche ist und bleibt, wie sich gerade aus der Entstehung der peripher ausgelösten Halluzination erkennen läßt, eine Prädisposition des gesamten Gehirns.

Was ist also nun im allgemeinen der eigentliche Grund der Halluzination? Darauf können wir nur antworten: die Geisteskrankheit selbst. Wenn wir normal sind, so stellen sich die reproduzierten gegenständlichen Bewußtseinsgebilde eben in der normalen Weise, mit dem Vorstellungscharakter behaftet, vor unser Bewußtsein. Werden wir geisteskrank, so können gewisse reproduzierte Gebilde den Wahrnehmungscharakter annehmen. Im übrigen können wir nur auf das in der vorigen Nummer Ausgeführte hinweisen. Wir haben da auseinandergesetzt, daß aus der pathologischen Steigerung der Grundmodifikationen

1) In diesem Sinne ist auch der Fall Hudovernings (Ein Fall von peripher entstandener Sinnestäuschung; Gau ps Centralbl. 29. 1906) zu beurteilen, bei welchem ein im Gehörgange steckender Wattepfropf Gehörstäuschungen auslöste, die nach der Entfernung desselben sofort sistierten, nach Wiedereinbringung sich aber ebenso prompt wieder einstellten. Hudoverning bemerkt selbst ausdrücklich, daB es sich um ein neuropathisches Individuum handelt.

In der Literatur findet sich noch eine große Anzahl von Mitteilungen über peripher ausgelöste Halluzinationen. Man kann aber bei ihnen allen mit Sicherheit sagen, daß der periphere Reiz nur die entferntere Bedingung war, die eigentliche Ursache für die Entstehung der Halluzination aber in der gesamten Hirnrinde lag. Besonders deutlich wird das in dem Fall von Jolly (Beiträge zur Theorie der Halluzination, Archiv f. Psych. 4), in welchem der Autor durch elektrische Reizung des Gehörsgangs sogar komplexe Halluzinationen auslösen konnte. In einem von Hoche erwähnten Fall mit Hemianopsia inferior erschienen dem Kranken die Gesichtshalluzinationen am Fixierpunkt wie abgeschnitten. 1)er Autor erklärt selbst den Fall für einen funktionellen. Ännlich sind die übrigen Fälle peripher ausgelöster Halluzinationen aufzufassen.

$\left.{ }^{2}\right)$ Heveroch l. c. 
des Gefühls, wie sie den Affektpsychosen, und aus der Umwandlung und Steigerung der Gefühlsreaktionen, wie sie den paranoischen Psychosen zugrunde liegen, die Halluzination hervorgeht. Wir haben auch auf die Halluzinationen und Pseudohalluzinationen hingewiesen, die wir bei Psychopathen und Hysterischen mit starkem Affekt- und Phantasieleben und auf dem Grunde lebhaft betonter Gefühle vorfinden.

Wenn man uns aber vorhalten sollte, daß wir hier nicht mehr bei der psychopathologischen, sondern bei der gehirnpathologischen Erklärung der Halluzination halten, und daß wir diese noch schuldig geblieben sind, so können wir nur erwidern, da $\beta$ wir überhaupt nicht die Aspiration hegen, die Halluzination gehirnpathologisch bzw. gehirnmechanisch, durch besonders lokalisierte oder gerichtete Leitungs- und Erregungsvorgänge irgendwelcher Art, in dem Sinne zu ,,erklären“", wie man dies von einer Erklärung im eigentlichen Sinne des Wortes verlangt. Wir können und wollen diese Erklärung aus dem einfachen Grunde nicht geben, weil wir damit den Erklärungsbegriff auf ein Gebiet übertragen würden, auf welchem er gar keine Anwendung finden kann. Es handelt sich hier wieder einmal um eine UUberspannung des Erklärungsbegriffs, um eine falsche Problemstellung.

Man wird sich zunächst vorhalten müssen, was wir von dem Begriff der „Erklärung"' in bezug auf das Verhältnis geistiger Vorgänge zu Gehirnvorgängen überhaupt verlangen dürfen. Erklären im kausalen Sinne des Wortes können wir, wie auseinandergesetzt wurde, auch nicht die normalen psychischen Vorgänge aus den normalen Gehirnvorgängen. Man kann doch weiter nichts sagen als: wenn die Gehirnrinde in ihrer Substanz normal ist und normal funktioniert, so haben wir normale Gefühle, Wollungen, Vorstellungen und Wahrnehmungen. Man kann deshalb auch weiter nichts sagen als: Ist die Gehirnrinde in ihrer Substanz erkrankt oder funktioniert sie nicht richtig, so sind auch die genannten psychischen Korrelate in ihren Äußerungen abnorm. Jene s pezielle psychische Abnormität aber, diewir Halluzination, nennen, kann erklärt werden nur aus psychopathologi schen Bedingungen, wie wir siez. B. im Früheren dargestellt haben.

Daß nicht aus einer ganz bestimmten Leitungsveränderung oder aus einer spezialisierten und lokalisierten Veränderung des Gehirns die Halluzination ,erklärt" werden kann, sollte uns schon die Tatsache lehren, daß alle Gehirnerkrankungen, welche mit Geisteskrankheit parallel gehen, zu Halluzinationen führen oder doch führen können. Der Hirnrindenprozeß kann dabei verschiedener Natur sein. Es kann sich um Degeneration und Schwund der Zellen handeln, wie bei Paralyse. Fs kann sich um eine Stoffwechselanomalie handeln wie wahrscheinlich bei der Dementia-praecox-(truppe, es kann sich um eine In- 
toxikation handeln, wie bei Alkohol-, Morphium- usw.-Vergiftung. Es kann sich um eine rein funktionelle Psychose handeln wie bei der Paranoia, beim manisch-depressiven Irresein, bei hysterischem oder degenerativem Irresein, kurz es kann sich um jede beliebige geistige Erkrankung handeln: jedesmal wird halluziniert oder kann doch halluziniert werden. Es wäre doch recht wunderbar, wenn jede dieser so verschiedenen substantiellen oder funktionellen Erkrankungen genau jene lokalisierte Reizung oder Leitungsveränderung hervorrufen sollte, welche als Ursache der Halluzinationen und Pseudohalluzinationen beschuldigt wird.

Wenn man also, was wir vom empirischen Standpunkt ja auch als durchaus zulässig, ja notwendig erklärten, eine kausale Beziehung zwischen körperlicher und psychischer Sphäre statuieren will, so kann man nur ganz im allgemeinen sagen: Wenn die Hirnrinde als Ganzes normal ist und normal funktioniert, dann ist der Mensch auch psychisch gesund; ist die Hirnrinde substantiell nicht normal oder funktioniert sie nicht normal, dann ist der Mensch psychisch erkrankt, und dann kann er auch halluzinieren und verabsäumt es auch meistens nicht.

Wir können also die Halluzination aus himpathologischen Bedingungen nur so weit erklären, als wir die Geisteskrankheit selbst aus solchen Bedingungen erklären können, und wie weit das geht oder nicht geht, das wissen wir ja. Denn über jene obige selbstverständliche Beziehung zwischen normaler Gehirnsubstanz und Funktion und normaler psychischer Funktion auf der einen Seite und pathologischer Gehirnsubstanz und -funktion und pathologischer psychischer Funktion auf der anderen Seite ist die ,Erklärung“ der Geisteskrankheit noch nicht hinausgekommen und kann es a uch prinzipiell nicht, da uns ja das Physische gar keine innere Beziehung zum Psychischen offenbart. So sehr wir auch unser Auge anstrengen, wir sehen unter dem Mikroskop immer nur Zellen und Gewebe, niemals etwas, was uns das geringste Geistige verriete. Man stellt eben die Aufgabe der Gehirnpathologie falsch, wenn man von ihr verlangt, sie solle aus dem Wesen der pathologisch-anatomischen oder funktionellen Veränderung die Art der psychopathologischen Symptome eruieren. Und wenn uns die Empirie lehrt, daß dieselben psychopathologischen Symptomenkomplexe sich auf dem Grunde prinzipiell verschiedener Gehirnveränderungen etablieren können, ja raß eine substantielle Gehirnveränderung als Ursache dieses selben Symptomenkomplexes überhaupt nicht vorhanden zu sein braucht, so sollte das doch ein genügender Beweis für die Unfruchtbarkeit aller theoretischen Spekulationen über den Hirnmechanismus sein, welcher den Halluzinationen und Pseudohalluzinationen substituiert werden könnte.

Wie wenig ein lokalisierter Prozeß geeignet ist, die Halluzination zu erklären, können uns auch die Hirntumoren lehren. Keineswegs 
rufen diese trotz der Reizung, die sie zweifellos auf die Umgebung ausüben, und die sich in so markanter Weise in den allgemeinen Hirndrucksymptomen kundgeben, Halluzinationen hervor, auch wenn sie direkt an den Stellen sitzen, in welchen wir die materiellen Korrelate der Erinnerungsbilder anzunehmen haben. Wenn aber dennoch Halluzinationen bei Hirntumoren hin und wieder beobachtet werden, so sind diese zugleich das Symptom einer Geisteskrankheit, welche offenbar durch die direkte und indirekte, zugleich aber über die ga nze Hirnrinde sich erstreckende Schädigung hervorgerufen wird. Und um solch eine Beeinträchtigung der Gesamthirnrinde herbeizuführen, braucht sich der Tumor keineswegs an den sog. Sinnesstätten zu etablieren.

Wir haben auch, meine ich, nicht den geringsten Anlaß, durch das gewonnene Resultat oder vielmehr durch den Nachweis der Unmöglichkeit für die kausale Erklärung der Halluzination ein spezielles gehirnpathologisches Resultat zu gewinnen, enttäuscht zu sein. Enttäuscht kann nur derjenige sein, welcher noch immer nicht die Hoffnung aufgibt, die spezielle Art normal psychischer und psychopathologischer Symptome aus speziellen Gehirnveränderungen zu erklären.

Eine Lokalisation psychischer Eigenschaften und Vorgänge etwa nach Art der Gallschen Schädellehre - wird ja wohl auch heute niemand vornehmen wollen. Es wird wohl auch niemand - ganz sicher sind wir dessen freilich nicht ${ }^{1}$ ) - die Absicht haben, etwa den Eifersuchts- oder Querulantenwahn lokalisatorisch zu erklären. Wenn jemand auf Grund irgendeiner Wahnbildung oder geistigen Erkrankung überhaupt, die ja in der Regel eine Bewußtseinseinwirkung in Form von mehr oder minder ausgesprochener Wahnbildung zur Folge hat, halluziniert, warum sollte da auf einmal eine der lokalisatorischen oder leitungsphysiologischen Erklärung bedürftige Änderung im Gehirn Platz gegriffen haben?

Aber es ist wohl klar, was überhaupt an diesem falsch gerichteten Erklärungsbedürfnis, das, wie wir sahen, schon zu so vielen vergeblichen Hypothesen geführt hat, Schuld trägt. Das ist die für die Gehirnpathologie außerordentlich, für die Psychiatrie im engeren Sinne nicht in demselben Maße bedeutungsvolle Auffindung der Sinnesstätten. Zu welchen weittragenden Ergebnissen die Entdeckung dieser für die Lehre von der Aphasie $^{2}$ ) geführt hat, ist bekannt.

Welche Schlüsse können wir aber für die Trugwahrnehmung aus der Bekanntschaft mit diesen Zentren ziehen? Etwa andere als für die

1) Wernicke hat das allerdings noch gewollt.

2) Die Ansicht Maries, daß es sich bei der Aphasie um eine Intelligenzstör'ung, also Geisteskrankheit im engeren Sinne, handle, ist wohl heute allgemein ad acta gelegt worden. 
Reproduktionsvorgänge überhaupt? Schon bei dieser findet ja, wie das so hübsch ausgedrückt worden ist, ein „Mithalluzinieren“ der Sinne statt. Wird man nun geisteskrank, so ist eben das Halluzinieren wirklich da. Die eventuelle Reizung oder Erregung im Gehirn erstreckt sich aber dabei über die gesamte Hirnrinde ${ }^{1}$.

Die wirkliche „Erklärung" der Halluzination aber liegt ebenso wie die Erklärung irgendeines normalen psychischen Vorganges, nicht auf der gehirnanatomischen und pathologischen Seite, sondern eben auf der psychischen. Wir ,erklären" die Reproduktion der normalen Vorstellungen aus den uns bekannten normalen Bedingungen für das Auftauchen eines im assoziativen Zusammenhange mit einer Leitvorstellung, einem Gefühle oder sonst einem psychischen Gebilde stehenden Vorstellungsresiduums und die Halluzination ,erklären“ wir aus der Umwandlung des schon normalerweise mit einem sinnlichen Anklang behafteten Vorstellungsgebildes in eine Trugwahrnehmung auf Grund der pathologischen Gefühlsveränderung.

Diese intrapsychische Erklärung wird man so lange als kausale Erklärung im vollen Sinne des Wortes gelten lassen müssen, als man wird zugestehen müssen, daß die Psychiatrie die Lehre von den - Geisteskrankheiten ist. So lange wird man eben erlauben müssen, daß der Psychiater die Symptome, welche er auf seinem Gebiet vorfindet, ebenso intrapsychisch erklärt, wie die anderen medizinischen Sonderdisziplinen die von ihnen zu erforsehenden körperlichen Symptome intrasomatiseh erklären.

Aber Geisteskrankheiten sind zugleich Gehirnkrankheiten, und dieser Umstand bewirkt es, daß nicht nur, wie hervorgehoben, die Hirnrinde jedesmal als Ganzes substantiell oder funktionell in Unordnung geraten ist, wenn das Individuum pathopsychische Symptome produziert, es kann auch, wenn es sich um sogenannte exogene Psychosen handelt, also um solche, deren Ursache wir in irgendeiner die Hirnrinde von der materiellen Seite angreifenden Schädigung zu suchen haben, die bestimmte Art, in welcher sich ein im übrigen intrapsychisch zu erklärendes symptom äußert, lurch jene materielle Krankheitsursache modifiziert werden. Nur insofern haben wir dann die kausale Erklärung auf der somatischen Seite zu suchen. Diese Modifikation zeigt sich auch bei der Halluzination. Trotzdem sie als psychopathologisches Elementarsymptom intrapsychisch zu erklären ist, gibt es Modifikationen an ihr, für welche wir unter bestimmten Umständen die Ursache in der Art des zugrunde liegenden somatischen Krankheitsprozesses zu suchen haben. Wenn der

1) Vgl. dagegen die ausgedehnte, u. E. aber unfruchtbare Diskussion zwischen Goldstein und Berze über die Erregung, Erregbarkeit, Reizung usw. der Sinnesstätten bei der Halluzination. 
Alkoholdelirant besonders schnell bewegte Tiere, der Kokaindelirant winzige Einzelheiten, wie kleine Löcher, Flecken usw. halluziniert, der Morphium- oder Fieberdelirant seine Halluzinationen wieder in anderer Form produziert, so sind das Modifikationen, die eben ihre Ursache in der spezifischen Art des krankhaften Rindenprozesses haben, die wieder ihre somatische Ursache in der Art des angreifenden Giftes hat.

Ebenso steht es zum Teil mit den Besonderheiten der Halluzinationen bei der Dementia praecox und der Dementia paralytica. Auch hier sind es spezifische Krankheitsgifte, die indirekt modifizierend auf die Art der psychopathologischen Symptome, also auch der Halluzinationen wirken müssen. Es sind ja auch noch andere klinische Eigentümlichkeiten, durch welche sich diese Psychosen voneinand erunterscheiden, und die ebenfalls ihre Ursache in der spezifischen exogenen Noxe und in anderen Umständen (Altersunterschiede!) haben. Aber niemals ist auch bei allen diesen exogen verursachten Psychosen die Halluzination als solche durch das Gift zu erklären, sondern durch die Geisteskrankheit, welche der somatischen Erkrankung, d.h. also hier derHirnrindenerkrankung, parallel geht.

Ja, in der psychopathologischen Erklärung der Halluzination sind wir weit besser gestellt als in der somatischen Erklärung ihrer Modifikationen. Niemals werden wir, selbst wenn wir die durch exogene Gifte, etwa durch Alkohol oder Kokain, bewirkte Hirnrindenveränderung bis in die Atomverschiebung kennen gelernt haben würden, imstande sein, anzugeben, warum nun bei dieser Art von Atomverschiebung der Delirant Mäuse und Schlangen, bei der anderen Löcher und Flecken sieht. Denn es gibt eben keine Brücke vom Materiellen zum Psychischen. Die psychopathologische Erklärung der Halluzination als solcher aber in der früher dargestellten Weise ist im Prinzip widerspruchslos und plausibel und findet ihre Grundlage im Wesen des Psychischen selbst, in der Beziehung der normalen Vorstellungsform zur normalen Gefühlsreaktion auf der einen, in der Beziehung der bis zur Pseudowahrnehmung gesteigerten Vorstellungsart zur pathologischen Gefühlsreaktion auf der anderen Seite.

Wie wenig Anlaß wir haben, ein besonderes lokalisatorisches oder leitungsphysiologisches Moment für die Erklrärung der Halluzination einzuführen, können uns auch die in der Gesundheitsbreite vorkommenden Halluzinationen und halluzinationsähnlichen Bewußtseinsphänomene zeigen: die Träume und die hypnagogen Halluzinationen, auf die wir noch mit einigen Worten eingehen müssen.

Von einer pathologischen Gehirnreaktion kann bei diesen Bewußtseinszuständen zunächst überhaupt nicht die Rede sein. Denn es handelt sich bei den beiden Phänomenen, sofern sie sich nicht durch die Intensität 
und die Massenhaftigkeit ihres Auftretens, also durch rein quantitative Momente auszeichnen, um durchaus normale Lebens- und Bewußtseinsäußerungen.

Es wird aber auch von vornherein als durchaus unstatthaft erscheinen müssen, die Ursache der Träume und hypnagogen Halluzinationen in einer besonderen lokalisierten Erregung zu suchen. Die Art des Rindenprozesses, welcher den Schlaf herbeiführt, können wir dahingestellt sein lassen. Welcher Art or aber auch sein mag, es ist doch jedenfalls die ganze Hirnrinde, auf welche er sich erstreckt. Es liegt also nicht die geringste Ursache vor, irgendeine lokalisatorische oder leitungsphysiologische Veränderung zu supponieren, welche die Modifikation des den Schlaf bewirkenden Hirnrindenprozesses auf einen Teil der Rinde beschränkt.

Von einer besonderen Erregung irgendeiner Hirnrindenregion, also etwa der Sinnesstätte, kann hier schon deshalb nicht die Rede sein, weil die Voraussetzungen für den Eintritt des Schlafes das Fernhalten jeder irgendwie gearteten Hirnerregung ist. Wir müssen unsere Sinne abschließen, damit aber zugleich unsere zentralen Sinnesstätten gewissermaßen nach außen verbarrikadieren, damit wir in die Bewußtlosigkeit oder vielmehr Bewußtseinsveränderung versinken, welche der Schlaf bedeutet. Und ebenso müssen wir die intellektuelle und Gefühlsseite unseres psychischen Lebens aufs äußerste depotenzieren, um den Ruhezustand des Schlafes herbeizuführen. Hierbei werden die Sinnesstätten stätten auch gewissermaßen nach innen verbarrikadiert.

Zugleich mit der Herabsetzung der psychischen Lebensäußerungen und der ihr parallel gehenden Gehirnrindenfunktion in allen ihren Teilen muß aber natürlich auch die Leitungserregung nach allen Seiten herabgesetzt sein, weil das Aufflackern einer Erregung an irgendeiner Stelle zugleich die gesamte Hirnrinde wieder in Funktion setzen würde. Es ist also gar kein Zweifel, daß i m Schlaf die Erregbarkeit der gesamten Hirnrinde, sowohl der Einzclregionen wie der Leitungsverbinclungen, in welcher diese stehen, herabgesetzt ist.

Es beginnt nun vermittels der Reproduktionsleistungen im Traume ein neues Bewußtseinsleben mit all den psychischen Äußerungen, welche wir auch im Wachsein produzieren. Nicht also daß sich, wie das manchmal so dargestellt wird, nun alle unsere Reproduktionen im Traume in Pseudowahrnehmungen umsetzen. Wir haben außer diesen im Traume auch Reproduktionen, die sich als solche, als Eigenvorstellungen darstellen, wir vollziehen ferner Denkakte und komplizierte Schlüsse, glauben sogar hinterher, schwierige Probleme, über welche wir bei Tage nicht zur Klarheit gekommen sind, in glücklichster Weise gelöst zu haben. Auch mannigfache Gefühle und Affekte erleben wir im Traume. 
Es ist ferner nicht so, daß die Pseudowahrnehmungen in isolierter Weise auftreten; es umgibt uns im Traume eine Scheinwelt wie im wachen Leben die wirkliche Welt, deren Abbild jene ist, und in dieser Scheinwelt erleben wir Einzelvorgänge und komplizierte Handlungen anderer und von uns selbst, und Gespräche, an welche unser Bewußtsein mit seinen Vorstellungen, Denkakten, Entschlüssen, Gesprächen, Handlungen ganz genau so anknüpft wie das wache Bewußtsein an die wirklichen Erlebnisse.

Das Wesentliche nun, wodurch die Traumerlebnisse den Halluzinationen und Wahnbildungen des Geisteskranken so nahe kommen, ist die ungehemmte gefühlsmäßige Motivierung. Von den Fesseln des kritikmäßigen Räsonnements, welches im Wachsein all unserTun, Denken und Erleben begleitet, befreit, produziert der Träumende häufig seine Gedanken und Pseudowahrnehmungen in ähnlicher Weise wie der unter der Wirkung einer Wahnbildung stehende Geisteskranke. Ja ebenso wie dieser seine Wahnbildung und seine Halluzinationen inhaltlich an die Erlebnisse seines früheren gesunden Bewußtseins anknüpft, diese nur psychotisch verarbeitet, knüpft der Träumende seine Gedanken und Pseudowahrnehmungen an die Gedanken und tatsächlich erlebten Wahrnehmungen seines Wachzustandes an. Man könnte sehr gut mit der Jaspersschen Begriffstechnik "verständliche" und „kausale" Zusammenhänge zwischen Schicksal und Traum konstruieren, wie es von Jaspers selbst zwischen Schicksal und Psychose unternommen worden ist.

In sehr interessanter Weise hat noch kürzlich Bleuler über einige solcher Träume berichtet. Das Individuum entledigt sich im Traume der Personen, mit denen es im Wachen unangenehm gefühlsbetonte Erlebnisse gehabt hat, selbst wenn diese Personen ihm im Leben noch so nahe stehen. Er gleicht also darin dem Paranoiker, der schon im vorparanoischen Stadium sich mißtrauisch gezeigt hat und nach Ausbruch der Psychose einfach den Revolver zieht, um selbst die ihm nächststehenden Personen niederzuknallen, nur daß der Träumende manchmal noch gewissermaßen kleine Kunstgriffe gebraucht, indem er nicht selbst die Henkersdienste vollzieht, sondern anderen dieses Amt zuschiebt $\left.{ }^{1}\right)$.

Wir sehen also, daß der psychische Mechanismus, welcher zu den halluzinatorischen Affektreaktionen im Traume und in der Psychose führt, der gleiche ist. Die Halluzinationen werden beide Male ausgelöst durch den Fortfall der ethisch-intellektuellen Hemmungen, welche im Wachen bzw. im normalen Zustande das Individuum verhindert, auf unangenehme Gefühlserlebnisse hemmungslos mit der Beseitigung des

1) s. Bleuler, Träume mit auf der Hand liegender Deutung. Münch. med. Wochenschr. 45. 1913. 
gefühlserregenden Reizes, oder, wenn es sich um positive gefühlsbetonte Erlebnisse handelt, hemmungslos mit der Aneignung des begehrten Objekts zu reagieren.

Was lernen wir nun aus diesen Traumvorgängen für die Frklärung der Halluzinationen in der Psychose? Wir sahen, da $\beta$ von irgendeiner lokalisierten gesteigerten Erregung oder von einem veränderten Leitungsvorgang im Schlafe nicht gesprochen werden kann, und nun sehen wir, daß trotzdem die psychischen Mechanismen im Traume prinzipiell gar nicht anders liegen wie in der Psychose. Wenn nun die Traumhalluzinationen einer Erklärung durch lokalisierte Erregungen oder veränderte Leitungsbedingungen unbedürftig sind, so wird wohl niemand einen plausiblen Grund anführen können, warum denn nun auf einmal in der Psychose eine solche lokalisierte Erregungssteigerung oder Umwandlung der Leitungserregung eintreten soll.

Wie schnell die Umwandlung des Vorstellungscharakters in den Wahrnehmungscharakter auf dem Boden ungehemmter Gefühlsmotivierung vor sich geht, sobald die Wachkritik nur ein wenig nachläßt, lehren uns dann weiter die hypnagogen Halluzinationen. Bei diesen werden wir natürlich ebensowenig wie bei den Träumen oder noch weniger Anlaß haben, eine in den Sinnesstätten lokalisierte Ubererregung oder eine Veränderung der Leitungserregung anzunehmen. Zugleich zeigt uns der Inhalt der hypnagogen Halluzinationen, da $\beta$ auch sie unzweifelhaft in Beziehung $\mathrm{zu}$ den im unbewußten Seelenleben schlummernden Gefühlskomplexen stehen. Denn es sind keineswegs irgendwelche gleichgültigen Gegenstände, sondern Gesichter, Fratzen usw., die sich vor das Bewußtsein stellen, manchmal auch gefühlsbetonte Gehörshalluzinationen.

Zugleich zeigt sich auch von dieser Seite der Wert der Goldsteinschen Untersuchungen über die Bedeutung des Urteils für das Realitätsbewußtsein. Denn wenn auch der Autor in der Annahme geirrt hat, daß das Realitätsbewußtsein bei der normalen Wahrnehmung durch das Urteil selbst zustande komme, und daß die Halluzination die direkte Folge des Verlustes der normalen Urteilsfähigkeit sei, so ist es doch zweifellos, daß zur Produzierung von Halluzinationen, sei es in der Geisteskrankheit, sei es im Schlafe, die normale Urteilstätigkeit aufgehoben sein muß. Es zeigt sich ganz allgemein, daß infolge dieser Aufhebung der normalen Urteilsbetätigung, wie sie in der Psychose und bei irgendwelchen Bewußtseinstrübungen regelmäßig eintritt, die gefühlsbetonten Vorstellungen nicht mehr imstande sind, den ihnen eigenen Charakter aufrechtzuerhalten, sondern sich unter dem ungehem mten Einflusse der Gefühlsmotivierung sofort in Wahrnehmungsgebilde umsetzen.

z. f. d. g. Neur. u. Psych. o. Xxrv. 
Hat es sich so von allen Seiten als unmöglich herausgestellt, die echte Halluzination durch eine lokalisierte Reizung oder durch eine Veränderung der Erregungsleitung zu erklären, so trifft natürlich dasselbe Schicksal auch die Pseudohalluzinationen. Die Gründe, warum es in dem einen Falle zu Halluzinationen, im anderen zu Pseudohalluzinationen kommt, sind ebenfalls auf psychopathologischem Gebiete zu suchen. Es lassen sich auch deren einige konstatieren und werden sich wohl in Zukunft in noch weiter gehendem Maße eruieren lassen. Wenn wir bedenken, daß Pseudohalluzinationen besonders häufig bei Hysterischen und Psychopathen vorkommen, wenn wir an jenen von uns beobachteten Fall denken, in welchem eine Hysterische ihre Pseudohalluzinationen in Halluzinationen umsetzte, als sie einen stärkeren Erregungszustand bekam, um nach Abklingen des Erregungszustandes die halluzinatorischen Inhalte sofort wieder als pseudohalluzinatorische zu produzieren, so werden wir wohl, was ja eigentlich auch von vornherein naheliegt, sagen können, daß die Unterschiede in den Ursachen beider nur in der Schwere des psychotischen Prozesses liegt. Ganz allgemein kann man dann auch sagen, daß, je eingreifender die funktionelle Gehirnveränderung ist, desto eher es zu Halluzinationen kommen wird.

Wir sprechen hier nur von der funktionellen Störung, weil wir annehmen, daß eine zu Geisteskrankheiten führende substantielle Veränderung der Hirnrinde, wie etwa die Paralyse, sich ohne weiteres in echten Halluzinationen äußert. Der Umstand, daß bei substantiellen Hirnerkrankungen Pseudohalluzinationen im allgemeinen seltener sind, weist wohl ohne weiteres darauf hin, daß letztere durch leichtere Veränderungen der Hirnrinde bedingt sind.

Gerade aber die nähere Betrachtung der Verhältnisse der Pseudohalluzinationen zu den echten kann uns zeigen, wie wenig wir in der Erklärung dieser Phänomene von irgendeiner hirnmechanischen Hypothese zu erwarten haben. Zugleich wird uns diese nähere Betrachtung auf den neuen Gesichtspunkt zurückleiten, welchen wir in die Behandlung des Halluzinationsproblems eingeführt haben.

Der Unterschied zwischen der Pseudohalluzination und der Halluzination besteht ja darin, daß jene sich dem Individuum in dem , $\mathrm{Be}$ wußtseinsraum" präsentiert, in welchem das normale Individuum seine Eigenvorstellungen erlebt, während die Halluzinationen in jenem ä ußeren $\mathrm{Raum}$ erscheinen, in welchen wir die wirklichen Wahrnehmungsgegenstände versetzen. Daß es nicht möglich ist, als materielles Korrelat für diese verschiedenartigen Raumvorstellungen das Bestehen bestimmter lokalisatorischer oder Leitungsveränderungen im Gehirn plausibel zu machen, haben wir gezeigt. Wie steht es aber überhaupt mit dem Verhältnis dieser beiden Raumvorstellungen zur erkennenden 
Tätigkeit? Ja, existieren vom Standpunkt der Erkcnntnis selbst durchgreifende Unterschiede zwischen beiden? Ist der Bewußtseinsraum wirklich ein anderer als der tatsächlich wahrgenommene? Besteht zwischen beiden, wie das Goldstein, Jas pers u. a. annehmen, wirklich vollkommene Diskontinuität?

Geben wir zunächst einem Autor das Wort, welcher das direkt leugnet! „Wenn ich eine leuchtende Kugel səhe," so sagt Eduard Hirt ${ }^{1}$ ), ,so sehe ich sie an einer bestimmten Stelle im Raume. Und dies an ,bestimmter Stelle' heißt eben, daß sie sich in einem bestimmten räumlichen Verhältnis zu anderen Wahrnehmungen befindet, zu denen ich durch Wandernlassen meiner Augen oder durch Veränderung meiner Körperstellung weitergehen kann. Bei diesem Weitergehen verharrt die leuchtende Kugel an ihrem ursprünglichen Orte, aus meinem Blickpunkte rückt sie mehr und mehr gegen die Peripherie meines Blickfeldes, und endlich verschwindet sie."

„Nun nehme ich die leuchtende Kugel, diesen realen . . Gegenstand, von dem Orte weg... Ich stecke ihn in die Tasche... Aber an seiner früheren Stelle ... stelle ich mir nun, dieselbe' leuchtende Kugel vor. Nicht nus für mein nachdenkendes BewuBtsein ist sie jetzt ebenso weit entfernt von den verschiedenen realen Dingen...., sondern ich sehe sie unmittelbar in dieser ganz bestimmten räumlichen (Ordnung. Ich wende nun wiederum den Blick in derselben Richtung, in der ich ihn von der realen Kugel wegwendete. Und nun ist zweierlei möglich: entweder die Kugel wandert mit meinem Blicke von ihrer Stelle... weg, schwebt durch die Luft und folgt mir, wohin ich sie haben will ... Oder: meine vorgestellte Kugel strebt, während ich den Blick wegwende, ebenso wie die wahrgenommene, allmählich gegen die Peripherie. Sie wird verschwommener, lichtloser, verschwindet..."

Hirt knüpft an diese Darstellung die Bemerkung, daß er die Behauptungen der Autoren über einen Unterschied und eine Diskontinuität zwischen Wahrnehmungs- und Vorstellungsraum nicht glauben könne. Und in der Tat ist diese Stellungnahme des Autors begreiflich, wenn wir zugleich bedenken, daß wir die vor uns liegende wahrgenommene Räumlichkeit durch eine hinter uns liegende vorgestellte ergänzen, und daß in dieser hinter uns vorgestellten Räumlichkeit sowohl die wirklichen Dinge wie die nur vorgestellten, wie schließlich sogar Gesichtshalluzinationen (extrakampine Halluzinationen Ble ulers) lokalisiert werden.

Würde nun Hirt recht haben, so würde wohl - das scheint mir wenigstens unausbleiblich - die ganze Lehre von den Pseudohalluzinationen unter den Tisch zu fallen; denn es ist doch nur der Externali-

1) Eduard Hirt, Zur Theorie der Trugwahrnchmungen. Zcitschr. f. Pathopychologie S. 434. 1912. 
tätsfaktor, durch welchen sich die echten Halluzinationen von den Pseudohalluzinationen unterscheiden. Externalität und äußere Räumlichkeit ist aber für unsere Erkenntnisbedingungen identisch. Wenn nun aber äußerer Raum und sog. Bewußtseinsraum zusammenfallen, wo bleiben dann die Pseudohalluzinationen? Das Bewußtsein der Abhängigkeit vom produzierenden Bewußtsein wird da wohl kaum das pseudohalluzinatorische Moment begründen können, denn wir erkannten, daß auch bei den Wahrnehmungen ein physiologisches Abhängigkeitsbewußtsein vorhanden ist - wenn wir die Augen schließen, nehmen wir nichts wahr. Es blieben höchstens noch die Pseudohalluzinationen bei geschlossenen Augen übrig. Die Pseudohalluzinationen des Gehörs würden eo ipso wegfallen, weil auf dem Gehörsgebiet das räumliche Moment überhaupt ein sekundäres ist. Und dennoch, wer könnte etwas Triftiges gegen die Betrachtungen und Folgerungen Hirts einwenden?

Wir kommen hier auf eine Grundfrage der Erkenntnis, die nur zu lösen ist aus den Erkenntnisbedingungen selbst. Diese richtig verstandenen Erkenntnisbedingungen, wie sie uns jener Denker gelehrt hat, der durch seine Kritik den größten Fortschritt im Denken der Menschheit überhaupt hervorgebracht hat, lehren uns, daß es so etwas wie einen Raum an sich überhaupt nicht gibt, sondern daß der Raum nur eine Form unseres Anschauens ist.

Wer diese Lehre Immanuel Kants verständnisvoll in sich aufgenommen hat und in einer clen modernen philosophisch-psychologischen Anforderungen entsprechenden Weise weiterbildet, für den löst sich die Frage nach dem Unterschiede zwischen wahrgenommenem. und vorgestelltem Raum dahin, - cla 3 diese Frage überhaupt nicht existiert. Einen Unterschied zwischen wahrgenommenem und vorgestelltem Raum gibt es dann in der Tat nur insofern, als wir die Form unseres Anschauens das eine Mal auf die Eigenprodukte unseres Vorstellens, das andere Mal auf die Wirklichkeit selbst anwenden. Tun wir das letztere, so scheint der Raum an der Wirklichkeit selbst teilzunehmen, also zu einem ,wahrgenommenen" Raum zu werden. Durch diese Wirklichkeit allein wird die ,Diskontinuität“ zwischen wahrgenommenem und vorgestelltem Raum hervorgerufen. Den Raum selbst aber kann man überhaupt nicht wahrnehmen, weil er, wie das schon vor Kant erkannt worden ist, an sich nicht existiert.

Das unterscheidende Kriterium $z$ wischen Halluzinationen und Pseudohalluzinationen ist dann aber nicht die Diskontinuität $z$ wischen wahrgenommenem Raum und BewuBtseinsraum, sondern die Diskontinuität zwischen Wirklichkeit und Unwirklichkeit. Erst durch das Bewußtsein der letzteren erhalten die Pseudohalluzinationen und auch die normalen Vorstellungen zugleich das Bewußtsein der reinen Abhängigkeit vom produzierenden 
Ich, und erst durch das Bewußtzein der letzteren verknüpfen sich die Halluzinationen und auch die normalen Wahrnehmungen mit dem Gefühle des Ergriffenseins des Subjekts durch einen tatsächlichen oder supponierten transsubjektiven Reiz.

Zugleich lehrt uns aber die Einsicht in die wahren Bedingungen unseres Erkennens die letzten Gründle, aus welchen es prinzipiell aussichtslos erscheinen muß, auf hirnphysiologischem Wege die Rä umlichkeit überha u pt zu ,,erklären“", womit dann jeder Versuch einer hirnphysiologischen Erklärung ,,wahrgenommener“" und vorgestellter Räumlichkeit wiederum als prinzipiell verfehlt erscheinen muß. Denn dieses Gehirn, aus dessen Funktion wir die Räumlichkeit zu erklären unternehmen würden, erscheint ja selbst schon ,räumlich“ und erweist sich damit selbst von den Bedingungen unserer Erkenntnis abhängig, die gar nicht anders als räumlich aufzufassen sind. Es ist dies ja immer und immer wieder von erkenntnistheoretischer Seite urgiert worden. Aber selbst diejenigen Autoren, welche in ihren trefflichen Abhandlungen zeigen, daß die Lehren der modernen Erkenntnistheorie nicht spurlos an ihnen vorübergegangen ist, empfinden nicht den Widerspruch, welchen sie begehen, wenn sie z. B. von einem, ,stereopsychischen" Zentrum im Gehirn reden.

Wir können nur sagen: Wir nehmen wahr, d. h. wir erleben einen tatsächlichen Raum, wenn die Wirklichkeit auf unser Gehirn wirkt. Wir stellen vor, d. h. wir erleben einen nur vorgestellten Raum, wenn die früher durch die Wirklichkeit angeregte Raumanschaung infolge-der Eigentätigkeit des Gehirn, reproduziert" wird. Wird das Gehirn krank, so werden aus den früher dargelegten psychopathologischen Gründen bestimmte Vorstellungsgebilde zu Pseudowahrnehmungen, zu Halluzinationen und Pseudohalluzinationen. 